\title{
COMPACTAÇÃO DO SOLO POR TRÁFEGO DE MÁQUINAS DE COLHEITA EM UM PLANTIO FLORESTAL DE EUCALYPTUS SALIGNA
}

\section{Maria Cristina Destri Ferreira \\ Engenheiro Mecânico}

Orientador: Prof. Dr. Marcos Milan

Dissertação apresentada à Escola Superior de

Agricultura "Luiz de Queiroz", Universidade de São Paulo, para obtenção do título de Mestre

em Agronomia, Área de Concentração:

Máquinas Agrícolas

\author{
PIRACICABA \\ Estado de São Paulo - Brasil \\ Janeiro - 1998
}


Dados Internacionais de Catalogação na Publicaçāo (CIP) DIVISĀO DE BIBLIOTECA E DOCUMENTAÇĀO - Campus "Luiz de Queiroz"/USP

\section{Ferreira, Maria Cristina Destri}

Compactação do solo por tráfego de máquinas de colheita em um plantio florestal de Eucalyptus saligna / Maria Cristina Destri Ferreira. - - Piracicaba, 1998.

$$
82 \text { p. : il. }
$$

Dissertação (mestrado) - - Escola Superior de Agricultura Luiz de Queiroz, 1998. Bibliografia.

1. Compactação do solo 2. Eucalipto 3. Fisica do solo 4. Mecanização florestal 5. Solo florestal I. Título 
Ofereço

Aos meus pais, Egídio e Maria

Aos meus irmãos, Eleonilson e Cristiana

Dedico esta dissertação ao meu marido, Adilson pelas diversas horas em que estive ausente na preparação desta. 


\section{COMPACTAÇÃO DO SOLO POR TRÁFEGO DE MÁQUINAS DE COLHEITA EM UM PLANTIO FLORESTAL DE EUCALYPTUS SALIGNA}

Maria Cristina Destri Ferreira

Aprovada em: 16.03 .98

Comissão Jugadora:

Prof. Dr. Marcos Milan ESALQ/USP

Prof. Dr. Fernando Seixas ESALQ/USP

Prof. Dr. Kléber Pereira Lanças FCAVUNESP 


\section{AGRADECIMENTOS}

A Escola Superior de Agricultura "Luiz de Queiroz", pela oportunidade de aperfeiçoamento profissional.

Ao Prof. Dr. Marcos Milan, pela orientação na elaboração desta dissertação.

A Cia Suzano de Papel e Celulose, pelo apoio logistico e financeiro deste trabalho. Ao Eng ${ }^{\circ}$ Jorge Takeshi, Eng ${ }^{\circ}$ José Luiz Gava e funcionários, pelas colaborações direta e indiretamente na realização desta.

Ao Eng $^{\circ}$ Gersio Zincone Jr. e Reginaldo Conceição pela colaboração do trabalho de campo.

A CNPQ pela concessão da bolsa de estudo que proporcionou este trabalho.

A Professora Sônia, pelas sugestōes e auxilio nas análises dos dados.

Aos Professores e funcionários do Departamento de Engenharia Rural Setor de Mecânica, pelo incentivo.

As bibliotecárias da ESALQ/USP, Katia e Eliana, pela colaboração com as referências bibliográficas.

Aos colegas de Pós-Graduação em especial, Atílio, Remi e Rogério pela amizade. 


\section{SUMÁRIO}

Página

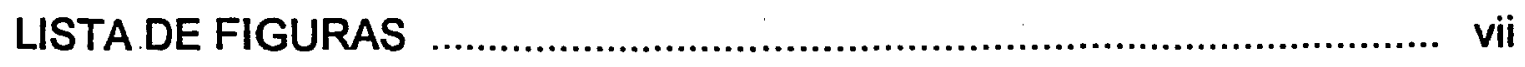

LISTA DE TABELAS

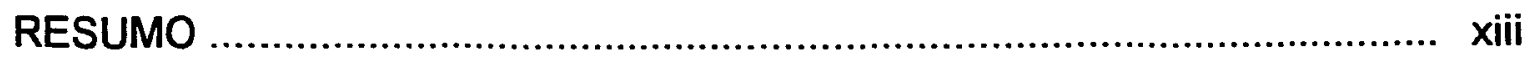

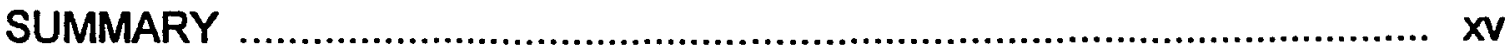

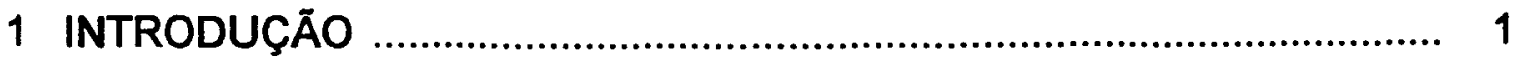

2 REVISÃO BIBLIOGRAFICA ………………………………….......... 3

2.1 Compactação do Solo ...................................................................... 3

2.2 Tráfego de veículos e ação de implementos .......................................... 4

2.3 A compactação do solo ..................................................................... 6

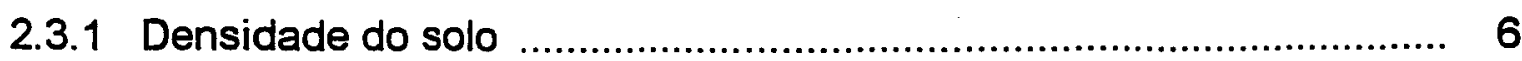

2.3.2 Resistência à penetração do solo ……………………..................... 7

2.3.3 Teor de água no solo ................................................................ 9

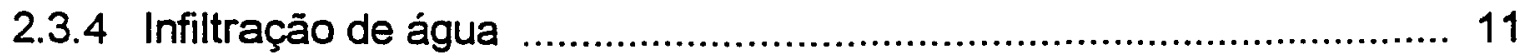

2.4 Efeitos da compactação do solo em culturas ..................................... 12

2.4.1 Efeitos da compactação do solo em povoamento florestais ............... 13

2.4.2 A compactação e os equipamentos florestais ................................... 14

2.4.3 Efeitos da compactação do solo em área agrícola ........................... 17

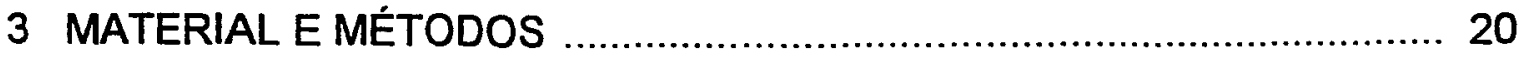

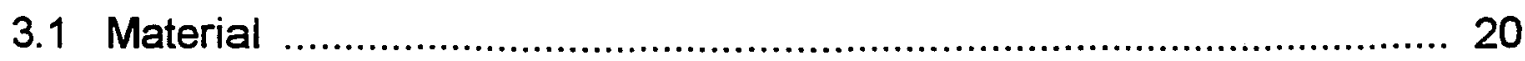

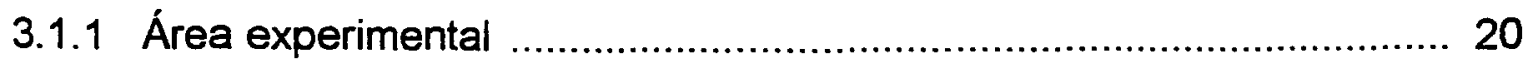

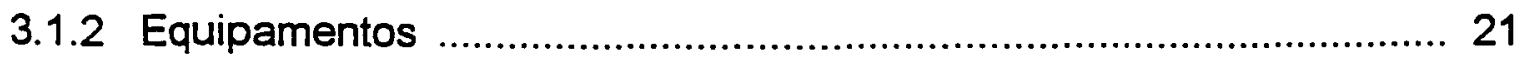

3.1.3 Equipamentos para a caracterização do solo ..................................... 24 


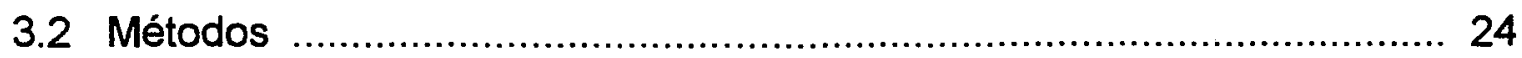

3.2.1 Delineamento experimental .................................................... 25

3.2.2 Parâmetro de compactação e características do solo ....................... 27

4 RESULTADOS E DISCUSSĀO ...................................................... 30

4.1 Área experimental ................................................................. 30

4.2 Equipamentos: Pressão de contato rodado/solo ................................. 34

4.3 Avaliação da compactação antes da colheita ..................................... 36

4.3.1 Resistência à penetração do solo.................................................. 36

4.3.1.1 Entrelinha: $\mathrm{RMa}$ e $\mathrm{RTr}$......................................................... 36

4.3.1.2 Linha ........................................................................ 42

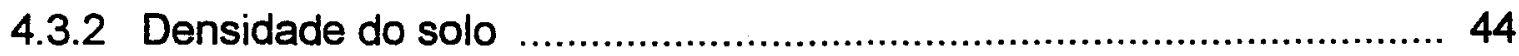

4.4 Avaliação da compactação depois da colheita ................................ 46

4.4.1 Cobertura Vegetal .............................................................. 47

4.4.2 Resistência à penetração do solo................................................ 48

4.4.2.1 Entrelinhas: RMa e RTr ........................................................ 48

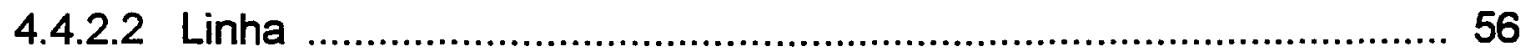

4.4.3 Densidade ....................................................................... 57

4.5 Considerações gerais .................................................................. 60

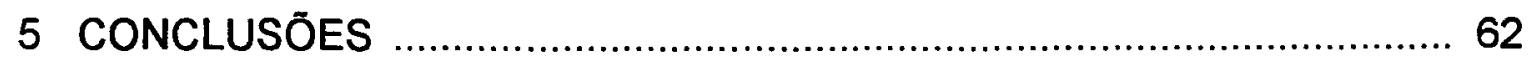

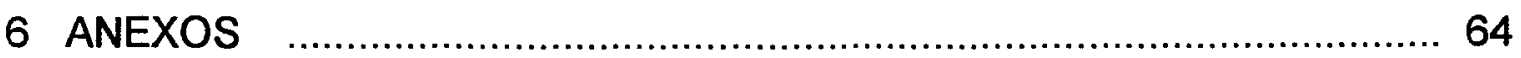

REFERÊNCIAS BIBLIOGRÁFICAS ................................................ 77 


\section{LISTA DE FIGURAS}

Página

1 Área experimental antes da colheita 22

2 Colhedora da marca AFM, montada sobre a plataforma de um trator de esteira, marca Caterpillar

3 Auto-carregável para a retirada da madeira, usando como fonte de potência um trator da marca Massey-Ferguson, modelo 610

4 Esquema da área experimental em um bloco com as amostragens efetuadas

4a Detalhe das amostras realizadas 26

5 Cobertura vegetal da área experimental depois da colheita 28

6 Teste de Proctor modificado 32

7 Histograma referente à altura $(\mathrm{m})$ das plantas 33 
8 Histograma referente ao diâmetro $(\mathrm{mm})$ na altura do peito (DAP) de plantas

9 Teor de água (\%) no solo antes da colheita, para os tratamentos RMa e RTr

10 Resistência à penetração do solo $(\mathrm{kPa})$ para o tratamento $\mathrm{RMa}$, antes da colheita 40

11 Resistência à penetração do solo $(\mathrm{kPa})$ para o tratamento $\mathrm{RTr}$, antes da colheita 42

12 Resistência à penetração do solo $(\mathrm{kPa})$ das linhas de plantas, comparandas com os valores das amostras 3 e 10, obtidas nas entrelinhas (antes da colheita) 43

13 Densidade do solo $\left(\mathrm{g} / \mathrm{cm}^{3}\right)$ para os tratamentos RMa e $\mathrm{RTr}$, antes da colheita 45

14 Densidade do solo $\left(\mathrm{g} / \mathrm{cm}^{3}\right)$ para as amostra 3 e 4, antes da colheita 46

15 Quantidade de cobertura vegetal $\left(\mathrm{kg} / \mathrm{m}^{2}\right)$, separados em classes, para os tratamentos das RMa e RTr

16 Teor de água (\%) no solo depois da colheita, para os tratamentos RMa e RTr

17. Resistência à penetração do solo $(\mathrm{kPa})$ para o tratamento $\mathrm{RMa}$, depois da colheita 
18 Resistência à penetração do solo(kPa) para o tratamento $\mathrm{RTr}$, depois da colheita 54

19 Resistência à penetração do solo(kPa) para a amostra 11, antes e depois da colheita 55

20 Resistência à penetração do solo $(\mathrm{kPa})$ das linhas de plantas, comparandas com os valores das amostras 3 e 10, obtidas nas entrelinhas (depois da colheita) 56

21 Densidade do solo $\left(\mathrm{g} / \mathrm{cm}^{3}\right)$ para os tratamentos RMa e $\mathrm{RTr}$, depois da colheita 58

22 Densidade do solo $\left(\mathrm{g} / \mathrm{cm}^{3}\right)$ para as amostras 3 e 4, depois da colheita 59

23 Densidade do solo $\left(\mathrm{g} / \mathrm{cm}^{3}\right)$ para as amostras 4 , antes e depois da colheita 


\section{LISTA DE TABELAS}

Páginas

1 Teor de água no solo (\%) até a profundidade de $50 \mathrm{~cm}$, obtido depois dos deslocamentos dos veículos nos dias da colheita e retirada da madeira e Capacidade de Campo e Ponto de Murcha Permanente (\% em peso) até a profundidade de $40 \mathrm{~cm}$.

2 Valores médios de DAP's e altura das plantas de eucalipto para as linhas 1, 2 e 3 de plantas

3 Pressão de contato estimada para os equipamentos utilizados no experimento 35

4 Valores de pressão de contato para máquinas florestais 35

5 Valores percentuais médios de teor de água do solo (\%), antes da colheita, para diferentes profundidades (cm) analisadas

6 Resultados médios da resistência à penetração do solo $(\mathrm{kPa})$ nas diferentes profundidades $(\mathrm{cm})$ analisadas antes da colheita para os tratamentos de RMa e RTr 
7 Resultados médios da resistência à penetração do solo ( $\mathrm{kPa}$ ) para as amostras $2,3,4,5$ e 6 nas diferentes profundidades $(\mathrm{cm})$ analisadas antes da colheita para 0 tratamento da $\mathrm{RMa}$

8 Resultados médios da resistência à penetração do solo (kPa) para as amostras 8, 9, 10, 11 e 12 nas diferentes profundidades $(\mathrm{cm})$ analisadas, antes da colheita para o tratamento da $\mathrm{RTr}$

9 Resultados médios de densidade do solo $\left(\mathrm{g} / \mathrm{cm}^{3}\right)$ nas diferentes profundidades $(\mathrm{cm})$ analisadas, antes da colheita para os tratamentos de RMa e RTr

10 Resultados médios da densidade do solo $\left(\mathrm{g} / \mathrm{cm}^{3}\right)$ para as amostras 3 e 4 nas diferentes profundidades $(\mathrm{cm})$ analisadas antes da colheita

11 Avaliação da cobertura vegetal para os tratamentos das ruas de madeira ( $R M a)$ e tráfego ( $R T r)$

12 Valores percentuais médios de teor de água (\%) do solo para a RMa, depois da colheita, para diferentes profundidades analisadas

13 Resultados médios da resistência à penetração do solo $(\mathrm{kPa})$ nas diferentes profundidades $(\mathrm{cm})$ analisadas, depois da colheita para os tratamentos da RMa e RTr 
14 Resultados médios da resistência à penetração do solo (kPa) para as amostras 2, 3, 4, 5 e 6 nas diferentes profundidades $(\mathrm{cm})$ analisadas, depois da colheita para $\circ$ tratamento da RMa

15 Resultados médios da resistência à penetração do solo ( $\mathrm{KPa})$ para as amostras $8,9,10,11$ e 12 nas diferentes profundidades $(\mathrm{cm})$ analisadas, depois da colheita para 0 tratamento da RTr 53

16 Resultados médios de densidade do solo $\left(\mathrm{g} / \mathrm{cm}^{3}\right)$ para as nas diferentes profundidades $(\mathrm{cm})$ analisadas, depois da colheita para os tratamentos da RMa e RTr

17 Resultados médios da densidade do solo $\left(\mathrm{g} / \mathrm{cm}^{3}\right)$ para as amostras 3 e 4 nas diferentes profundidades $(\mathrm{cm})$ analisadas, depois da colheita para o tratamento da $\mathrm{RTr}$

18 Resultados médios de densidade do solo $\left(\mathrm{g} / \mathrm{cm}^{3}\right)$ nas diferentes profundidades $(\mathrm{cm})$ analisadas, para a amostra 4 antes e depois da colheita 


\section{COMPACTAÇÃO DO SOLO POR TRÁFEGO DE MÁQUINAS PARA A COLHEITA EM UM PLANTIO FLORESTAL DE EUCALYPTOS SALIGNA}

Autora: MARIA CRISTINA DESTRI FERREIRA Orientador: Prof. Dr. MARCOS MILAN

\section{RESUMO}

A compactação do solo em áreas florestais pode causar um aumento na erosão e queda na produtividade. Ela altera as características básicas do solo, impedindo a infiltração de água e dificultando a aeração e a penetração das raizes.

O presente trabalho teve como objetivo avaliar os valores da compactação por ocasião da colheita em uma floresta implantada de Eucalyptus saligna localizada no municipio de São Miguel Arcanjo, Estado de São Paulo.

O experimento foi realizado com três blocos ao acaso, correspondendo a três fileiras com vinte plantas cada bloco. Foram avaliadas as caracteristicas dimensionais das plantas, cobertura vegetal, a pressão de contato do rodado/solo dos equipamentos. a resistência do solo à penetração $e$ densidade do mesmo.

Os resultados obtidos mostraram que os equipamentos utilizados na colheita elevaram a resistência à penetração do solo e densidade do mesmo 
em áreas localizadas e que os efeitos do preparo do solo permaneceram ao longo do ciclo da cultura: para a resistência à penetração do solo os valores máximos foram obtidos na faixa de 5 a $15 \mathrm{~cm}$ de profundidade com valores de $1075,2 \mathrm{kPa}$ e $1666,4 \mathrm{kPa}$ nas amostragens realizadas antes e depois da colheita. Para a densidade do solo os valores máximos ocorreram na faixa de $15-20 \mathrm{~cm}$ de profundidade, o resultado obtido antes da colheita foi de 1,22 $\mathrm{g} / \mathrm{cm}^{3}$ e depois $1,40 \mathrm{~g} / \mathrm{cm}^{3}$. 


\title{
SOIL COMPACTATION BY TRAFFIC OF HARVEST MACHINES IN A FOREST PLANTING OF EUCALYPTUS SALIGNA
}

\author{
Author: Maria Cristina Destri Ferrreira \\ Advisor: Marcos Milan
}

\section{SUMMARY}

The compactation in forest places may cause an increase of erosion rates and a decrease in yield. It changes the basic characteristic of soil, blocking the water infiltration, complicating the air circulation and root growth.

This work had the objective to evaluate the value who had been established of compactation at the time of harvesting in a planted forest of Eucalyptus saligna, located in São Miguel Arcanjo, São Paulo.

The experiment was made with three blocks, at random, corresponding to three rows of twenty trees each block. It were studied the dimension characteristics of trees, vegetable covering, pressure between contact among the tyres and the soil, cone index and soil density.

The results obtained showed that the equipments used for harvesting increased the cone index and density in determined areas and the effect of soil preparation remained along of tillage cycle. To the cone index the depth who showed the biggest value were among 5 and $15 \mathrm{~cm}$ with 1075,2 kPa before harvesting and $1666,4 \mathrm{kPa}$ after harvesting. To the density the depth who 
showed the biggest value were among $15-20 \mathrm{~cm}$, with $1,22 \mathrm{~g} / \mathrm{cm}^{3}$ before harvesting and $1,40 \mathrm{~g} / \mathrm{cm}^{3}$ after harvesting. 


\title{
1 INTRODUÇÃO
}

\begin{abstract}
A compactação dos solos na área florestal é um problema que vem preocupando os pesquisadores e produtores ao longo dos anos. A compactação pode ter efeitos nos índices de erosão e até na queda da produtividade. Uma das principais necessidades para o desenvolvimento adequado das culturas é a de que o solo apresente condições ideais ao seu desenvolvimento. Uma distribuição adequada do espaço poroso é essencial para fornecer as condições de água, aeração e temperatura necessárias ao bom desenvolvimento das raízes.
\end{abstract}

Desde o momento que o homem passou a utilizar o solo de forma mais intensiva vem ocorrendo alterações, sendo que a utilização da maquinaria é um fator importante para a compactação dos solos. $\mathrm{Na}$ área florestal, a mecanização é utilizada em todas as etapas desde a implantação à colheita, o que contribui para a expansão da degradação devido à pressão exercida sobre o solo pelos equipamentos. Os efeitos desse tráfego ainda não são bem conhecidos para as condições do pais.

A compactação é o resultado de vários fatores entre eles o peso da máquina, a área de contato, o número de vezes que ocorre o trafego no local, a umidade, o tipo de solo entre outros.

O estudo da compactação e suas consequências, em termos de risco para a planta, são de difícil avaliação, por isso o conhecimento dos problemas que ocasionam são de fundamental importância para manejo racional do solo. 
Este trabalho foi realizado com $\circ$ objetivo de avaliar a compactação do solo em uma floresta implantada de eucalipto (Eucalyptus saligna), causada pelo tráfego de máquinas para a colheita de madeira. 


\section{REVISÃO BIBLIOGRÁFICA}

\subsection{Compactação do solo}

A compactação do solo é o ato ou ação de forçar a agregação das partículas do solo, reduzindo o volume por elas ocupado, Seixas (1988).

Em um perfil de solo, podem aparecer camadas adensadas, que são aquelas em que a sua compacidade é devida a processos pedogenéticos, isto é, não ocorrendo a influencia direta do homem. O termo de camada compactada é reservado para a situação em que a redução no volume é devido ao manejo do solo, Grohmann (1972). A compactação e o adensamento podem produzir os mesmos efeitos desfavoráveis ao solo, causando um impedimento físico ao desenvolvimento do sistema radicular e restringindo o movimento da água e do ar ao longo do perfil, Jorge (1985).

O volume total de um solo é formado por partículas minerais e poros, usualmente preenchidos com água e com ar, Chancellor (1977). Um solo é considerado ideal quando mantém um equilíbrio entre as fases sólida, líquida e gasosa, contendo cerca de $50 \%$ de sólidos, $20 \%$ de poros grandes (macroporos), que abrigam o ar, e $30 \%$ de poros pequenos (microporos), que retém a água, Jorge (1986).

Voorhees (1977) compara o solo compactado com uma esponja úmida comprimida, sendo que os poros tendem a diminuir de tamanho. Se a compactação for excessiva, alguns destes poros são eliminados, o que reduz a infiltração de água, tendo como consequência o escoamento superficial e a 
erosão. Ela influencia também na densidade aparente e na resistência à penetração, que são utilizadas como parâmetros físicos para entender as causas e os efeitos da compactação, Corsini (1993),

As causas da compactação podem ser por forças internas e externas aplicadas no solo. As forças internas são as originárias de dentro da massa do solo: congelamento e descongelamento, umidecimento e secamento: As externas são atribuídas ao tráfego de veículos e ou ferramentas, além dos efeitos das chuvas, Cohron (1971).

As características do solo que influenciam na compactação são textura e estrutura, teor de água e topografia. Em relação aos equipamentos, o peso e tamanho da máquina, dimensões dos pneus, patinamento, velocidade de operação, Burger (1983), Sirois et al. (1985) citado por Reisinger et al. (1988).

Segundo Beltrame et al. (1980), varias técnicas podem ser empregadas como prevenção ao nível de compactação, destacando-se: diminuir o número de operações de preparo do solo; utilizar implementos que causam menos compactação; trabalhar o solo em níveis corretos de umidade; utilizar pressão correta nos pneus e aumentar a área de contato dos pneus com o solo.

\subsection{Tráfego de veículos e ação de implementos}

Uma das causas da compactação é o tráfego de máquinas em solos cultivados. Para analisar este problema deve-se mensurar e calcular a distribuição da pressão no solo em função da carga do rodado e pressão de insuflagem do pneu, Sohne (1958).

Segundo Camargo (1983), as características do pneu e da superfície do solo determinam a pressão de inflação, pois a pressão média entre o pneu e a superficie é aproximadamente igual à pressão de inflação. Quando a carga vertical sobre o pneu cresce, a pressão permanece constante, 
enquanto o pneu se deforma suficientemente de forma que o resultado da pressão média distribuída na área de contato seja igual a carga vertical. Se a carga no pneu é constante e a pressão de inflação é reduzida, o pneu se achatará para aumentar a área de contato.

Wästerlund (1992) relata que várias passadas de veículos em áreas florestais, principalmente na realização da colheita e retirada da madeira, foram responsáveis pela compactação do solo e influenciaram na alteração do índice de infiltração. Descreve ainda que a primeira passada contribuí com mais de $50 \%$ do prejuízo para o solo.

Fernandes et al. (1987) verificaram o efeito do tráfego de tratores agrícolas de rodas nas propriedades físicas de dois solos, em um experimento de cultivo mínimo, durante 7 anos consecutivos. Retiraram-se amostras antes da realização de cada plantio nas áreas com e sem trafego, para as profundidades 0 a 10,10 a 20 e 20 a $30 \mathrm{~cm}$. Os autores concluíram que o tráfego reduziu a porosidade total, aumentou a densidade aparente e a água capilar, reduzindo os diâmetros dos poros maiores, a condutividade hidráulica e a porosidade livre da água. Observaram que este efeito foi mais acentuado na profundidade de 10 a $20 \mathrm{~cm}$, não atingindo a profundidade 20 a $30 \mathrm{~cm}$.

Para Klein (1990) a ação de implementos, principalmente as grades de discos, funcionam como um rolo compactador na subsuperfície do solo, formando o denominado "pé de grade". A compactação fica disfarçada pela camada de solo solto localizado na superfície, podendo causar sérios problemas de erosão. 


\subsection{A compactação do solo}

\subsubsection{Densidade do solo}

Segundo Jorge (1986), a densidade do solo é a razão entre a massa seca e o volume do solo ao natural, incluindo os espaços ocupados pelo ar e pela água, e varia dependendo da estrutura e compactação do solo. A massa específica apresenta valor maior, quando o solo é menos estruturado e mais compactado. A densidade influencia na resistência do solo, no crescimento das plantas, na infiltração de água e na força requerida pelo implemento. Muitas vezes a densidade é mensurada para avaliar a eficiência das operações de cultivo ou os danos causados por veículos.

Koger et al. (1985) avaliaram três tipos de solos (argiloso, areno argiloso e argilo arenoso) em diferentes situações: onde não houve tráfego, com uma, duas, três e quatro passadas de um skidder de pneus. Verificaram que a maior alteração ocorreu entre o solo não perturbado e a primeira passada: nesta situação, o aumento na densidade, em percentagem, para o solo argiloso foi $37,86 \%$, para o areno argiloso de $15,23 \%$ e argilo arenoso de $6,0 \%$. Os autores concluíram, através dos testes, que o efeito de passadas em relação a densidade varia significativamente para cada tipo de solo, observaram também que os índices mais elevados são obtidos na primeira passada.

Em um solo areno argiloso, Meek et al. (1992) verificaram que a diminuição da pressão de inflação de um pneu de 408 para $41 \mathrm{kPa}$ com a redução da carga de $2724 \mathrm{~kg}$ para $1248 \mathrm{~kg}$, resultou em uma diminuição na densidade de $1,91 \mathrm{~g} / \mathrm{cm}^{3}$ para $1,74 \mathrm{~g} / \mathrm{cm}^{3}$, na profundidade de $10-15 \mathrm{~cm}$. Neste mesmo trabalho, verificou-se que um aumento na densidade de $1,7 \mathrm{~g} / \mathrm{cm}^{3}$ para $1,89 \mathrm{~g} / \mathrm{cm}^{3}$, ocasionou um aumento de três vezes na resistência à penetração do solo e uma diminuição de quatro vezes na infiltração de água. 
Borges et al. (1996) estudaram os efeitos de diferentes niveis de compactação em um Latossolo Vermelho-Escuro álico, após umedecido com $70 \%$ da capacidade de campo para as camadas de $10-30 \mathrm{~cm}$. Submetendo as amostras às pressões de 0,$00 ; 5,94 ; 9,05$ e 13,58 $\mathrm{MPa}$, obtiveram os valores de densidades de 1,32 (sem compactação); 1,47; 1,62; $1,77 \mathrm{~g} / \mathrm{cm}^{3}$. A amostra do solo com o nível de compactação zero, ou seja, densidade de $1,32 \mathrm{~g} / \mathrm{cm}^{3}$, apresentou valores médios para conteúdo de sólidos de $49,47 \%$ e de $50,80 \%$ para a porosidade total, sendo que $17,3 \%$ estavam ocupados com água e $33,2 \%$ com ar. Os autores descrevem que estes atributos físicos são próximos aos considerados adequados ao desenvolvimento das plantas. A compactação executada para obter a densidade do solo de $1,77 \mathrm{~g} / \mathrm{cm}^{3}$ reduziu os poros livres de água (poros de aeração) de $33,24 \%$ para $12,08 \%$.

Klein (1996) avaliou a densidade de um Latossolo Vermelho Escuro distrófico, com 3 anos de plantio direto. $O$ autor realizou um delineamento experimental na área constando de cinco tratamentos: plantio direto (testemunha), aração com arado de disco, escarificação com um escarificador protótipo (baseado no modelo "paraplow") e escarificador com hastes parabólicas e a grade de disco. Os resultados obtidos demonstraram que, ainda existia diferença significativa entre os tratamentos e o plantio direto. Concluiu através da análise da densidade do solo, que a compactação persiste por aproximadamente um ano.

\subsubsection{Resistência à penetração do solo}

A resistência mecânica do solo à penetração pelo uso de um penetrômetro é, segundo Chancellor (1977), um indicador indireto da compactação e não é uma medida física direta de uma condição específica. Ela é afetada por outros fatores como o teor de água, textura e densidade do solo. A utilização da leitura do penetrômetro na mensuração da compactação é limitada a medições comparativas feitas no mesmo solo com o mesmo teor de 
água. O penetrômetro é usado para indicações comparativas da compactação por causa da facilidade e rapidez com que numerosas medições podem ser feitas.

Durante cinco anos, Voorhees et al. (1978) avaliaram a resistência e a densidade em tratamentos com e sem tráfego em um solo argiloso com rotações de culturas de milho (Zea mays $L$ ) e soja (Glycine hispida Max), onde o mesmo se encontrava com um teor de água em torno de 18 a $22 \%$. Descreveram que a resistência à penetração pode ser um indicador mais sensivel do que a densidade, podendo estar mais relacionado com o crescimento das raízes. Foi verificado um aumento de $20 \%$ para a densidade enquanto que os resultados da resistência do solo aumentaram em $400 \%$.

Em quatro unidades de solo no Estado de São Paulo, Areia Quartizosa, Latossolo Vermelho-Escuro, Latossolo Vermelho-Amarelo álico e Latossolo Vermelho-Amarelo distrófico, Jorge et al. (1988), verificaram que existe uma grande diferença entre eles, para a resistência à penetração. A areia quartzosa apresenta uma menor resistência em todas as profundidades e a maior no Latossolo Vermelho-Amarelo Álico. Concluíram que não ocorreu correlação entre a classe textural e resistência à penetração.

Khalilian et al. (1991) conduziram ensaios durante três anos, em um solo argilo arenoso com a intercalação das culturas trigo e soja. Determinaram os dados da resistência à penetração do solo durante o período de dois e oito meses após o plantio da soja, nos tratamentos com e sem tráfego, sendo que os resultados não apresentaram diferenças significativas. Encontraram uma boa correlação $(R=0,874)$ entre o elongamento das raízes da soja com a resistência à penetração.

Ayers et al. (1992) reportaram a relação existente entre a densidade, o teor de água e a resistência à penetração do solo, através do teste de Proctor, com um esforço de compactação de $42,24 \mathrm{~N}$. O solo apresentava $50 \%$ de argila e $50 \%$ de areia. O resultado apresentou uma densidade máxima de $2,37 \mathrm{~g} / \mathrm{cm}^{3}$ quando o solo estava com teor de água de 
$10 \%$, e a resistência à penetração máxima no valor de $3300 \mathrm{kPa}$, obtida com um teor de água de $5 \%$. Verificaram que a máxima resistência à penetração não ocorre para um teor de água que produz a máxima densidade. Concluíram que a densidade influencia na resistência à penetração quando o solo possui baixo teor de água, apresentando menor influencia quando o teor de água for mais elevado.

Avaliando o comportamento do solo em relação a resistência à penetração, em parcelas com controle de tráfego de máquinas agrícolas em plantio direto e convencional, Daniel et al. (1993), verificaram que quando o teor de água no solo estava na faixa de 3,3 a $6,8 \%$, para a profundidade de $7,5 \mathrm{~cm}$, a resistência do solo nos locais por onde houve deslocamento dos pneus, atingiu um valor médio de $3188,25 \mathrm{kPa}$.

Daniel et al. (1995) verificaram o efeito da formação e localização de camadas compactadas em um Podzólico Vermelho Amarelo, em diferentes métodos de manejo, através do parâmetro de resistência à penetração do solo, para as profundidades até $60 \mathrm{~cm}$ nos anos de 92 a 95 . Concluíram que os tratamentos com maior grau de mobilização do solo (arado de disco, grade de disco e enxada rotativa) indicaram formações e presença de camadas de solos compactadas, os valores de resistência a penetração, considerada pelos autores como condição não desejável ao solo, estavam acima de $1962 \mathrm{kPa} e$ de forma mais pronunciada nas camadas de 15 à $30 \mathrm{~cm}$. Equipamentos de menor grau de mobilização do solo (escarificador, sistema alternado de implementos e plantio direto) condicionam o solo a apresentar camadas compactadas em profundidades maiores e resultados menores de $1962 \mathrm{kPa}$.

\subsubsection{Teor de água no solo}

A compactação altera a estrutura do solo, afetando na maior parte a mudança de volume, tamanho e espaço poroso, o qual determina a transmissão e o teor de água, Warkentin (1971). 
Em dois tipos de solo argilo arenoso e areno argiloso, Ohu et al. (1987) estudaram os efeitos de três diferentes aplicações de esforços para avaliar a compactação através do teste de Proctor com 5, 10 e 15 golpes e seis niveis de umidade $(5,10,15,18,22$ e $25 \%)$. Obtiveram os resultados para o solo argiloso com uma umidade ótima de $12,5 \%$. A densidade do solo resultou em 1,66; 1,69 e $1,73 \mathrm{~g} / \mathrm{cm}^{3}$ em relação ao golpes. Para o solo areno argiloso a umidade ótima foi de $16 \%$ resultando em 1,$64 ; 1,67,1,69 \mathrm{~g} / \mathrm{cm}^{3}$. Isto demostrou que o solo argilo arenoso é mais susceptivel à compactação do que o solo areno argiloso.

Beltrame et al. (1980) relatam que diferentes causas e fatores contribuem para aumentar os níveis de compactação sendo a umidade do solo no momento de aplicação de forças uma delas.

Howard et al. (1981) pesquisaram a influencia do teor de água em seis diferentes tipos de solo em áreas florestais da Califórnia. Para promover a compactação, os autores utilizaram-se em laboratório do teste de Proctor, através de 30, 50 e 100 golpes a 221, 368 e $737 \mathrm{Nm}$, sendo o solo submetido a capacidade de campo, com uma pressão de $-32,37 \mathrm{kPa}$. Os autores confirmaram a importância do teor de água na compactação, avaliando a interação entre o teor de água e o esforço de compactação, que prediz como o solo reage.

Coleti et al. (1983) realizaram estudos de compactação tendo como variáveis o numero de passadas de um caminhão com 15 ton. e o período em horas após uma precipitação simulada. Foram efetuadas 1, 2, 3, 4 e 10 passadas com o veículo no período de Oh (antes da chuva simulada), 20, $30,46,68$ hs (após a chuva simulada) após a precipitação simulada no valor de $100 \mathrm{~mm}$. Os autores concluíram que os maiores valores de compactação foram obtidos no período de até 20 horas após a precipitação e que de 50 a $60 \%$ são obtidos nas primeiras passadas. Como recomendação sugerem que o tráfego deve ser permitido somente após 30 horas após o termino das chuvas. 
Segundo Camargo (1983), a compactação aumenta a quantidade de água retida na faixa de disponibilidade (10 a $1500 \mathrm{kPa}$ ) para as plantas. $\mathrm{O}$ tamanho dos poros determina o potencial de água neles retido $e$ consequentemente a sucção necessária para esvaziá-los. Quanto maior o tamanho, menor será a sucção a ser aplicada à água, necessária para retirá-la e vice-versa.

Segundo Scopel et al. (1992), a densidade do solo sob um esforço de compressão constante aumenta progressivamente com o conteúdo de água até um ponto máximo, diminuindo com o aumento da umidade. Este ponto é conhecido como conteúdo ótimo de água para a compactação, sendo que os valores do ponto ótimo decrescem com o aumento nas forças de compactação.

\subsubsection{Infiltração de água}

Estudos realizados por Baver et al. (1972) demonstraram que o tráfego de máquinas em operações agrícolas, desde a semeadura até a colheita, causam a compactação em várias profundidades, restringindo a infiltração de água e a aeração. Um exemplo sobre os valores da taxa de infiltração em relação ao tráfego de máquinas, demostra que onde ocorreram 4 passadas de um trator sobre o solo, resultou em $2 \mathrm{~cm} / \mathrm{h}$ e em áreas que não houve tráfego, $8 \mathrm{~cm} / \mathrm{h}$.

A infiltração é influenciada por vários fatores como a superfície e a textura do solo, podendo determinar a compactação somente por medições comparativas no mesmo solo. O valor da taxa de infiltração como medida de compactação do solo é restrita para casos onde o efeito da compactação é conhecida, Chancellor (1977).

Beltrame et al. (1981) avaliaram o efeito da condutividade hidráulica de dois tipos de solo: Latossolo Vermelho Escuro álico e Planossolo, no qual obtiveram densidades de 2,67 e $2,61 \mathrm{~g} / \mathrm{cm}^{3}$ respectivamente. Verificaram uma redução maior nos valores de condutividade 
hidráulica do Latosso Vermelho Escuro pelo fato de obter válores máximos de densidade e para o Planossolo provocou efeito de compactação nas camadas subsuperficiais, reduzindo em 1/5 o valor da condutividade hidráulica.

Segundo Silva (1989) citado por Scopel (1992), as condições físicas de um Latossolo Roxo, em Ibirubá, RS, para implantação de um povoamento florestal ou outras culturas em cinco área distintas, que são: área com mata, área cultivada com pastagem, área sob plantio, direto, área desmatada com trator de esteira e área sob cultivo convencional. Observaram que a taxa de infiltração foi reduzida pelo aumento da densidade na área de desmatamento efetuado com trator de esteira e na área de mata encontraram uma menor densidade e resistência a penetração.

Nóbrega et al. (1996) pesquisaram o efeito da taxa de infiltração de água de um Latossolo Vermelho-Amarelo sob cultivo contínuo e em floresta remanescente. Obtiveram curvas de infiltração para as duas áreas, observando que não houve diferença significativa na infiltração inicial, porém aos 120 minutos a velocidade de infiltração na floresta foi de $174,47 \mathrm{~cm} / \mathrm{h}$ e na área de cultivo foi de $102,20 \mathrm{~cm} / \mathrm{h}$ com uma redução de $41,42 \%$.

\subsection{Efeitos da compactação do solo em culturas}

Os efeitos que a compactação do solo causam nas plantas segundo Mantovani (1987), são: a demora na emergência, diminuição no tamanho, folhas com coloração não característica, sistema radicular superficial e raízes mal formadas.

As culturas sensíveis a deficiências hídricas têm sua produtividade diminuída em razão da limitação imposta pela compactação ao volume de solo explorado pelas raízes em busca de água, Beltrame et al. (1980). 


\subsubsection{Efeitos da compactação do solo em povoamento florestais}

Foil et al. (1967) em condições de laboratório, provocaram a compactação em três tipos de solo: argiloso, arenoso e argilo arenoso. Os dados foram coletados em uma floresta de Pinus taeda $\mathrm{L}$. com os seguintes tratamentos: solo solto, imperturbado, com pressão de $342,35 \mathrm{kPa}, 686,70 \mathrm{kPa}$ e $1030,05 \mathrm{kPa}$. Verificou-se a menor densidade $\left(0,86\right.$ a $\left.1,38 \mathrm{~g} / \mathrm{cm}^{3}\right)$ para o solo argiloso e maior densidade $\left(0,95\right.$ a $\left.1,32 \mathrm{~g} / \mathrm{cm}^{3}\right)$ para o solo argilo arenoso.

Em um estudo realizado por Sands et al. (1978) para verificar o comportamento das raízes de Pinus radiata em vasos, os autores observaram que a densidade estando entre 1,35 a $1,48 \mathrm{~g} / \mathrm{cm}^{3}$ ocorreu $17 \%$ da redução das raízes e entre 1,48 a $1,60 \mathrm{~g} / \mathrm{cm}^{3}$ esta redução passou para a faixa de 37 a $48 \%$. Porém, comparados os efeitos da redução das raízes no campo estes valores podem ser mais elevados. Outro estudo realizado por Sands et al. (1979) avaliaram que a penetração de raízes foi severamente restringida a uma resistência à penetração do solo de $3000 \mathrm{kPa}$.

Davis et al. (1983) verificaram a distribuição de raízes de Pinus radiata relacionados com as características físicas e químicas do solo para cinco diferentes tipos de solo localizados na Tasmânia. A maior concentração de raízes foi de $11,56 \mathrm{~mm} / \mathrm{cm}^{3}$ para a camada de 0 a $10 \mathrm{~cm}$ e a menor foi de $0,13 \mathrm{~mm} / \mathrm{cm}^{3}$ para a camada de 30 a $40 \mathrm{~cm}$. Concluiram que o teor de matéria orgânica tem uma maior correlação com a concentração de raízes e a densidade pode ser um bom indicativo para esta concentração.

Nambiar (1983) pesquisou o desenvolvimento e a configuração de Pinus radiata e verificou que 80 a $90 \%$ das raízes laterais concentram-se nos primeiros $30 \mathrm{~cm}$ de profundidade.

Borges et al. (1986) realizaram um experimento em casa de vegetação para verificar a influencia da densidade no desenvolvimento inicial de três espécies de eucaliptos (Eucalyptus grandis, E. tereticornis e E. camaldulensis). Para tanto utilizaram-se de vasos com amostras de um 
Latossolo Vermelho-Escuro na região de Sete Lagoas, MG, para diferentes densidades: 0,$85 ; 1,05 ; 1,15 ; 1,25 ; 1,35 \mathrm{~g} / \mathrm{cm}^{3}$. Observaram que houve um pequeno decréscimo na produção da parte aérea e a produção de raízes na camada compactada foi sensivelmente reduzida a partir da densidade de 1,05 $\mathrm{g} / \mathrm{cm}^{3}$. Através dos resultados obtidos, perceberam que não se pode tirar uma conclusão definitiva a respeito da compactação em relação às plantas. Relataram também que em solos intensamente compactados subsuperficialmente existe impedimento à rápida infiltração, porém não havendo limitação por água e nutrientes, a compactação não deverá constituir grandes prejuizos à produtividade das culturas. A longo prazo o processo erosivo causará intensas perdas de solo e nutrientes.

Stewart et al. citado por Wästerlund (1992) descrevem que em áreas florestais do Estados Unidos com clima quente e com lenta recuperação do solo após a colheita e retirada da madeira, não ocorrendo um correto preparo do solo, pode afetar a segunda rotação reduzindo a produtividade em 6 a $16 \%$. Wästerlund (1992) relata que a recuperação do solo pode persistir durante 5 a 10 anos.

Segundo Silva et al. (1995) o crescimento em altura de plantas de um povoamento florestal de Eucalyptus grandis em um solo podzólico Vermelho Amarelo não estão associados com teor de água e resistência à penetração do solo.

\subsubsection{A compactação e os equipamentos florestais}

Segundo Hatchell et al. (1970), o tráfego de máquinas aumenta gradualmente a densidade na superfície do solo a cada passada, observando que $10 \%$ deste aumento ocorreu após a nona passada. Observaram também que a compactação do solo em áreas florestais que ocorre através de colheita e do transporte de madeira, pode persistir durante 19 anos. 
Campbell et al. (1973) analisaram as propriedades físicas de um solo areno argiloso na Georgia (EUA), antes e após a passagem de um trator empregado para o transporte de madeira. $\mathrm{Na}$ área estava implantada uma floresta de pinus, e o solo apresentava uma umidade de aproximadamente $30 \%$. Os resultados mostraram um aumento de $10 \%$ na densidade, de 1,25 para $1,35 \mathrm{~g} / \mathrm{cm}^{3}$. Os autores observaram que a sobrevivência e crescimento das plantas não foram afetados pela compactação.

King (1979), após estudar cinco tipos de máquinas florestais, observou que o problema da compactação não está na primeira fase que é a da colheita com os "harvester" e sim com a remoção da madeira feita pelo "forwarder" e "skidder".

King et al. (1979) realizaram uma pesquisa usando um "harvester" TH-105 e um "forwarder" em uma plantação de Pinus elliotti Engelm. O peso do "harvester" foi de 9,55 ton. e o "forwader" 12,30 ton. Descrevem que não foi detectado danos ao solo, pois a distribuição da cobertura vegetal, contribui para uma minimização da compactação.

Em um solo areno argiloso, Kreh et al. (1984) pesquisaram os efeitos em uma floresta de Pinus virginiana Mill de dois tipos de máquinas: "skidder" de pneus e um trator de esteiras, com pressão de contato 58 e 114 $\mathrm{kPa}$ respectivamente. Os tratamentos utilizados foram referentes a múltiplas passadas $(0,1,3$ e 9$)$ com teor de água de 18 e $21 \%$. Observaram que mesmo com diferentes pressões de contato, as duas máquinas causaram um aumento na densidade do solo. Os dois níveis de umidade afetaram a densidade após nove passadas aumentando em $13 \%$ seu valor e o volume foi reduzido em $34 \%$ após uma passada e $54 \%$ após a nona passada.

Jakobsen et al. (1985) estudaram em dois tipos de solos, arenoso e argilo arenoso, a compactação em uma floresta de pinus causada pelo tráfego de um "forwarder" pesando 26 ton. Observaram que os valores da resistência à penetração do solo aumentaram de 196 a $294 \mathrm{kPa}$ a cada passada da máquina. 
Myhrman (1990) fez um teste com nove diferentes máquinas florestais para verificar a formação de sulcos no solo devido ao tráfego. Para o teste utilizou-se de cinco "forwarders" com oito rodas, três "harvesters" com quatro rodas e um com seis. Para os "forwarders" que estavam carregados com $75 \%$ de sua capacidade máxima, a profundidade do sulco foi determinada após a passagem de uma carga útil equivalente a $50 t$ e a pressão de contato variou entre 54 a $86 \mathrm{kPa}$. Notou-se que para uma pressão no solo acima de $75 \mathrm{kPa}$ a camada superficial de vegetação foi quebrada pelo peso da máquina e a formação de sulcos aumentou rapidamente. A relação entre a profundidade (cm) e a pressão de contato no solo $(\mathrm{kPa})$ resultou em ordem crescente para os seguintes "forwarders": Valmet 828 (14,75 ton.), FMG 678 (15,8 ton.), FMG $250 / 800$ (22,8 ton.), Bruun Super Mini (17,84 ton.), Valmet 838 (20,1 ton.) e FMG 250/600 (22 ton.). O equipamento FMG 250 foi testado com pneus de larguras diferentes, 600 e $800 \mathrm{~mm}$, observando que com o aumento da largura ocorreu a redução na formação do sulco.

Keilen (1992) realizou um estudo na Estação de Pesquisas Florestais de Rheinlend-Pfalz verificando o efeito do tráfego em um solo argiloso com e sem cobertura de galhada. Realizou cinco passadas no tratamento com cobertura de galhada e para o tratamento sem cobertura uma e três passadas. Concluiu que não foi possível constatar aumento nos índices de compactação abaixo da galhada e nem o local da passagem do veículo. Onde não existia a cobertura os índices aumentaram mais para a primeira passada, formando trilhos no local de tráfego nas passagens subsequentes.

Reisinger et al. (1992) verificaram o comportamento de um solo limo argiloso após a colheita. Foram selecionados seis tipos de locais com florestas similares, sendo que as amostras de densidade foram coletadas em dois locais para cada ano 1984, 1986 e 1988. O equipamento de colheita utilizado foi um "skidder" de pneus. Observaram que a densidade no período 84 a 86 , aumentou de 1,19 a $1,28 \mathrm{~g} / \mathrm{cm}^{3}$ e 86 a 88 anos decresceu em $17 \%$. Concluíram que para o solo se recuperar ele necessita de pelo menos 4 anos. 


\subsubsection{Efeito da compactação do solo em área agrícola}

Flocker et al. (1960) estudaram o efeito da compactação nas culturas de batata (Solanum tuberosum L.) e tomate (Lycopersicum esculentum Mill) em um solo areno argiloso, em Davis na Califórnia, onde foram aplicados três tratamentos: compactação severa, moderada e não-compactado. Observaram que a produtividade do tomate não foi reduzida pela compactação, mas para a batata a produtividade e a qualidade foram afetadas, alcançando uma redução de $50 \%$. De acordo com os autores existem duas possibilidades que expliquem estes resultados: a) a compactação impediu que as sementes emergissem, podendo ser atribuída ao aumento da densidade no solo; b) as raízes da batata permanecem naturalmente na superfície, e a compactação limita o volume de solo que as raízes podem explorar.

Grohmann et al. (1966), submeteram a esforços de compactação, dois tipos de solo: Latossolo roxo e Podzólico Vermelho Amarelo-orto. Os ensaios foram realizados em condições de laboratório a fim de testarem a capacidade de penetração das raízes de arroz. Os resultados mostraram que houve um impedimento ao desenvolvimento do sistema radicular para o Latossolo roxo quando compactado até a densidade $1,42 \mathrm{~g} / \mathrm{cm}^{3}$ e teor de água a $33 \%$ e para o Podzólico vermelho Amarelo-orto, $1,38 \mathrm{~g} / \mathrm{cm}^{3}$ com $30 \%$ de teor de água.

Taylor et al. (1969) mensuraram a força de crescimento das raízes do algodão (Gossypium hirsutum L.), ervilha (Pisum sativum L.) e amendoim (Arachis hypogaea L.) através de "strain gage". O resultado apresentado foi de $922,14 \mathrm{kPa}, 1275,3 \mathrm{kPa}$ e $1128,15 \mathrm{kPa}$ respectivamente para cada variedade. Segundo Taylor (1974) citado por Mielniczuk et al. (1985) a resistência à penetração do solo correlaciona com o desenvolvimento radicular, porém não reflete exatamente a resistência do solo que oferece pela raiz.

Fernandes (1979) realizou um trabalho com o objetivo de verificar o comportamento da cana-de-açúcar (Saccharum ssp), variedade CB 41-76, cujo 
sistema radicular tenha se desenvolvido com diferentes intensidades de compactação em um Latossolo Vermelho-Escuro. Utilizou-se para o trabalho de um caminhão com 15 ton. de peso bruto realizando uma, duas e três passadas sobre a área, mantendo uma testemunha. Verificou o efeito acumulativo de compactação, quando ocorreu as passadas do veículo para duas e três vezes na mesma faixa, observando um maior índice de compactação nas entrelinhas. Após 12 meses, os valores de densidade obtidos foram de 1,$25 ; 1,25 ; 1,35$; $1,40 \mathrm{~g} / \mathrm{cm}^{3}$ respectivamente. Observou que os locais mais compactados apresentaram maior população de colmos por metro de sulco o peso dos colmos diminuiu com o aumento do número de passadas do veículos.

Hemsath et al. (1974) estudaram a elongação da raiz do sorgo (Sorghum bicolor L.) com uma mistura de areia-argila em vasos com densidades de 1,$0 ; 1,25 ; 1,5 ; 1,75 \mathrm{~g} / \mathrm{cm}^{3}$. As amostras foram posicionadas sobre um prato poroso e adicionado água até a saturação, aplicando pressões para obter matriz de sucção de 15, 33, 170 e $860 \mathrm{kPa}$. Através deste estudo avaliou-se a relação entre o comprimento da raiz e a resistência à penetração que resultou em um valor crítico de $1960 \mathrm{kPa}$, o qual afetou o crescimento da raiz.

Fernandes et al. (1983) determinaram a compactação de um Latossolo Vermelho Escuro argiloso, para a cultura de cana-de-açúcar. Após a última colheita realizou-se a compactação do solo, nas linhas e entrelinhas utilizando-se de um caminhão de 16 ton. 0 experimento constou de tratamentos onde o solo não estava compactado e com compactação referente a 1, 2, 3 passadas de veículos, com umidade do solo de $32 \%$. Com 12 meses analisou-se o comportamento da cultura, concluindo-se que a compactação reduziu a evaporação da água na superfície e contribuiu para a brotação de maiores números de gemas da touceira. Porém, se esta compactação se tornar mais elevada seria prejudicial ao desempenho das novas raízes emitidas pela planta em formação, tornando as canas mais curtas e finas. 
Mielniczuk et al. (1985) estudaram o comportamento de raízes em solos compactados para as culturas de colza (Brassica nopus $\mathrm{L}$ ), soja, tremoço (Lupinus albus $\mathrm{L}$ ), aveia (Avena sativa $\mathrm{L}$ ), milheto e trigo (Triticum vulgare $\mathrm{L}$ ), com três niveis de compactação (1,2 e 3) com densidade de 0,$9 ; 1,3$ e 1,5 $\mathrm{g} / \mathrm{cm}^{3}$ e resistência à penetração de 196,$2 ; 2354,4 ; 3139,2 \mathrm{kPa}$. O solo apresentava teor de água de $28,4 \%$. Os resultados obtidos demostraram que não houve penetração de raízes no nível mais alto de compactação e uma redução no sistema radicular para os niveis 1 e 2 .

Segundo Borges et al. (1988) sobre o efeito da compactação ainda não se pode tirar uma conclusão definitiva, pois em algumas culturas ela leva a redução da produtividade e em outras ocorre o aumento.

Ngunjiri et al. (1995) analisaram os efeitos do tráfego em um solo com $21 \%$ de argila, $67 \%$ de silte e $12 \%$ de areia para verificar a produtividade da cultura de milho nos anos de 1992 e 1993. Os resultados obtidos no ano de 1992 para os tratamentos analisados que foram os que receberam tráfego na área total e sobre as linhas, obtiveram os valores de 61.000 plantas/ha comparado com 59.000 plantas/ha obtidos nas áreas sem e com tráfego nas entrelinhas. Porém em 1993 os resultados foram opostos; o tráfego na área total e sobre as linhas obtiveram 63.000 plantas/ha e os tratamentos obtidos das áreas com e sem tráfego nas entrelinhas foram de 65.000 plantas/ha. Concluíram que o tráfego na área total reduziu a produtividade de milho, enquanto que nas entrelinhas, não influenciou na produtividade. 


\section{MATERIAL E MÉTODOS}

\subsection{Material}

\subsection{1 Área experimental}

O experimento foi realizado em área de plantio comercial da Cia. Suzano de Papel e Celulose, onde o cultivo do Eucalyptus saligna encontravase com nove anos de idade, primeira rotação e segundo ciclo.

A área experimental está localizada no Município de São Miguel Arcanjo, Estado de São Paulo e apresenta as seguintes coordenadas: Latitude $23^{\circ} 51^{\prime} \mathrm{S}$; Longitude $47^{\circ} 54^{\prime} \mathrm{W}$; e Altitude $725 \mathrm{~m}$. O relevo tem uma declividade na faixa de 0 a $6^{0}$.

O solo é classificado como Podzólico Vermelho Amarelo, tb, distrófico, A moderado de textura franco-argilo arenoso, correspondente a $50,74 \%$ de argila e $31,11 \%$ de areia. A análise granulométrica e química esta sendo apresentada nos Anexos A e B.

O histórico da área experimental, fornecido pela Cia. Suzano, mostra que a atual cultura foi implantada de acordo com três etapas básicas correspondentes ao preparo do solo, o plantio e a aplicação de defensivos. $O$ preparo do solo foi realizado com um sulcador monohaste com adubadora, fabricação própria da Cia Suzano, com peso aproximado de $10,2 \mathrm{kN}$ acoplado a um trator marca Valmet, modelo 985 . A profundidade de trabalho foi de 30 $\mathrm{cm}$, aplicando-se na mesma operação fertilizante e herbicidas ( pré e pós- 
emergente). O plantio foi realizado manualmente em outubro/87 e após quatro meses foi efetuada uma capina mecânica e a desbrota manual. Após sete meses da data do plantio efetuou-se a aplicação de herbicida, com pulverizador de barras tratorizado. Na Figura 1 é apresentada a área antes da realização da colheita.

A precipitação mensal verificada na sede da Cia Suzano, próxima ao local do ensaio, para o período de janeiro de 1987 a dezembro de 1996 é apresentada no Anexo $\mathrm{C}$.

O DAP das árvores foi medido através de uma suta, marca Haglof e a altura das plantas com um altímetro, marca Haga.

\subsubsection{Equipamentos}

Os equipamentos aqui descritos referem àqueles utilizados para a colheita e retirada da madeira, na avaliação da compactação e características do solo e para a determinação das características dimensionais e ponderais das plantas.

A colheita foi realizada com uma colhedora, doravante denominada de "harvester" da marca' AFM, modelo 60, montada sobre plataforma de um trator de esteiras, marca Caterpillar modelo 320 , com potência $95 \mathrm{~kW}$ a 1800 rpm no motor e peso de 187,18 kN (Figura 2).

\footnotetext{
${ }^{1}$ As marcas comerciais utilizadas pelo autor não significam recomendações técnicas
} 


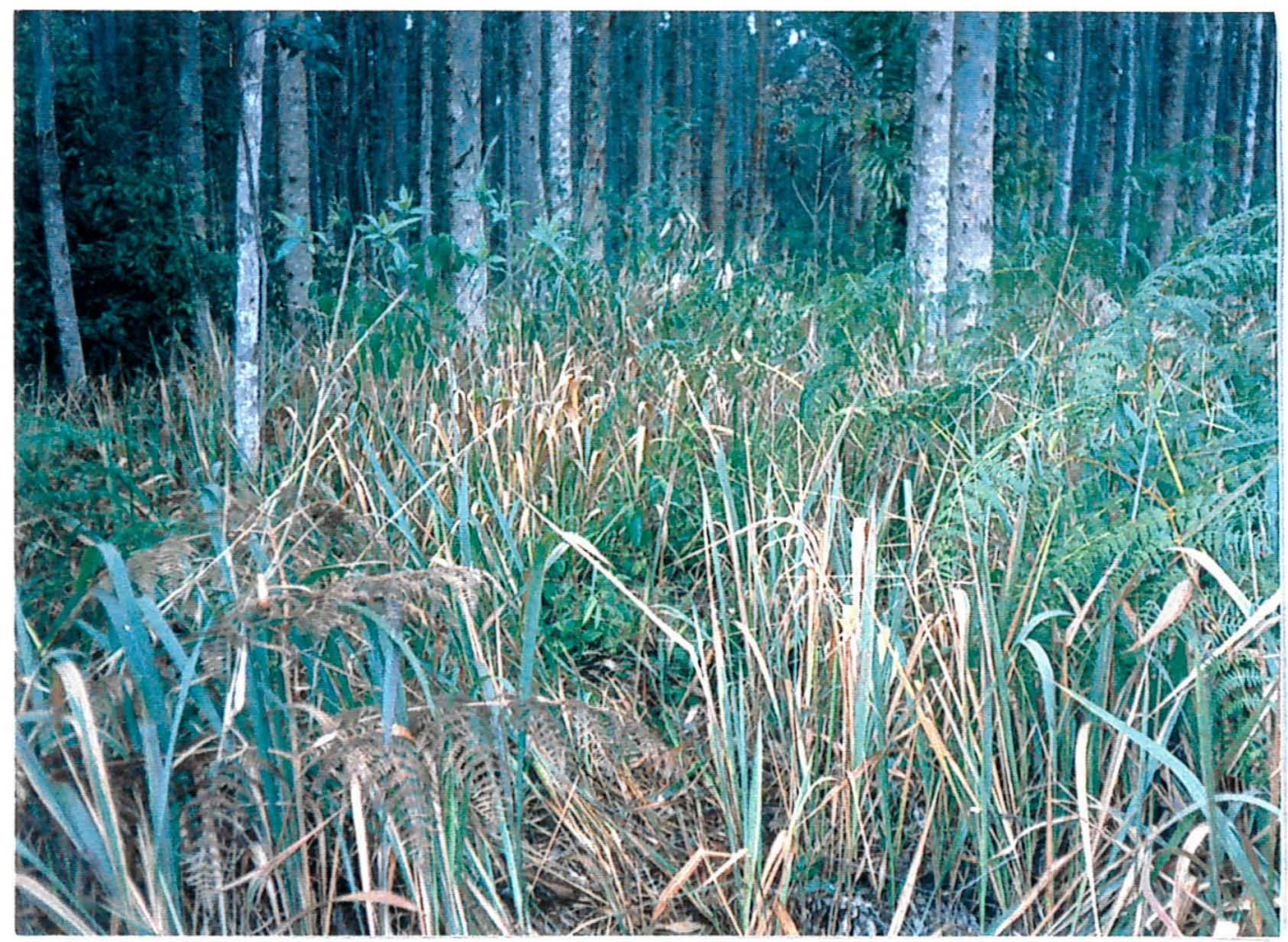

Figura 1 - Área experimental antes da colheita

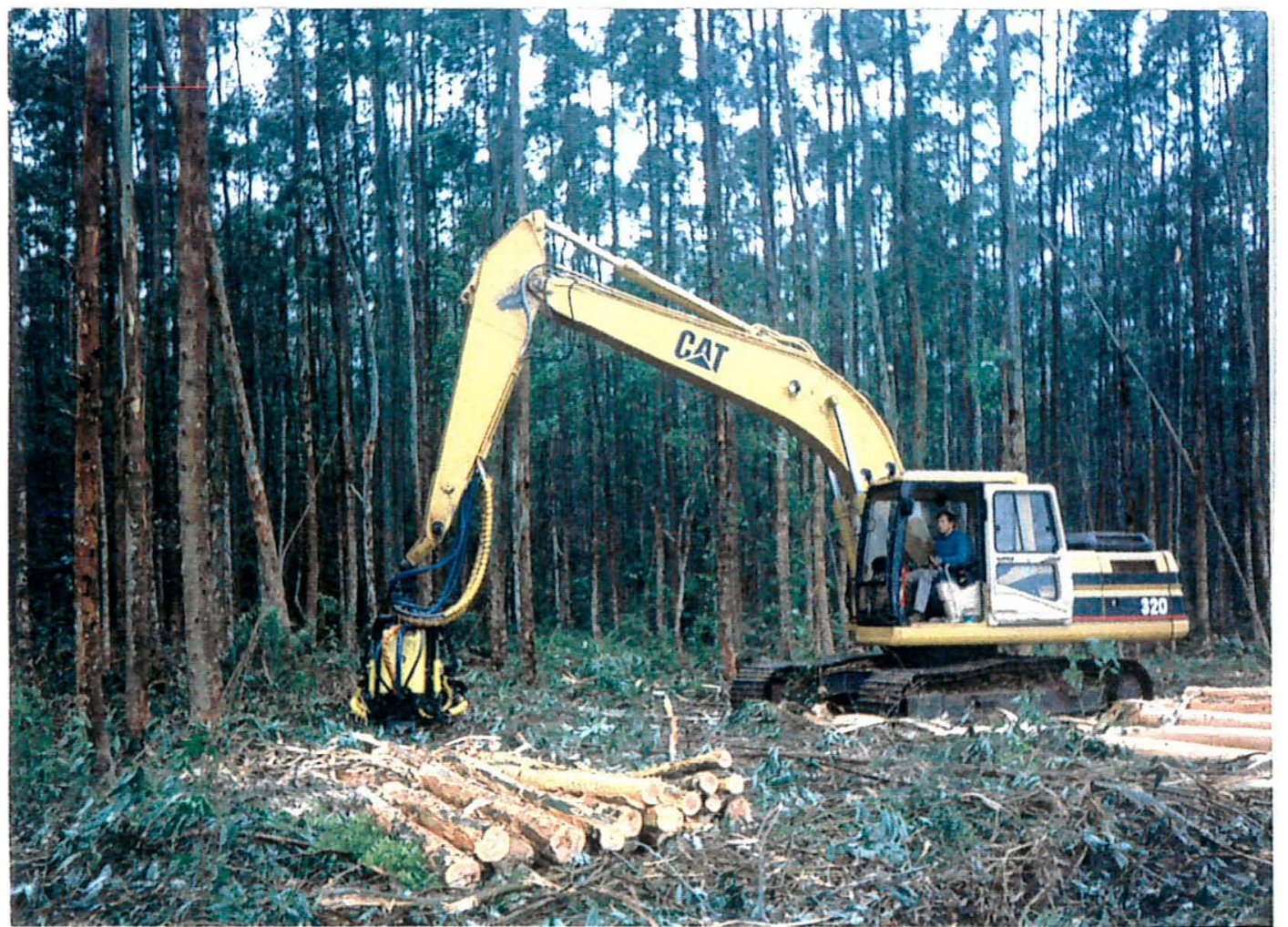

Figura 2 - Colhedora da marca AFM, montada sobre a plataforma de um trator de esteira, marca Caterpillar 
O transporte da madeira para fora do talhão foi executado por um conjunto do tipo auto-carregável, composto de um trator com uma carreta e um guincho hidráulico. O trator da marca Massey-Ferguson, modelo 610, tração dianteira auxiliar, com potência $63 \mathrm{~kW}$ a $2200 \mathrm{rpm}$ e peso de 49 kN, estava equipado com pneus traseiros $18.4 \times 34 \mathrm{R} 1$ e dianteiros $14.9 \times 24 \mathrm{R} 1$. A carreta era constituída por dois eixos com peso liquido de $24,60 \mathrm{kN}$ e pneus $9.0 \times 20$. 0 guincho hidráulico (grua) possuía o peso de $16,66 \mathrm{kN}$. O conjunto auto carregavel pode ser visualizado na Figura 3.

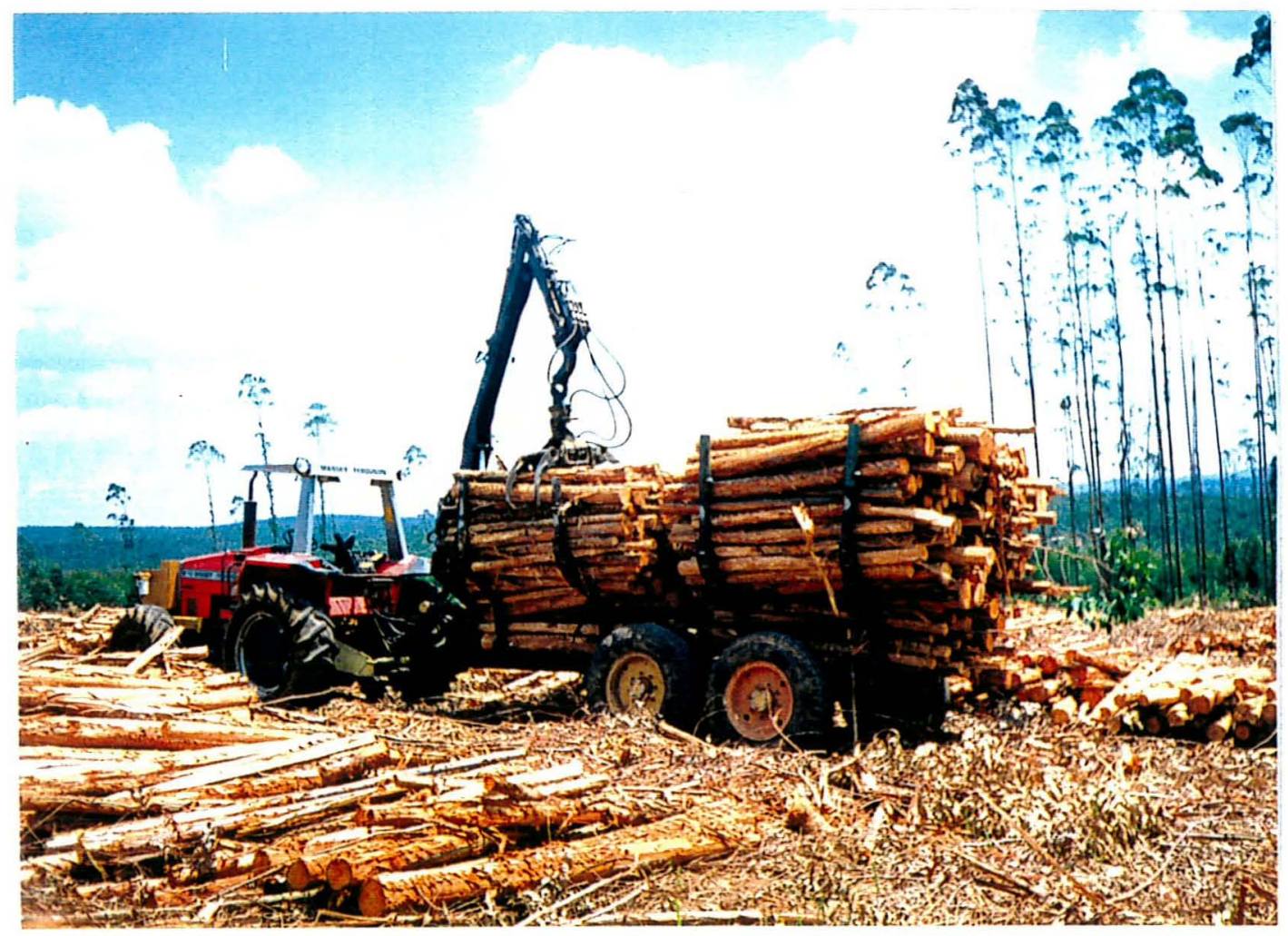

Figura 3 - Auto-carregável para a retirada da madeira, usando como fonte de potência um trator da marca Massey-Ferguson, modelo 610 


\subsubsection{Equipamentos para a caracterização do solo}

Para a avaliação dos índices de compactação e das características do solo foram utilizados os seguintes equipamentos:

- Um penetrômetro, marca Kamaq, confeccionado em aço inoxidável AISI-416, com a ponta em ângulo sólido de $30^{\circ}$ e área da base de $1,20 \mathrm{~cm}^{2}$, seguindo as dimensões padronizadas pela $\mathrm{ASAE}^{2} \mathrm{~S} 313.2$ (1983), para a determinação da resistência à penetração do solo.

- Uma sonda, marca Sondaterra, para a determinação do teor de água. As amostras foram secadas em uma estufa, marca Fanem modelo 320SE e pesadas em uma balança de precisão com resolução de $0,01 \mathrm{~g}$, marca Mettler, modelo PE2000.

- Um coletor de amostra de solo indeformável, marca AMS, com anel volumétrico de 2" de diâmetro, para a determinação da densidade.

Além destes equipamentos foram utilizados sacos plásticos, caixa de isopor para o acondicionamento das amostras, trena, máquina fotográfica, e catálogo das máquinas.

\subsection{Métodos}

As determinações foram efetuadas em duas etapas distintas, sendo a primeira antes da colheita das plantas, no período de 23 a 27 de setembro de 1996 e a segunda logo depois da colheita e a retirada da madeira do talhão, correspondendo ao período de 27 a 31 de outubro de 1996. A primeira etapa foi denominada de "antes da colheita" e a segunda "depois da colheita".

\footnotetext{
${ }^{2}$ ASAE - American Society of Agricultural Engineers
} 


\subsubsection{Delineamento Experimental}

O delineamento experimental adotado foi o de três blocos casualizados, com 2 tratamentos. Cada bloco constou de três fileiras de plantas de eucalipto, com espaçamento de $3 \mathrm{~m}$ na entrelinha e $2 \mathrm{~m}$ na linha, com 20 plantas por fileira correspondendo a uma área útil de $228 \mathrm{~m}^{2}$. Para a área de bordadura demarcou-se um espaço correspondente a 2,5 linhas no sentido de maior comprimento para cada bloco o que totaliza $798 \mathrm{~m}^{2}$ por bloco.

De acordo com o deslocamento dos equipamentos para a colheita, onde o "harvester" e o auto carregável foram orientados a operar "a cavalo" sobre a linha de plantas, definiu-se duas situações básicas. A entrelinha onde ocorreu o tráfego foi denominada de rua de tráfego (RTr) e onde foi depositada a madeira para posterior transporte com o auto carregável denominou-se de rua de madeira (RMa). Para que os tratamentos tivessem a mesma condição de campo após a colheita e retirada da madeira, monitorou-se as passadas dos veículos. Para a colheita, o "harvester" deslocou-se uma vez sobre o solo. Para a retirada da madeira, o deslocamento do auto-carregável foi de 15 passadas para cada um dos três blocos para o tratamento de tráfego. $\mathrm{Na}$ figura 4 , apresenta-se o esquema de um bloco, mostrando as situações RMa e RTr, e das amostragens efetuadas na área.

Com a finalidade de se determinar o teor de água na ocasião do tráfego das máquinas para a colheita e a retirada da madeira, coletou-se amostras nos rastros dos pneus e esteira, até a profundidade de $50 \mathrm{~cm}$ para a realização do teste de Proctor, que produziu uma curva densidade-umidade específica para o solo do experimento.

O teor de água do solo foi determinado pelo método gravimétrico. As amostras foram colocadas em sacos plásticos, lacradas, identificadas, e acondicionadas em uma caixa de isopor para posteriormente serem transportadas ao laboratório, onde foram secadas em uma estufa elétrica, a $110^{\circ} \mathrm{C}$ durante 36 horas, obtendo o peso constante (EMBRAPA, 1979). 


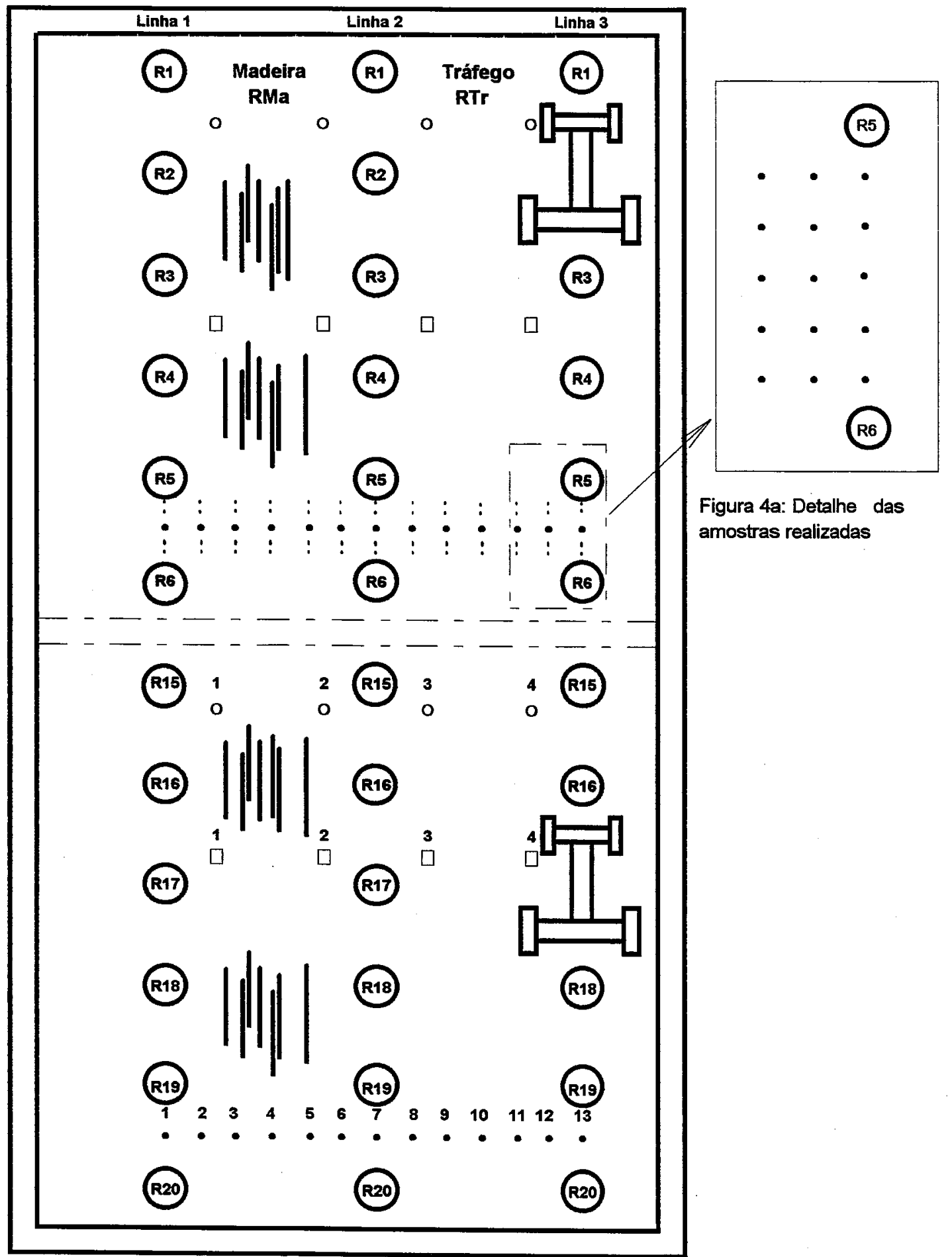

Figura 4 - Esquema da área experimental em um bloco com as amostragens efetuadas

o Teor de água

$\square$ Densidade

- Resistência do solo à Penetração

Ri Repetição das amostragens de DAP e altura de plantas 
Os levantamentos relacionados com as características dimensionais das plantas, altura e DAP, foram efetuados pela equipe de dendrometria da Cia. Suzano. Cada linha de planta no bloco foi denominadas de linha 1 (L1), linha 2 (L2) e linha 3 (L3).

Determinou-se a área de contato estimada do solo/pneu para o auto-carregável estacionando-o em um local plano e pulverizando ao redor dos pneus com cal. Em seguida retirou-se o veículo com cuidado, fotografando as marcas que permaneceram sobre o solo ao lado de uma folha de papel com dimensões conhecidas; a área de contato foi obtida através de planímetro. Para o "harvester", a área de contato foi calculada com base na largura e comprimento da esteira, medida.

Para a obtenção do peso total do auto-carregável, foram utilizados - peso da máquina estimado (catálogo) e a determinação das cargas adicionais: guincho (grua) e madeira (volume médio, multiplicando pela sua densidade).

\subsubsection{Parâmetro de compactação e características do solo}

A cobertura vegetal foi determinada, depois da colheita, com base na metodologia descrita por Dallmeyer (1994). Coletou-se duas amostras para cada tratamento nos três blocos, arremessando-se aleatoriamente um quadrado de dimensões $0,5 \mathrm{~m}$ de lado. Retirou-se todo o material contido no interior do quadrado, acondicionado-o em sacos plásticos identificados. No laboratório separou-se os materiais em: folhas, cascas, galhos e restos vegetais (material que não foi possível a identificação, devido ao estado de decomposição). Colocou-se em saco de papel, identificou-se e foi levado para a estufa, para secagem. Após a secagem sua massa foi convertida para $\mathrm{kg} / \mathrm{m}^{2}$. $\mathrm{Na}$ Figura 5 pode ser visualizado o aspecto da cobertura vegetal na área experimental. 


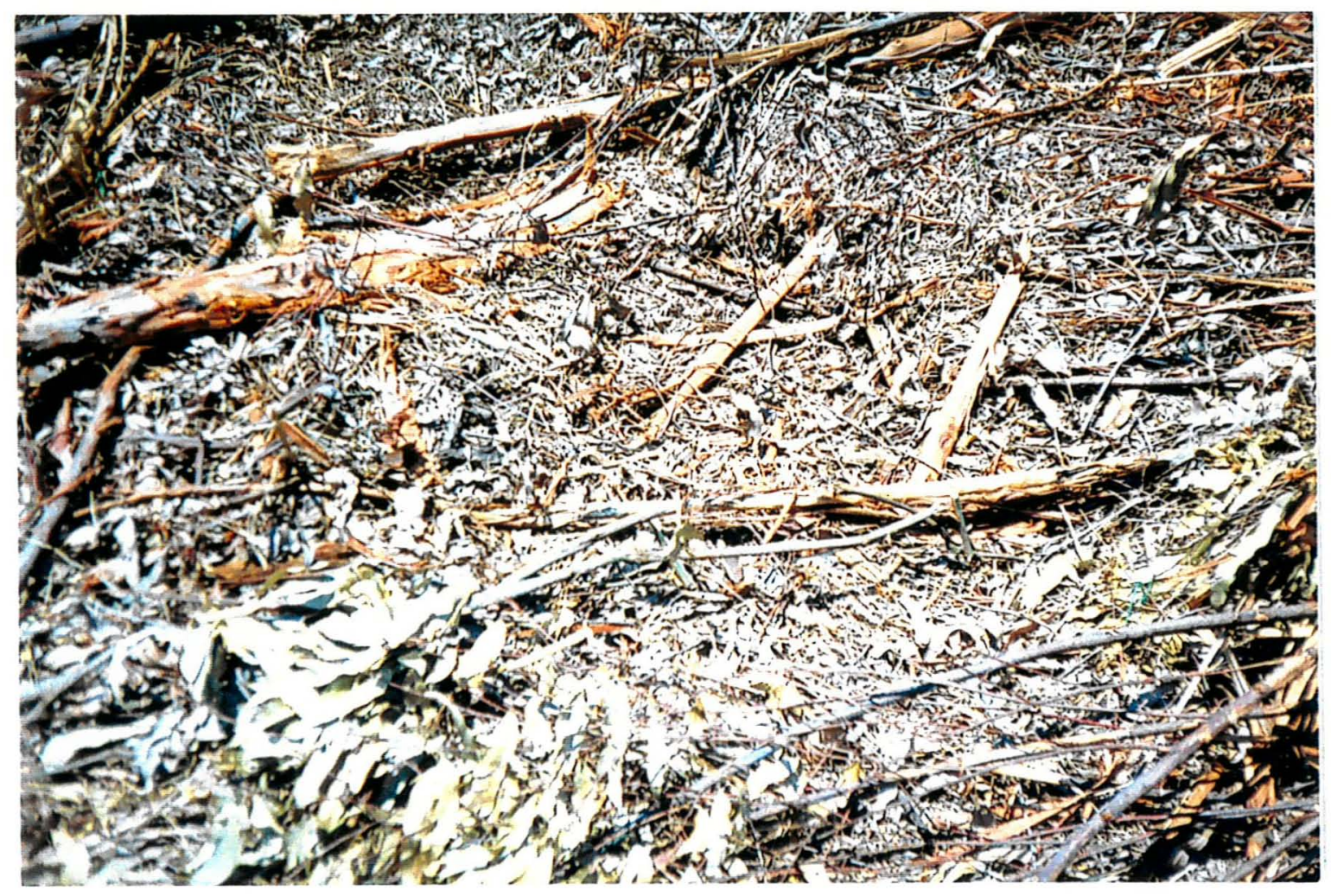

Figura 5 - Cobertura vegetal da área experimental depois da colheita.

A resistência à penetração do solo foi realizada com amostragens alocadas transversalmente às linhas de plantas em números de 13 , espaçadas entre si de $0,5 \mathrm{~m}$, com três pontos referentes as linhas e dez nas entrelinhas, com 25 repetições totalizando 325 pontos por bloco. As posições das amostragens correspondem são as seguintes: 1, 7 e 13 nas linhas de plantas; 2, 3, 4, 5 e 6 para RMa; 8, 9, 10, 11, 12 para RTr. A amostra 11 foi coletada no local onde ocorreu o deslocamento da esteira e dos pneus (rastro), os dados foram coletados até a profundidade de $50 \mathrm{~cm}$. Simultaneamente foram efetuadas as amostras do teor de água até a profundidade de $50 \mathrm{~cm}$, em intervalos de $10 \mathrm{~cm}$ em $10 \mathrm{~cm}$, com dez repetições e quatro amostras eqüidistantes, nas entrelinhas das plantas. O teor de água do solo foi determinado pelo método gravimétrico. 
Para a densidade do solo foram efetuadas quatro amostras retiradas eqüidistantes, nas entrelinhas com dez repetições, para as profundidades de $5-10 \mathrm{~cm}, 15-20 \mathrm{~cm}$ e $25-30 \mathrm{~cm}$. Amostras 1 e 2 correspondem a RMa e a 3 e 4 a RTr, sendo a amostra 4 coletada no rastro onde ocorreu o deslocamento da esteira e dos pneus. 


\section{RESULTADOS E DISCUSSÃO}

Os resultados do trabalho podem ser divididos em três etapas. A primeira apresenta e discute as características das áreas ensaiadas, a segunda refere-se aos equipamentos utilizados na operação de colheita e a terceira avalia os niveis de compactação antes e depois da colheita.

Para a análise estatística, os dados foram submetidos a análise de variância e nos casos de significância realizou-se comparações múltiplas das médias através do teste de Tukey, utilizando o programa estatístico SAS ${ }^{3}$.

\section{1 Área experimental}

A precipitação média acumulada verificada na sede da Cia Suzano Papel e Celulose, correspondente ao período de janeiro a setembro de 1996 atingiu a $923 \mathrm{~mm}$. No periodo correspondente aos ensaios, 27 de setembro a 27 de outubro, o índice pluviométrico acumulado atingiu $145 \mathrm{~mm}$.

$\mathrm{O}$ teor de água no solo atingiu no mês de outubro, quando ocorreu a colheita, $30,98 \%$ e por ocasião da retirada da madeira $32,66 \%$, na profundidade de 0 a $10 \mathrm{~cm}$, conforme pode ser observado na Tabela 1.

\footnotetext{
${ }^{3}$ SAS - Statistical Analyis System
} 
Tabela 1 - Teor de água no solo (\%) até a profundidade de $50 \mathrm{~cm}$, obtido depois dos deslocamentos dos veículos nos dias da colheita e retirada da madeira e Capacidade de Campo e Ponto de Murcha Permanente (\% em peso) até a profundidade de $40 \mathrm{~cm}$.

\begin{tabular}{ccc|ccc}
\hline \multicolumn{3}{c|}{ Teor de água (\%) } & \multicolumn{3}{c}{$\begin{array}{c}\text { Capacidade de Campo e Ponto de Murcha } \\
\text { Permanente (\% em peso) }\end{array}$} \\
\hline $\begin{array}{c}\text { Profund. } \\
(\mathrm{cm})\end{array}$ & Colheita & $\begin{array}{c}\text { Retirada da } \\
\text { madeira }\end{array}$ & Saturado & 0,1 ATM & 15,0 ATM \\
\hline $0-10$ & 30,98 & 32,66 & 38,77 & 29,64 & 26,58 \\
$10-20$ & 31,21 & 30,09 & 37,42 & 26,79 & 22,86 \\
$20-30$ & 29,31 & 28,78 & 34,99 & 27,41 & 23,51 \\
$30-40$ & 27,96 & 26,55 & 35,92 & 25,37 & 23,03 \\
$40-50$ & 26,87 & 26,47 & & & \\
\hline
\end{tabular}

Com a finalidade de se determinar os valores máximos de compactação que o solo das áreas podem atingir, realizou-se o teste de Proctor modificado, cujos resultados podem ser observados na Figura 6 através da curva densidade - teor de água.

$O$ teste de Proctor modificado realizado mostra que a densidade máxima que o solo pode atingir é $1,72 \mathrm{~g} / \mathrm{cm}^{3}$ quando o teor de água está em $16,1 \%$, sendo estes valores inferiores àqueles obtidos durante as operações de colheita e retirada da madeira. Este fato indica que nesta época, o solo não atingiria o índice de compactação máximo pois o teor de água era superior ao limite critico. 


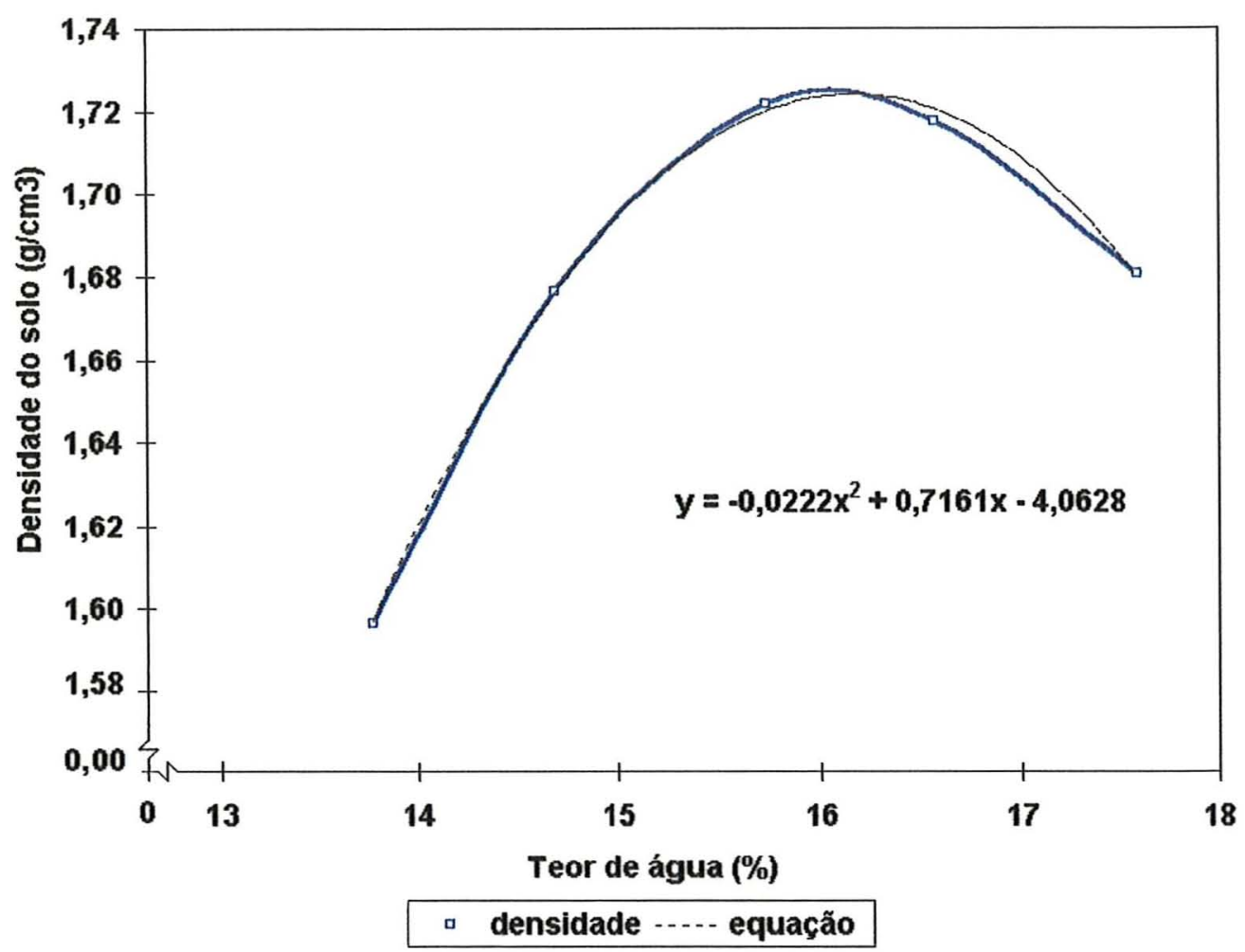

Figura 6 - Teste de Proctor modificado

Com a finalidade de se avaliar as dimensões das plantas, após o ciclo de crescimento de nove anos, efetuou-se as medições de DAP e altura das plantas, não sendo observadas diferenças significativas entre as linhas, conforme apresentado na Tabela 2. O coeficiente de variação tem valores elevados, $65 \%$ e $66 \%$ para DAP e altura respectivamente, indicando a não uniformidade no crescimento da floresta. $O$ índice médio de falhas atingiu a $23,3 \%$. 
Tabela 2 - Valores médios de DAP e altura das plantas de eucalipto para as linhas 1,2 e 3 de plantas.

\begin{tabular}{ccc}
\hline Tratamentos & $\begin{array}{c}\text { DAP (médio) } \\
(\mathbf{m m})\end{array}$ & $\begin{array}{c}\text { Altura de plantas (média) } \\
(\mathbf{m})\end{array}$ \\
\hline Linha 1 & $132.33 \mathrm{a}^{*}$ & $19.64 \mathrm{a}$ \\
Linha 2 & $148.58 \mathrm{a}$ & $21.67 \mathrm{a}$ \\
Linha 3 & $127.25 \mathrm{a}$ & $18.03 \mathrm{a}$ \\
\hline C.V.** $(\%)$ & 65 & 66 \\
\hline
\end{tabular}

* Médias seguidas da mesma letra não diferem significativamente entre si.

${ }^{\star *}$ C.V. - Coeficiente de Variação (\%)

A Figura 7 apresenta o histograma para todas as plantas analisadas em relação à altura das plantas e a sua conformação do tipo multi-modal, confirma a sugestão de não uniformidade.

Altura das Plantas

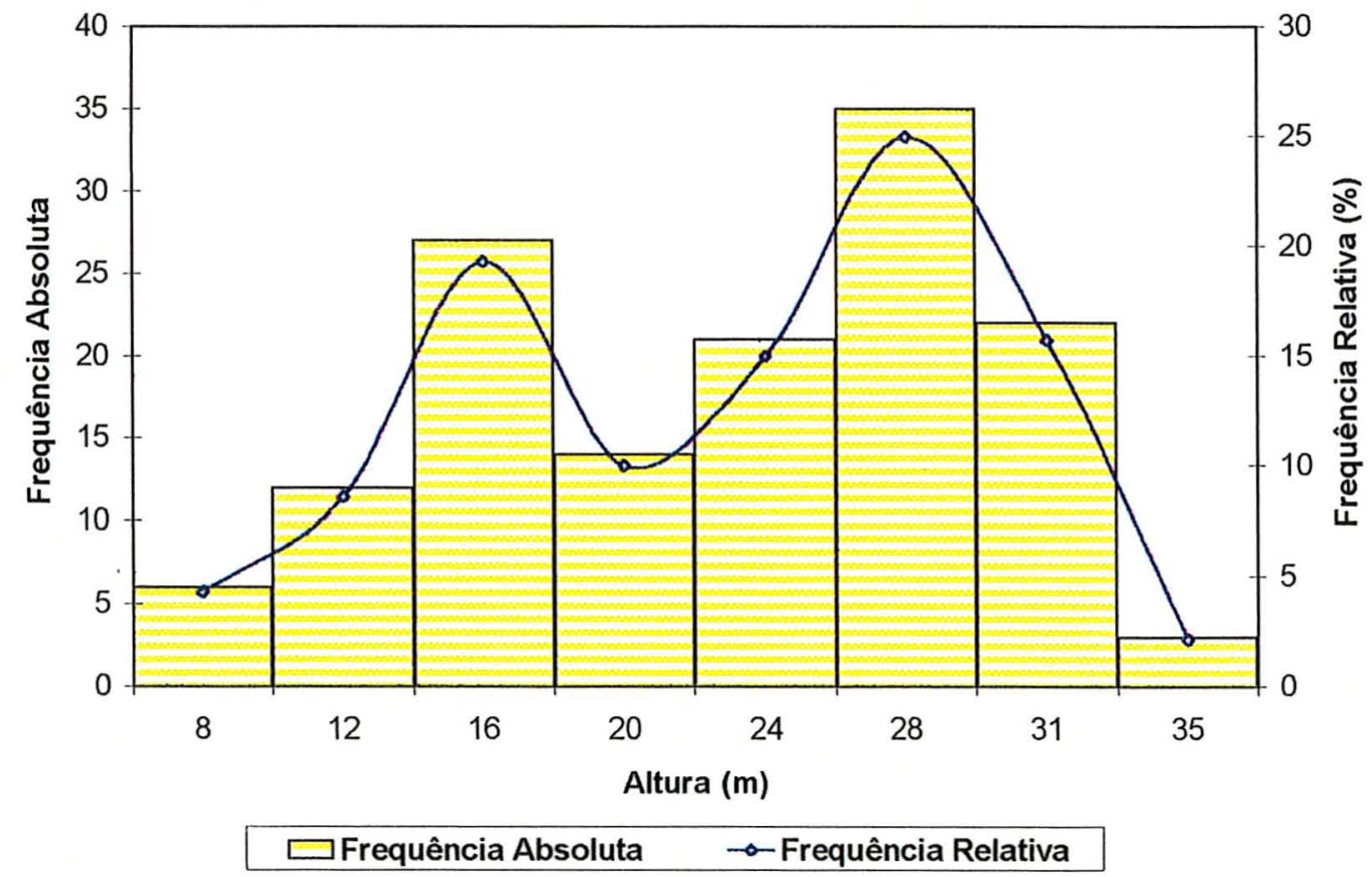

Figura 7 - Histograma referente a altura $(m)$ das plantas. 
Na Figura 8 é apresentado o histograma referente ao DAP com aproximadamente $34 \%$ das plantas na classe de 124 a $156 \mathrm{~mm}$, constatando-se também uma distribuição não uniforme .

\section{DAP das Plantas}

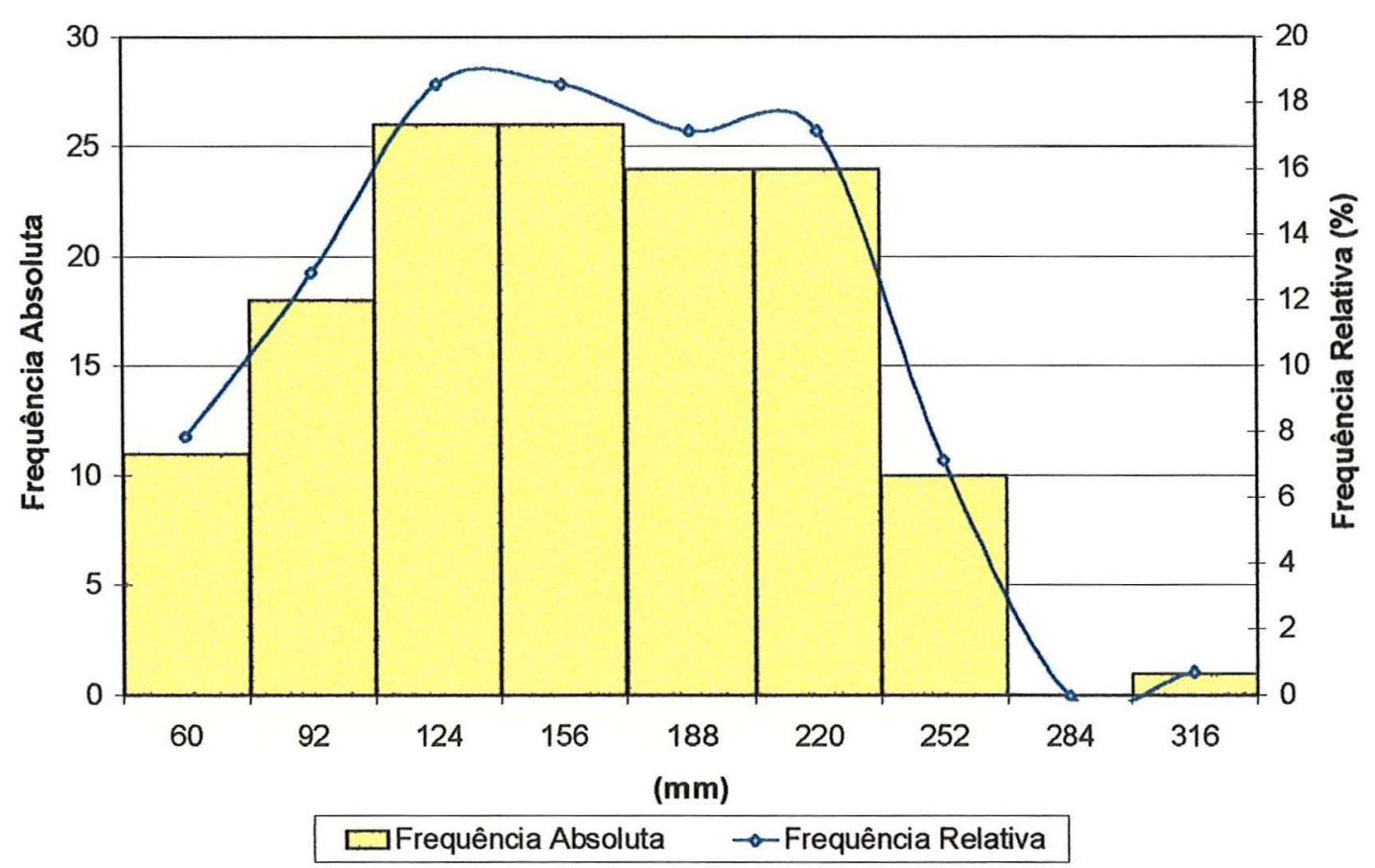

Figura 8 - Histograma referente ao diâmetro $(\mathrm{mm})$ na altura do peito (DAP) das plantas.

\subsection{Equipamentos: Pressão de contato rodado/solo}

De acordo com a metodologia utilizada, os valores estimados para a pressão de contato rodado-solo demostram que o "harvester" é o equipamento de menor valor, Tabela 3. A carreta utilizada para a retirada da madeira apresenta um valor para a pressão 17 vezes maior do que "harvester" com um peso 3,8 vezes menor sendo que a explicação está no tipo de rodado utilizado. Enquanto que o "harvester" utiliza-se de esteira, a carreta tem pneus convencionais de uso veicular, com pequena área de contato. Em relação ao 
trator a pressão dos pneus da carreta é superior em 9,4 vezes para os pneus dianteiro e 5,8 vezes para os pneus traseiros.

Tabela 3 - Pressão de contato estimada para os equipamentos utilizadas no experimento.

\begin{tabular}{ccccc}
\hline Tipo de Máquina & $\begin{array}{c}\text { Tipo de } \\
\text { Rodado }\end{array}$ & $\begin{array}{c}\text { Área de } \\
\text { Contato } \\
\left(\mathbf{c m}^{2}\right)\end{array}$ & $\begin{array}{c}\text { Peso da } \\
\text { Máquina } \\
(\mathbf{k N})\end{array}$ & $\begin{array}{c}\text { Pressão de } \\
\text { Contato } \\
(\mathbf{k P a})\end{array}$ \\
\hline "Harvester" & Esteira & 41880,00 & 21,80 & 52,11 \\
Massey Ferguson 610 & Pneus Diant & 1932,08 & 18,08 & 93,68 \\
& Pneus Tras & 2016,18 & 31,01 & 153,51 \\
Carreta+madeira+grua* & Quatro Pneus & 935,06 & $82,87^{*}$ & 887,10 \\
& (Diant +Tras) & & & \\
\hline
\end{tabular}

* Peso unitário: Carreta 24,60 kN; madeira 41,70 kN; guincho (grua) $16,66 \mathrm{kN}$

Em estudos realizados por Fernandes (1979) com caminhão empregado para o transporte de cana, os valores de pressão de contato pneusolo situaram-se no intervalo de $101 \mathrm{kPa}$ a 496,38 kPa. A Tabela 4 apresenta valores de pressão de contato aproximado para algumas máquinas florestais, Seixas (1996).

Tabela 4 - Valores de pressão de contato para máquinas florestais.

\begin{tabular}{lc}
\hline \multicolumn{1}{c}{ Equipamentos } & Pressão (kPa) \\
\hline "Skidder" de esteiras flexíveis & $30-40$ \\
Trator de esteira & $50-60$ \\
"Skidder" de pneus & $55-85$ \\
"Forwarder" com eixo duplo traseiro & $85-100$ \\
"Forwarder" com eixo simples traseiro & $105-125$ \\
\hline
\end{tabular}

Fonte: Seixas, 1996 
Pode-se ressaltar que os valores obtidos pela carreta são superiores a todos os equipamentos bem como ao caminhão aplicado ao transporte de cana, considerando um dos veículos mais críticos para a compactação do solo. Para este caso o valor obtido foi superior em $78,7 \%$, mostrando a inadequação da carreta sob o ponto de vista de conservação do solo. Em relação ao forwarder com eixo simples traseiro, os valores da pressão de contato da carreta superam em $609,7 \%$.

\subsection{Avaliação da compactação antes da colheita}

Com a finalidade de avaliar os efeitos do tráfego sobre a área foram efetuadas medições referentes ao teor de água, resistência à penetração do solo e densidade nas áreas de ensaio, antes e depois da colheita. Verificou-se também a cobertura vegetal na área após a colheita.

\subsubsection{Resistência à penetração do solo}

\subsubsection{Entrelinha: RMa e Rtr}

Para a situação antes da colheita, a localização da RMa e RTr foi feita aleatoriamente pois a empresa não possuía um histórico da área, não sendo possível determinar onde ocorreu o tráfego na colheita anterior.

Os valores médios obtidos para o teor de água demonstram que em relação aos dois tratamentos ocorreram diferenças estatísticas, sendo que para a RMa os resultados foram inferiores a RTr, Tabela 5. Os valores diminuíram com o aumento da profundidade assim como o coeficiente de variação. 
Tabela 5 - Valores percentuais médios de teor de água do solo (\%), antes da colheita, para diferentes profundidades $(\mathrm{cm})$ analisadas.

\begin{tabular}{ccccccc}
\hline & \multicolumn{5}{c}{ Profundidade (cm) } \\
\hline & Tratamento & $0-10$ & $10-20$ & $20-30$ & $30-40$ & $40-50$ \\
\hline Teor de água (\%) & $\mathrm{RMa}$ & $26,46 \mathrm{a}$ & $26,19 \mathrm{a}$ & $25,38 \mathrm{a}$ & $23,96 \mathrm{a}$ & $23,78 \mathrm{a}$ \\
antes da colheita & $\mathrm{RTr}$ & $27,74 \mathrm{~b}$ & $27,52 \mathrm{~b}$ & $26,00 \mathrm{~b}$ & $25,05 \mathrm{~b}$ & $24,79 \mathrm{~b}$ \\
\hline C. V. (\%) & & 8,39 & 8,76 & 5,17 & 5,82 & 10,16 \\
\hline
\end{tabular}

Valores precedidos de mesma letras não diferem estatisticamente para o teste de Tukey ao nível de $5 \%$ de significância.

$\mathrm{Na}$ Figura 9 pode-se visualizar as diferenças para as duas situações. Conforme já apresentado, o teor de água encontra-se acima dos níveis que causam uma compactação máxima de acordo com o teste de Proctor modificado.

ANTES DA COLHEITA

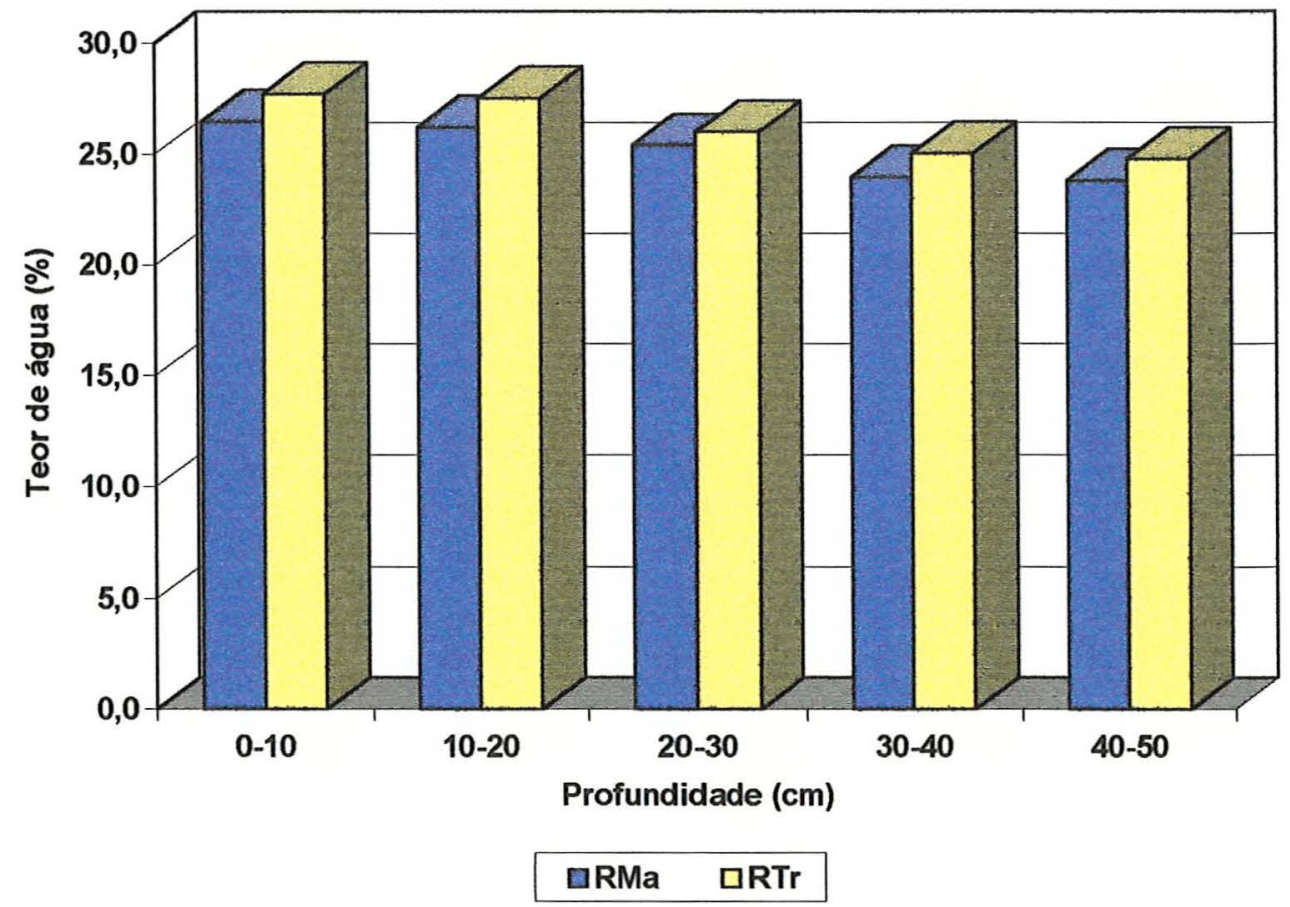

Figura 9 - Teor de água (\%) no solo antes da colheita, para os tratamentos $\mathrm{RMa}$ e RTr. 
Os valores médios obtidos para a resistência à penetração do solo nas entrelinhas demonstram que para o tratamento $\mathrm{RTr}$ os resultados foram estatisticamente inferiores àqueles referentes ao $\mathrm{RMa}$, Tabela 6 . A resistência do solo a penetração diminui com a profundidade, bem como o coeficiente de variação para ambas as situações, o que nesse caso significa que as condições do solo são mais homogêneas com o aumento da profundidade.

Tabela 6 - Resultados médios da resistência à penetração do solo $(\mathrm{kPa})$ nas diferentes profundidades $(\mathrm{cm})$ analisadas antes da colheita para os tratamentos de RMa e RTr.

\begin{tabular}{cccccc}
\hline \multicolumn{7}{c}{ Resistência à penetração do solo (kPa) } \\
\hline Tratamentos & Prof. 10cm & Prof. $20 \mathrm{~cm}$ & Prof. $30 \mathrm{~cm}$ & Prof. $40 \mathrm{~cm}$ & Prof. $50 \mathrm{~cm}$ \\
\hline RMa & $1462.95 a$ & $1089.29 a$ & $908.95 a$ & $819.60 \mathrm{a}$ & $737.42 \mathrm{a}$ \\
$\mathrm{RTr}$ & $1266.86 \mathrm{~b}$ & $984.64 \mathrm{~b}$ & $840.70 \mathrm{~b}$ & $771.06 \mathrm{~b}$ & $715.65 \mathrm{~b}$ \\
\hline C. V. (\%) & 33.77 & 18.32 & 12.60 & 9.78 & 8.38 \\
\hline
\end{tabular}

Médias seguidas da mesma letra não diferem significativamente entre si pelo teste de Tukey ao nível de $5 \%$ de probabilidade.

As analises individuais das amostras para as diferentes posições nas entrelinhas nas profundidades avaliadas do tratamento $\mathrm{RMa}$, são apresentados na Tabela 7 . 
Tabela 7 - Resultados médios da resistência à penetração do solo (kPa) para as amostras 2, 3, 4, 5 e 6 nas diferentes profundidades $(\mathrm{cm})$ analisadas antes da colheita para o tratamento da RMa.

\begin{tabular}{|c|c|c|c|c|c|}
\hline \multicolumn{6}{|c|}{ Resistência à penetração do solo (kPa) } \\
\hline Tratamentos & Prof. $10 \mathrm{~cm}$ & Prof. $20 \mathrm{~cm}$ & Prof. $30 \mathrm{~cm}$ & Prof. $40 \mathrm{~cm}$ & Prof. $50 \mathrm{~cm}$ \\
\hline Amostras 2 & $1478,31 \mathrm{a}$ & $1096,67 a$ & $913,28 a$ & $829,67 a$ & $737,99 a$ \\
\hline Amostras 3 & $1521,82 a b$ & $1088,05 a$ & $905,58 a$ & $817,14 a$ & $740,34 a$ \\
\hline Amostras 4 & $1307,23 a$ & $1068,95 a$ & $888,31 a$ & $810,15 a$ & $743,83 a$ \\
\hline Amostras 5 & $1524,03 b$ & $1098,95 a$ & $911,90 a$ & $822,39 a$ & $743,42 a$ \\
\hline Amostras 6 & $1483,35 b$ & $1093,65 a$ & $925,67 a$ & $818,62 a$ & $721,51 \mathrm{a}$ \\
\hline C. V. (\%) & 26,81 & 11,40 & 9,25 & 7,73 & 8,20 \\
\hline
\end{tabular}

Verifica-se que para as condições RMa praticamente não existem diferenças entre as amostras da entrelinha, exceto na profundidade de $10 \mathrm{~cm}$, onde as amostras 5 e 6 diferem das demais. Os maiores índices são obtidos na faixa de 5 a $15 \mathrm{~cm}$ de profundidade conforme a Figura 10. 


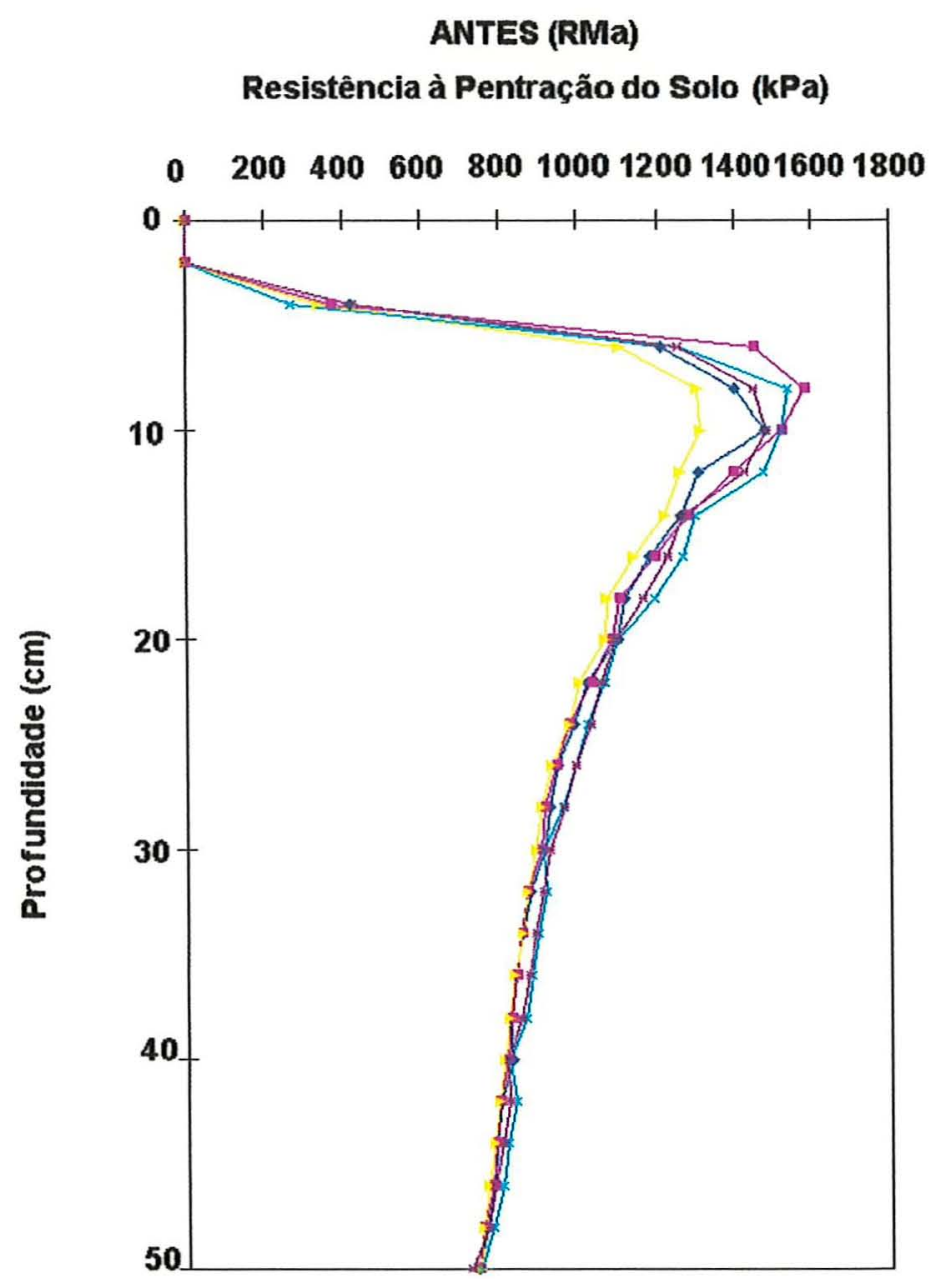

- Amostra $2-$ Amostra 3 Amostra $4-*$ Amostra $5-$ Amostra 6

Figura 10 - Resistência à penetração do solo $(\mathrm{kPa})$ para o tratamento $\mathrm{RMa}$, antes da colheita

Já para a condição $\mathrm{RTr}$, Tabela 8 , não se verificou um padrão definido, pois as amostras 8 e 9 não diferiram entre si enquanto que as amostras 10, 11 e 12 apresentam condições diversas. A explicação para essa tendência fica prejudicada pela falta de maior informação com relação ao 
histórico da área. A obtenção dos maiores índices na profundidade de $10 \mathrm{~cm}$ permanece, Figura 11.

Tabela 8 - Resultados médios da resistência à penetração do solo ( $\mathrm{kPa}$ ) para as amostras $8,9,10,11$ e 12 nas diferentes profundidades $(\mathrm{cm})$ analisadas, antes da colheita para o tratamento da $\mathrm{RTr}$.

\begin{tabular}{cccccc}
\hline \multicolumn{7}{c}{ Resistência à penetração do solo (kPa) } \\
\hline Tratamentos & Prof. 10cm & Prof. 20cm & Prof. 30cm & Prof. 40cm & Prof. 50cm \\
\hline Amostras 8 & $1431,48 \mathrm{a}$ & $1294,77 \mathrm{a}$ & $887,44 \mathrm{a}$ & $805,36 \mathrm{a}$ & $730,85 \mathrm{a}$ \\
Amostras 9 & $1530,05 \mathrm{a}$ & $1294,08 \mathrm{a}$ & $879,98 \mathrm{a}$ & $786,53 \mathrm{ab}$ & $725,49 \mathrm{a}$ \\
Amostras 10 & $842,64 \mathrm{c}$ & $818,90 \mathrm{c}$ & $752,53 \mathrm{c}$ & $729,46 \mathrm{c}$ & $697,67 \mathrm{~b}$ \\
Amostras 11 & $1344,99 \mathrm{ab}$ & $1214,47 \mathrm{ab}$ & $855,58 \mathrm{ab}$ & $770,25 \mathrm{ab}$ & $714,24 \mathrm{ab}$ \\
Amostras 12 & $1185,12 \mathrm{~b}$ & $1131,08 \mathrm{~b}$ & $827,92 \mathrm{~b}$ & $763,68 \mathrm{ac}$ & $709,97 \mathrm{ab}$ \\
\hline C. V. (\%) & 33,35 & 20,67 & 13,44 & 10,42 & 7,91 \\
\hline
\end{tabular}

Médias seguidas da mesma letra não diferem significativamente entre si pelo teste de Tukey ao nivel de $5 \%$ de probabilidade. 


\section{ANTES (RTr)}

Resistência à Penetração do Solo (kPa)

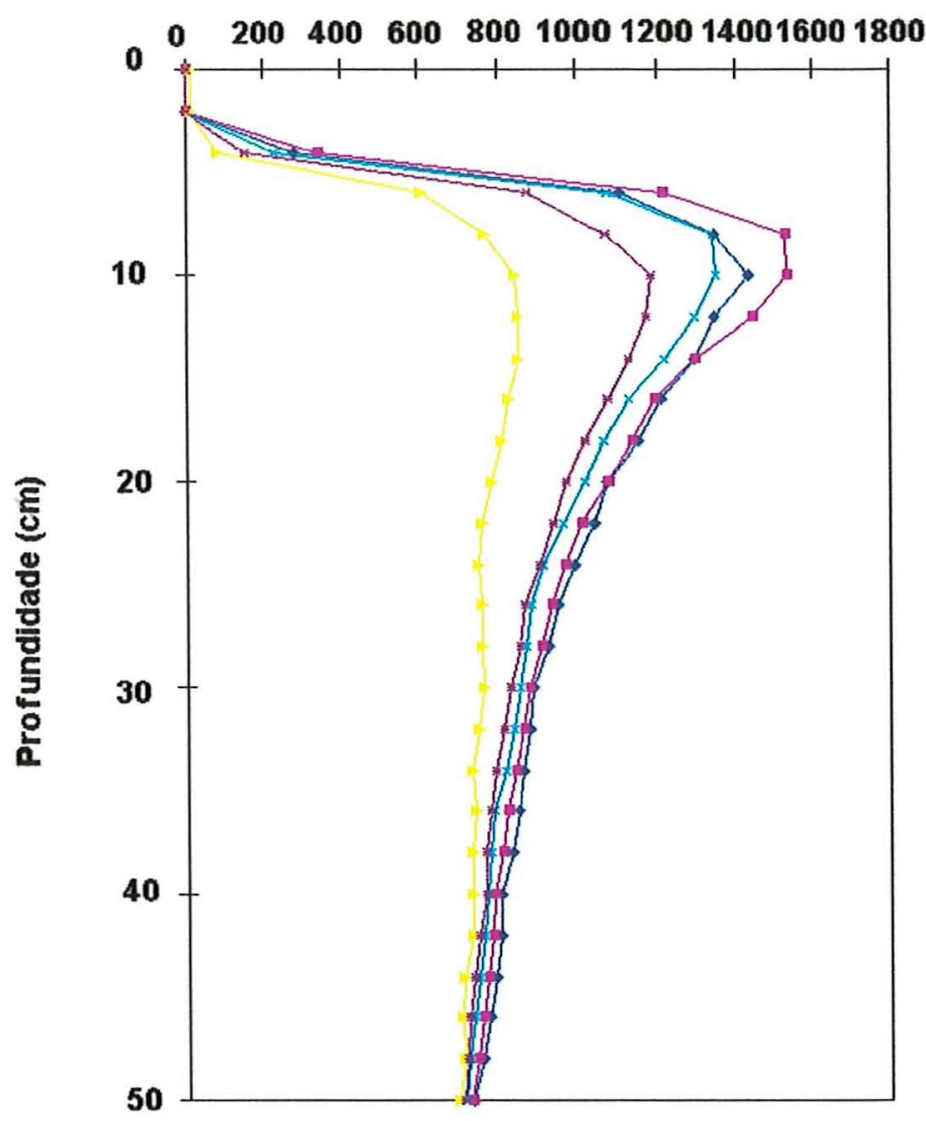

Amostra $8-\square-$ Amostra $9 \multimap$ Amostra $10-$ Amostra $11-$ Amostra 12

Figura 11 - Resistência à penetração do solo $(\mathrm{kPa})$ para o tratamento $\mathrm{RTr}$, antes da colheita

\subsubsection{Linha}

Para as linhas das plantas, as tendências foram diferentes quando comparados com as entrelinhas. As camadas mais superficiais apresentaram índices menores do que as mais profundas. Além disso, os valores obtidos para 
a resistência do solo à penetração na linha de planta são de $40 \%$ a $60 \%$ menores em média em relação as amostras 2 a 6 e 8 a 12.

ANTES (LINHAS DE PLANTAS, AMOSTRAS 3 e 10)

Resistência à Penetração do Solo (kPa)

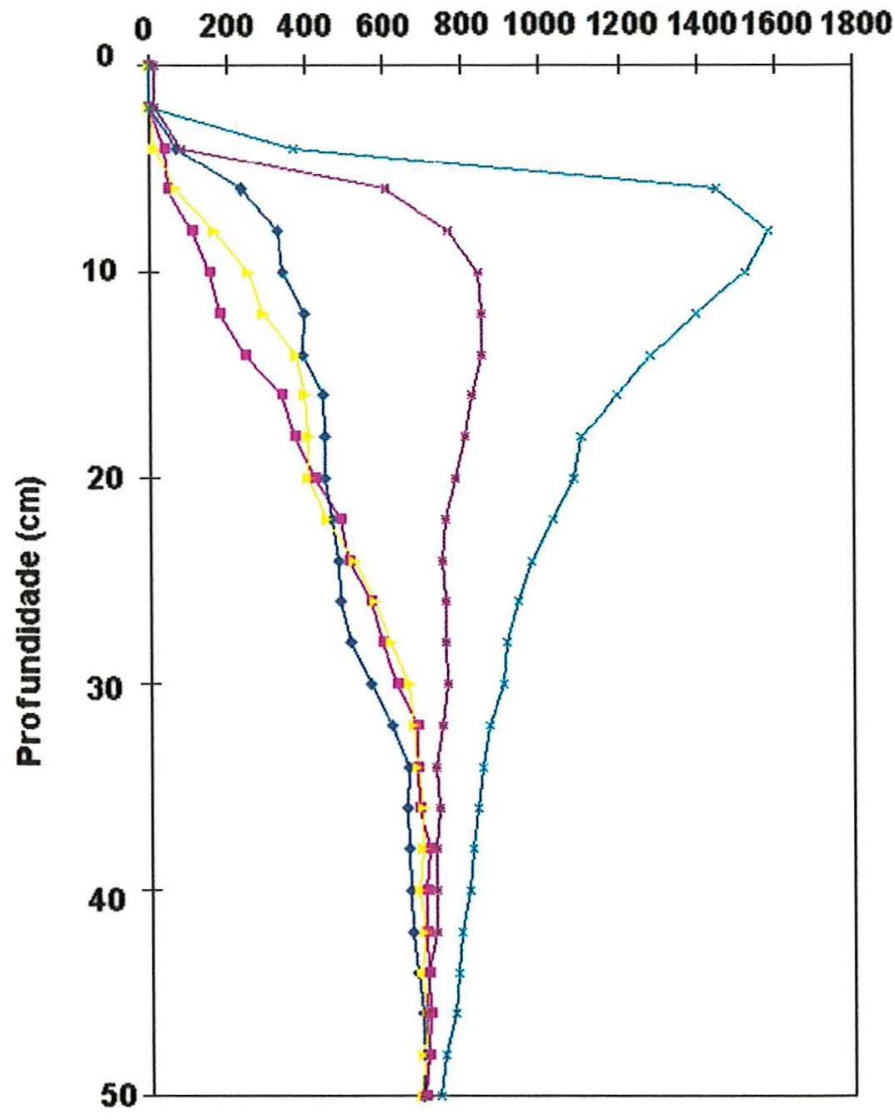

Amostra1 - Amostra7

Amostra13 - Amostra $3-*$ Amostra 10

Figura 12 - Resistência à penetração do solo $(\mathrm{kPa})$ das linhas de plantas comparando com os valores das amostras 3 e 10, obtidos nas entrelinhas (antes da colheita).

Na Figura 12 são apresentados os valores médios da resistência à penetração do solo referentes as linhas de plantas (amostras 1, 7 e 13), comparando com os valores obtidos nas entrelinhas (amostras 3 e 10). A amostra 3 refere-se aos maiores índices obtidos e a 10 aos menores. Enquanto 
que na entrelinha existe uma camada mais adensada localizada entre 5 a 15 $\mathrm{cm}$, nas linhas a tendência é de um aumento gradativo dos valores com o aumento da profundidade. Este fato pode estar refletindo o tipo de preparo executado por ocasião da implantação dos talhões, onde foi utilizada a sulcação das linhas para a colocação das mudas.

\subsubsection{Densidade do solo}

Os valores médios para a densidade do solo foram superiores na rua de madeira ( $R M a$ ) em relação à rua de tráfego ( $R T r$ ) para todas as profundidades analisadas, conforme apresentado na Tabela 9. Os valores para a $\mathrm{RTr}$ foram de $5 \%$ a $7 \%$ menores do que a RMa, Figura 13 , sendo a mesma tendência observada quanto à resistência à penetração do solo. $\mathrm{O}$ coeficiente de variação das amostragens foi inferior ao da resistência à penetração $e$ principalmente nas camadas mais superficiais do solo

Tabela 9 - Resultados médios de densidade do solo $\left(\mathrm{g} / \mathrm{cm}^{3}\right)$ nas diferentes profundidades $(\mathrm{cm})$ analisadas, antes da colheita para os tratamentos de RMa e RTr.

\begin{tabular}{cccc}
\hline \multicolumn{4}{c}{ Densidade do solo $\left(\mathrm{g} / \mathrm{cm}^{3}\right)$} \\
\hline Tratamentos & Prof. 5-10 $(\mathrm{cm})$ & Prof. 15-20 $(\mathrm{cm})$ & Prof. 25- 30(cm) \\
\hline RMa & $1.34 \mathrm{a}$ & $1.36 \mathrm{a}$ & $1.38 \mathrm{a}$ \\
RTr & $1.27 \mathrm{~b}$ & $1.26 \mathrm{~b}$ & $1.28 \mathrm{~b}$ \\
\hline C.V. (\%) & 6.90 & 9.71 & 10.48
\end{tabular}

Médias seguidas da mesma letra não diferem significativamente entre si pelo teste de Tukey ao nível de $5 \%$ de probabilidade. 


\section{ANTES DA COLHEITA}

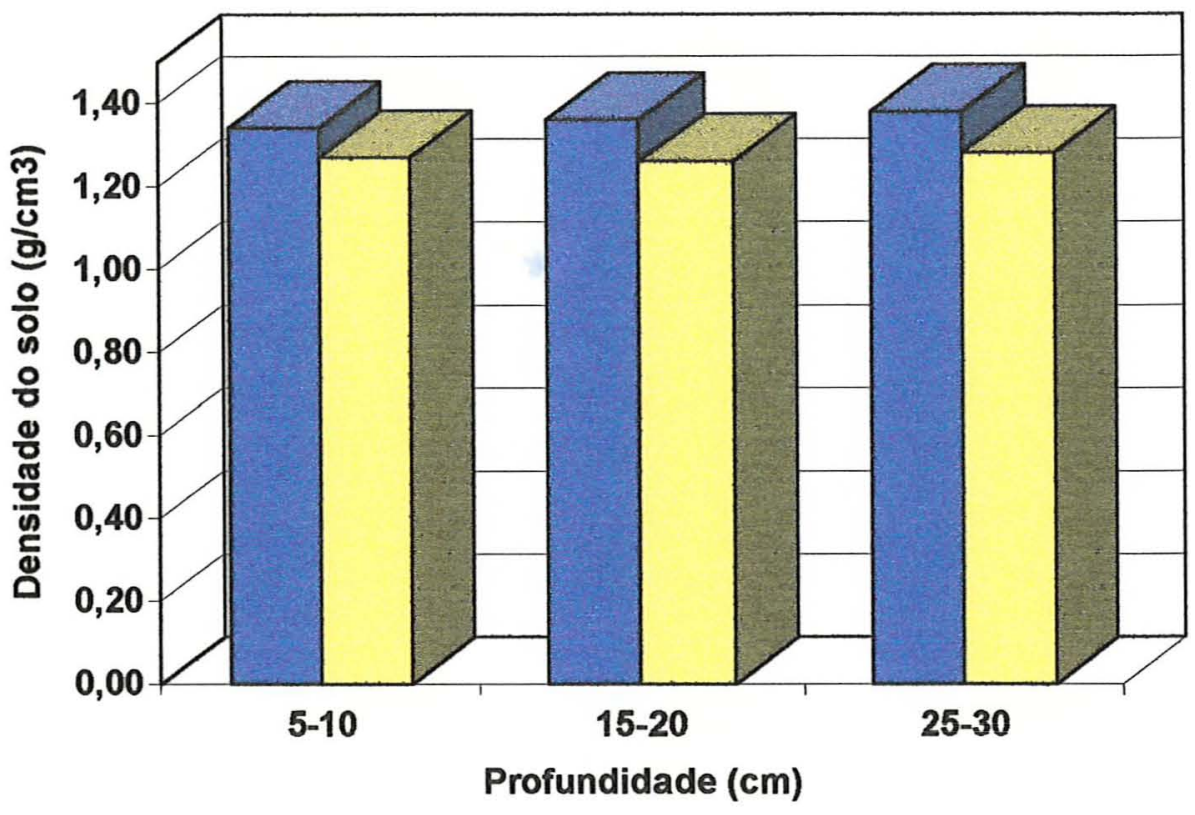

口RMa $\mathrm{RRTr}$

Figura 13 - Densidade do solo $\left(\mathrm{g} / \mathrm{cm}^{3}\right)$ para os tratamentos RMa e RTr, antes da colheita.

As análises individuais das amostras nas entrelinhas para a $\mathrm{RTr}$ revelam que existem diferenças estatísticas entre as amostras, Tabela10, demonstrando que os valores da amostra 4 foram inferiores à amostra 3 , Figura 14.

Tabela 10 - Resultados médios da densidade $\left(\mathrm{g} / \mathrm{cm}^{3}\right)$ do solo para as amostras 3 e 4 nas diferentes profundidades $(\mathrm{cm})$ analisadas antes da colheita.

$$
\text { Densidade do solo }\left(\mathrm{g} / \mathrm{cm}^{3}\right)
$$

\begin{tabular}{cccc}
\hline Tratamentos & Prof. 5-10 $(\mathrm{cm})$ & Prof. 15-20 $(\mathrm{cm})$ & Prof. 25- 30(cm) \\
\hline Amostra 3 & $1,32 \mathrm{a}$ & $1,38 \mathrm{a}$ & $1,40 \mathrm{a}$ \\
Amostra 4 & $1,23 \mathrm{~b}$ & $1,22 \mathrm{~b}$ & $1,25 \mathrm{~b}$ \\
\hline C.V. (\%) & 5,84 & 6,95 & 7,82
\end{tabular}

Médias seguidas da mesma letra não diferem significativamente entre si pelo teste de Tukey âo nível de $5 \%$ de probabilidade. 


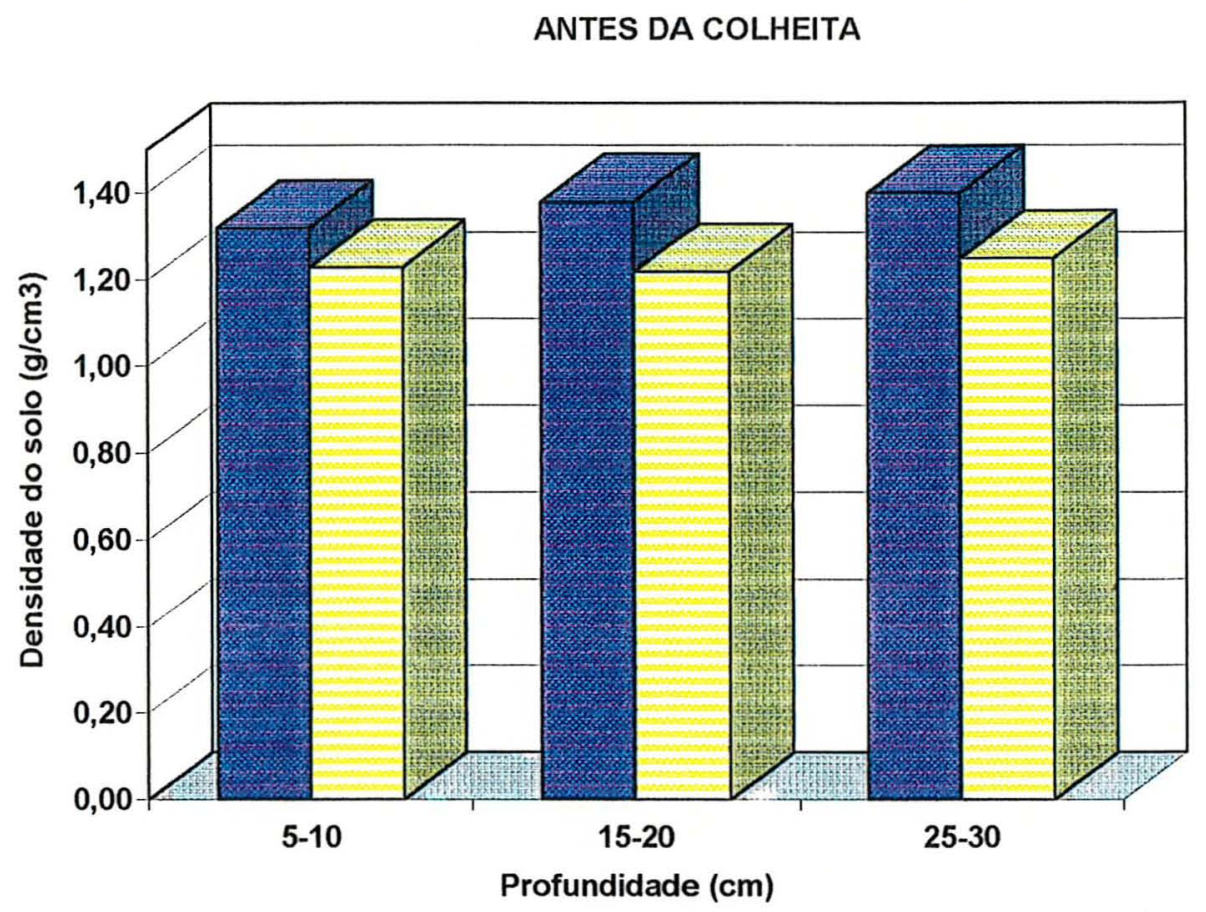

圆amostra 3 口amostra 4

Figura 14 - Densidade do solo $\left(\mathrm{g} / \mathrm{cm}^{3}\right)$ para as amostras 3 e 4 , antes da colheita.

\subsection{Avaliação da compactação depois da colheita}

Este levantamento foi efetuado 30 dias após a coleta de dados correspondente a situação antes da colheita. Neste intervalo de tempo, o índice pluviométrico acumulado atingiu $145 \mathrm{~mm}$. Primeiramente, avaliou-se a cobertura vegetal deixada sobre o terreno e depois, utilizando-se da mesma metodologia, a resistência à penetração e a densidade. 


\subsubsection{Cobertura vegetal}

A avaliação da cobertura vegetal, entre as ruas de madeira (RMa) e tráfego (RTr), revela que praticamente não existe diferença estatística entre os dois tratamentos, com exceção feita para as folhas, Tabela 11.

Tabela 11 - Avaliação da cobertura vegetal para os tratamentos das ruas de madeira ( $R M a)$ e tráfego ( $R T r)$.

\begin{tabular}{cccccc}
\hline \multicolumn{6}{c}{ Cobertura Vegetal $\left(\mathrm{kg} / \mathbf{m}^{2}\right)$} \\
\hline Tratamento & Folha & Galho & Casca & Res. Vegetais & Total \\
\hline RMa & $0,14 a(100)^{*}$ & $0,40 a(100)$ & $0,34 a(100)$ & $0,82 a(100)$ & $1,70(100)$ \\
RTr & $0,05 b(35,7)$ & $0,19 a(47,5)$ & $0,68 a(200)$ & $0,64 a(78)$ & $1,56(91,7)$ \\
\hline C.V. (\%) & 55.14 & 69.08 & 120.55 & 64.39 &
\end{tabular}

* Médias seguidas da mesma letra não diferem significativamente entre si pelo teste de Tukey ao nível de $5 \%$ de probabilidade.

Por outro lado, observa-se o alto coeficiente de variação nas amostragens o que significa uma deposição irregular de material sobre o solo, Figura 15. Atribuindo-se o índice 100 para o tratamento RMa, obtêm-se os índices 35,$7 ; 47,5 ; 200 ; 78$ e 91,7 para as condições da RTr, para folha, galho, casca, restos vegetais e total respectivamente. Um fato a ser notado é o alto índice de resíduos orgânicos que estão sendo deixados sobre o solo com a situação apresentada: RMa obteve $1,70 \mathrm{~kg} / \mathrm{m}^{2}$ (17000 kg/ha) e RTr $1,56 \mathrm{~kg} / \mathrm{m}^{2}$ (15600 kg/ha), Figura 15. 


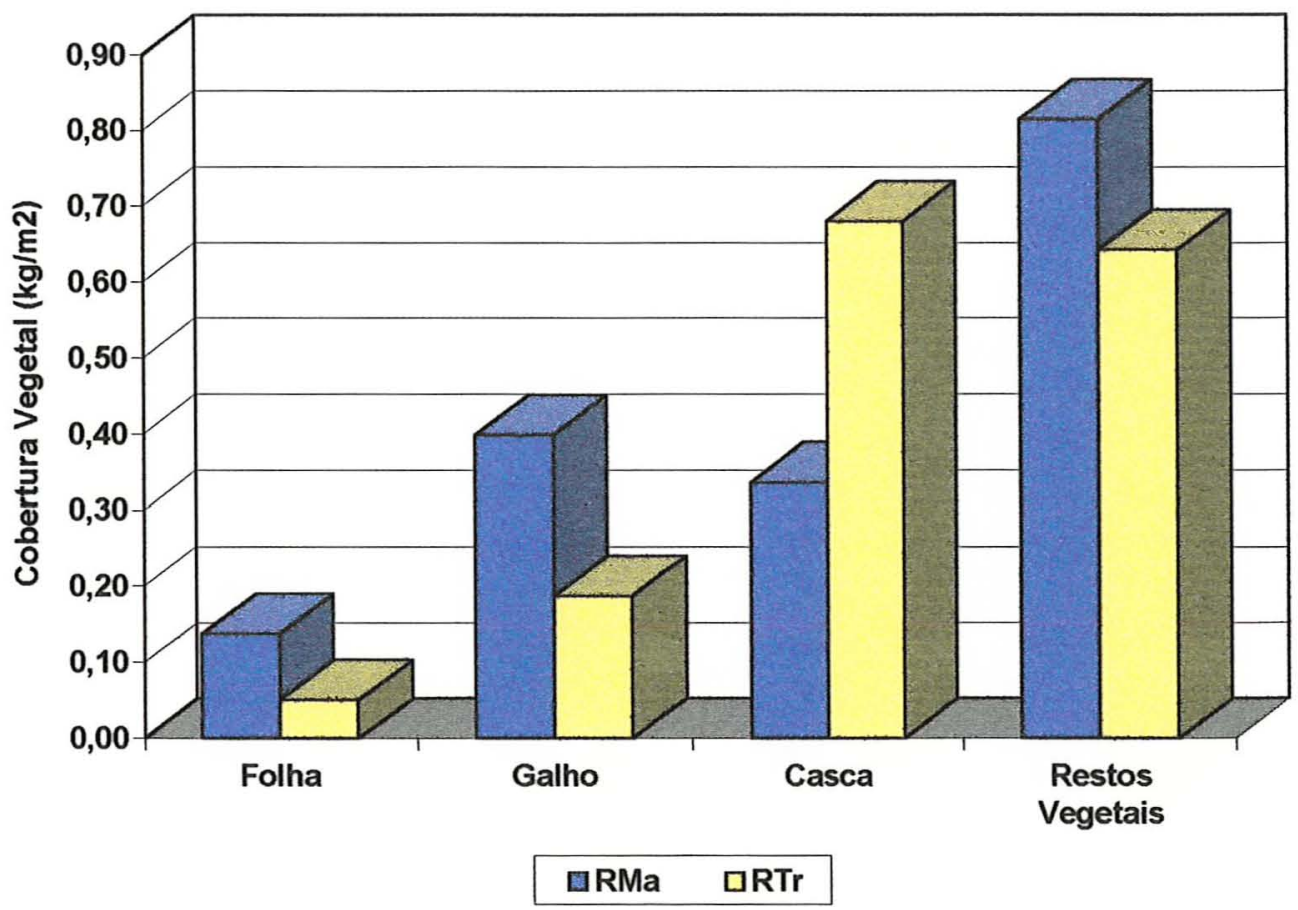

Figura 15 - Quantidade de cobertura vegetal $\left(\mathrm{kg} / \mathrm{m}^{2}\right)$, separados em classes, para os tratamentos das RMa e RTr.

\subsubsection{Resistência à penetração do solo}

Para esta situação, depois da colheita, a localização da rua de madeira (RMa) e da rua de tráfego ( $R T r$ ) foi feita de acordo com o tráfego dos veículos sobre a área, conforme apresentado no esquema da Figura 4, mantendo-se a mesma denominação (RMa e RTr) e localização da situação anterior.

\subsubsection{Entrelinha: RMa e RTr}

Através dos resultados médios obtidos para o teor de água, verificou-se diferença estatística nas profundidades de $10-20 \mathrm{~cm}$ e 30-40 $\mathrm{cm}$, para os tratamentos RMa e RTr. A Tabela 12 apresenta os valores para as profundidades até $50 \mathrm{~cm}$ para as condições depois da colheita. Pode-se 
observar também que o teor de água foi superior em $8 \%$ a $27 \%$ comparado a condição antes da colheita.

Tabela 12 - Valores percentuais médios de teor de água (\%) do solo para a RMa, depois da colheita, para diferentes profundidades analisadas.

Profundidade $(\mathrm{cm})$

\begin{tabular}{ccccccc}
\hline & Tratamento & $0-10$ & $10-20$ & $20-30$ & $30-40$ & $40-50$ \\
\hline Teor de água (\%) & $\mathrm{RMa}$ & $29,00 \mathrm{a}$ & $28,20 \mathrm{a}$ & $27,21 \mathrm{a}$ & $25,90 \mathrm{a}$ & $25,62 \mathrm{a}$ \\
depois da colheita & $\mathrm{RTr}$ & $29,84 \mathrm{a}$ & $29,90 \mathrm{~b}$ & $28,03 \mathrm{a}$ & $26,70 \mathrm{~b}$ & $25,94 \mathrm{a}$ \\
\hline C. V. (\%) & & 13,31 & 10,08 & 11,09 & 6,25 & 6,78
\end{tabular}

Valores precedidos de mesma letras não diferem estatisticamente para o teste de Tukey ao nível de $5 \%$ de significância.

A Figura 16 apresenta os resultados referentes ao teor de água para as profundidades até $50 \mathrm{~cm}$ e para a situação depois da colheita.

\section{DEPOIS DA COLHEITA}

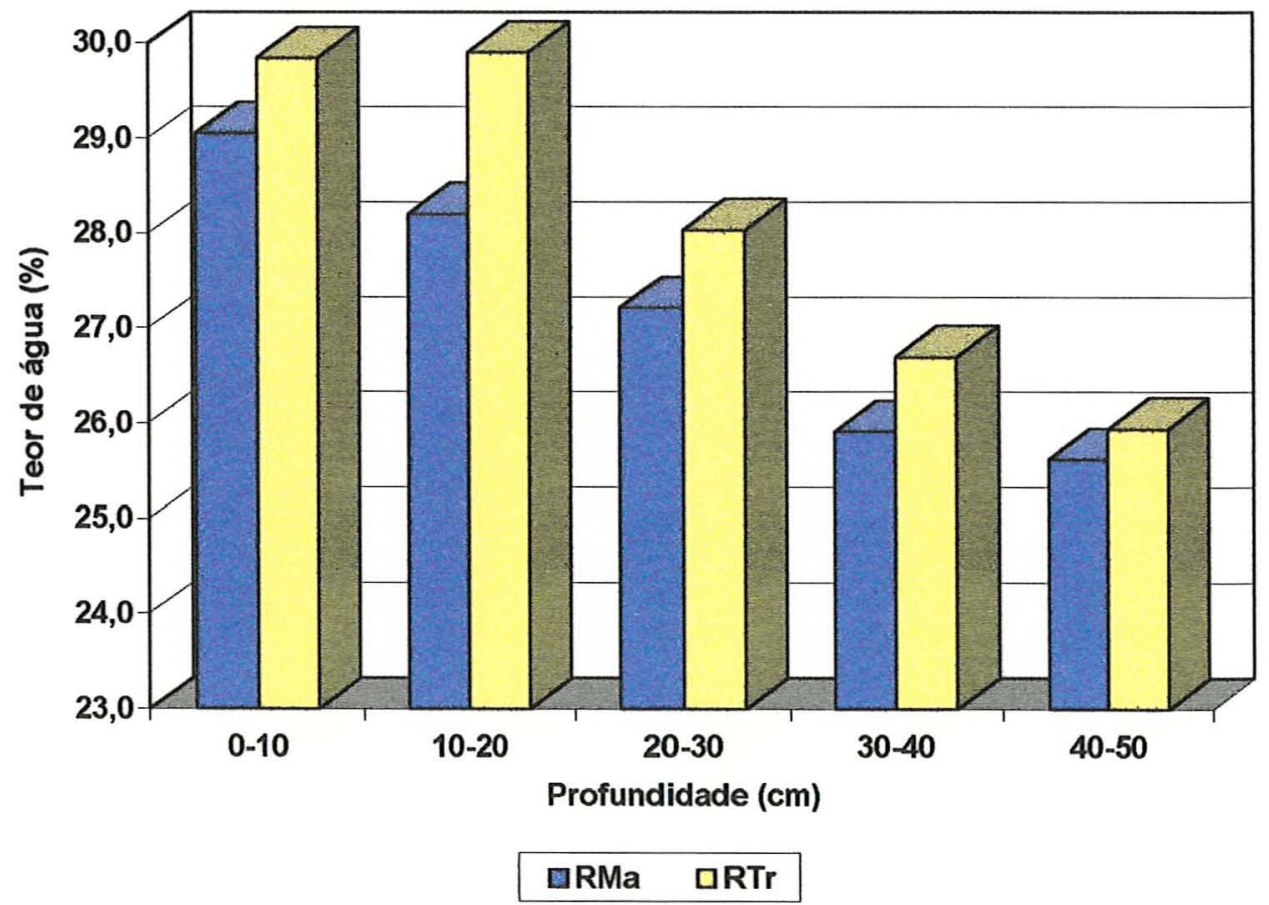

Figura 16 - Teor de água (\%) no solo depois da colheita, para os tratamentos $\mathrm{RMa}$ e RTr 
Comparando-se os resultados médios referentes à resistência à penetração do solo, para as entrelinhas, observa-se que a tendência dos valores de $\mathrm{RMa}$ serem superiores a RTr continua, embora na camada superficial de 0 a $10 \mathrm{~cm}$ sejam iguais; a diminuição do valor com o aumento da profundidade também é observada, conforme apresentado na Tabela 13. Os valores são inferiores quando comparados a situação antes da colheita o que pode ser atribuído ao maior teor de água do solo na ocasião.

Tabela 13 - Resultados médios da resistência à penetração do solo $(\mathrm{kPa})$ nas diferentes profundidades $(\mathrm{cm})$ analisadas, depois da colheita para os tratamentos da RMa e RTr.

\begin{tabular}{cccccc}
\hline \multicolumn{7}{c}{ Resistência à penetração do solo (kPa) } \\
\hline Tratamentos & Prof. 10cm & Prof. 20cm & Prof. $30 \mathrm{~cm}$ & Prof. 40cm & Prof. 50cm \\
\hline RMa & $1182.00 \mathrm{a}$ & $920.81 \mathrm{a}$ & $801.48 \mathrm{a}$ & $737.42 \mathrm{a}$ & $690.46 \mathrm{a}$ \\
RTr & $1148.55 \mathrm{a}$ & $870.84 \mathrm{~b}$ & $762.14 \mathrm{~b}$ & $711.95 \mathrm{~b}$ & $679.57 \mathrm{~b}$ \\
\hline C.V. (\%) & 29.43 & 13.01 & 8.75 & 6.44 & 4.30 \\
\hline
\end{tabular}

Médias seguidas da mesma letra não diferem significativamente entre si pelo teste de Tukey ao nível de $5 \%$ de probabilidade.

Para as amostras nas entrelinhas referentes a rua de madeira (RMa) existem variações sem uma tendência definida, conforme apresenta a Tabela 14. O coeficiente de variação diminui com a profundidade, passando $31,13 \%$ em $10 \mathrm{~cm}$ para $5,33 \%$ a $50 \mathrm{~cm}$. 
Tabela 14 - Resultados médios da resistência à penetração do solo $(\mathrm{kPa})$ para as amostras $2,3,4,5$ e 6 nas diferentes profundidades $(\mathrm{cm})$ analisadas, depois da colheita para o tratamento da RMa.

Resistência à penetração do solo $(\mathrm{kPa})$

\begin{tabular}{|c|c|c|c|c|c|}
\hline Tratamentos & Prof. $10 \mathrm{~cm}$ & Prof. $20 \mathrm{~cm}$ & Prof. $30 \mathrm{~cm}$ & Prof. $40 \mathrm{~cm}$ & Prof. $50 \mathrm{~cm}$ \\
\hline Amostras 2 & $1146,38 b$ & $937,17 a b$ & $822,40 a$ & $750,89 a$ & $699,27 a$ \\
\hline Amostras 3 & $1261,45 a$ & $954,46 a$ & $823,66 a$ & $755,46 a$ & $700,64 a$ \\
\hline Amostras 4 & $1069,59 b$ & $885,63 b$ & $778,57 b$ & $725,74 b$ & $684,57 a b$ \\
\hline Amostras 5 & $1240,57 a$ & $927,54 a b$ & $799,22 a b$ & $734,50 a b$ & $687,26 a b$ \\
\hline Amostras 6 & $1189,21 b$ & $898,19 b$ & $783,15 b$ & $720,40 b$ & $680,51 b$ \\
\hline C. V. (\%) & 31,13 & 13,46 & 9,81 & 7,47 & 5,33 \\
\hline
\end{tabular}

Médias seguidas da mesma letra não diferem significativamente entre si pelo teste de Tukey ao nível de $5 \%$ de probabilidade.

Os maiores valores de resistência à penetração do solo foram obtidos na profundidade que esta na faixa de 5 a $15 \mathrm{~cm}$, decrescendo com o aumento da profundidade, Figura17. 
DEPOIS (RMa)

Resistência à Penetração do Solo $(\mathrm{kPa})$

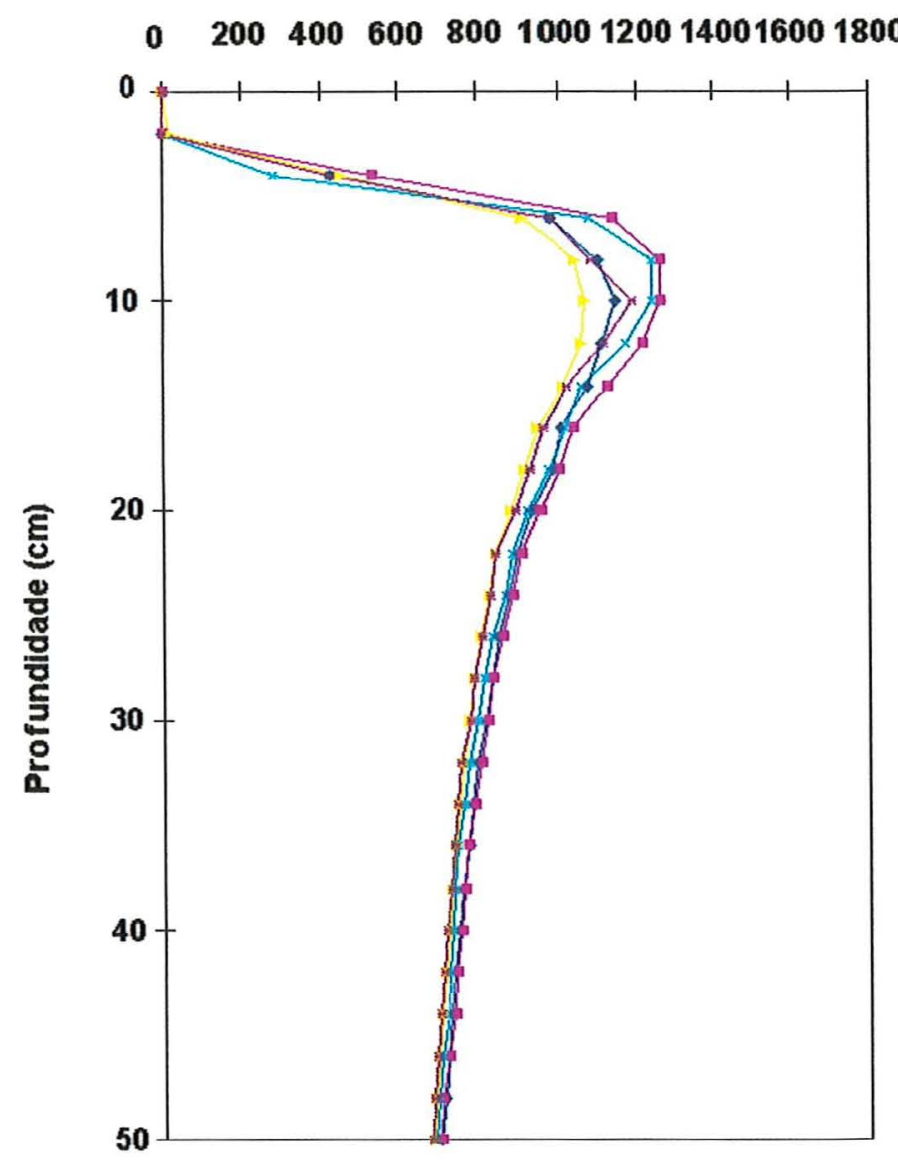

Amostra $2-$-Amostra $3-$ Amostra $4-*$ Amostra $5-$ Amostra 6

Figura 17 - Resistência à penetração do solo $(\mathrm{kPa})$ para o tratamento $\mathrm{RMa}$, depois da colheita 
Para a condição da RTr, Tabela 15, não existiu diferença entre as amostras com exceção da amostra 11 que corresponde ao ponto de passagem do rodado da carreta. Os valores obtidos foram sempre maiores com relação as outras amostras, com diferença mínima de $667,99 \mathrm{kPa}$ em relação a amostra 9 e máxima de $902,10 \mathrm{kPa}$ para a amostra 8 , na profundidade $6 \mathrm{~cm}$. Com o aumento da profundidade, as diferenças diminuiram significativamente, Figura 18.

Tabela 15 - Resultados médios da resistência à penetração do solo $(\mathrm{kPa})$ para as amostras $8,9,10,11$ e 12 nas diferentes profundidades $(\mathrm{cm})$ analisadas, depois da colheita para o tratamento da RTr.

\begin{tabular}{cccccc}
\hline \multicolumn{6}{c}{ Resistência à penetração do solo (kPa) } \\
\hline Tratamentos & Prof. 10cm & Prof. 20cm & Prof. 30cm & Prof. 40cm & Prof. 50cm \\
\hline Amostras 8 & $1087,67 \mathrm{~b}$ & $854,44 \mathrm{~b}$ & $754,78 \mathrm{~b}$ & $709,81 \mathrm{~b}$ & $677,45 \mathrm{~b}$ \\
Amostras 9 & $1115,58 \mathrm{~b}$ & $861,61 \mathrm{~b}$ & $750,49 \mathrm{~b}$ & $705,12 \mathrm{~b}$ & $679,27 \mathrm{ab}$ \\
Amostras 10 & $1054,46 \mathrm{~b}$ & $834,03 \mathrm{~b}$ & $750,60 \mathrm{~b}$ & $704,68 \mathrm{~b}$ & $677,96 \mathrm{~b}$ \\
Amostras 11 & $1423,34 \mathrm{a}$ & $954,41 \mathrm{a}$ & $799,00 \mathrm{a}$ & $730,21 \mathrm{a}$ & $686,00 \mathrm{a}$ \\
Amostras 12 & $1061,70 \mathrm{~b}$ & $849,69 \mathrm{~b}$ & $755,83 \mathrm{~b}$ & $709,91 \mathrm{~b}$ & $677,13 \mathrm{~b}$ \\
\hline C. V. (\%) & 23,23 & 10,46 & 5,62 & 3,94 & 2,30
\end{tabular}

Médias seguidas da mesma letra não diferem significativamente entre si pelo teste de Tukey ao nivel de $5 \%$ de probabilidade. 


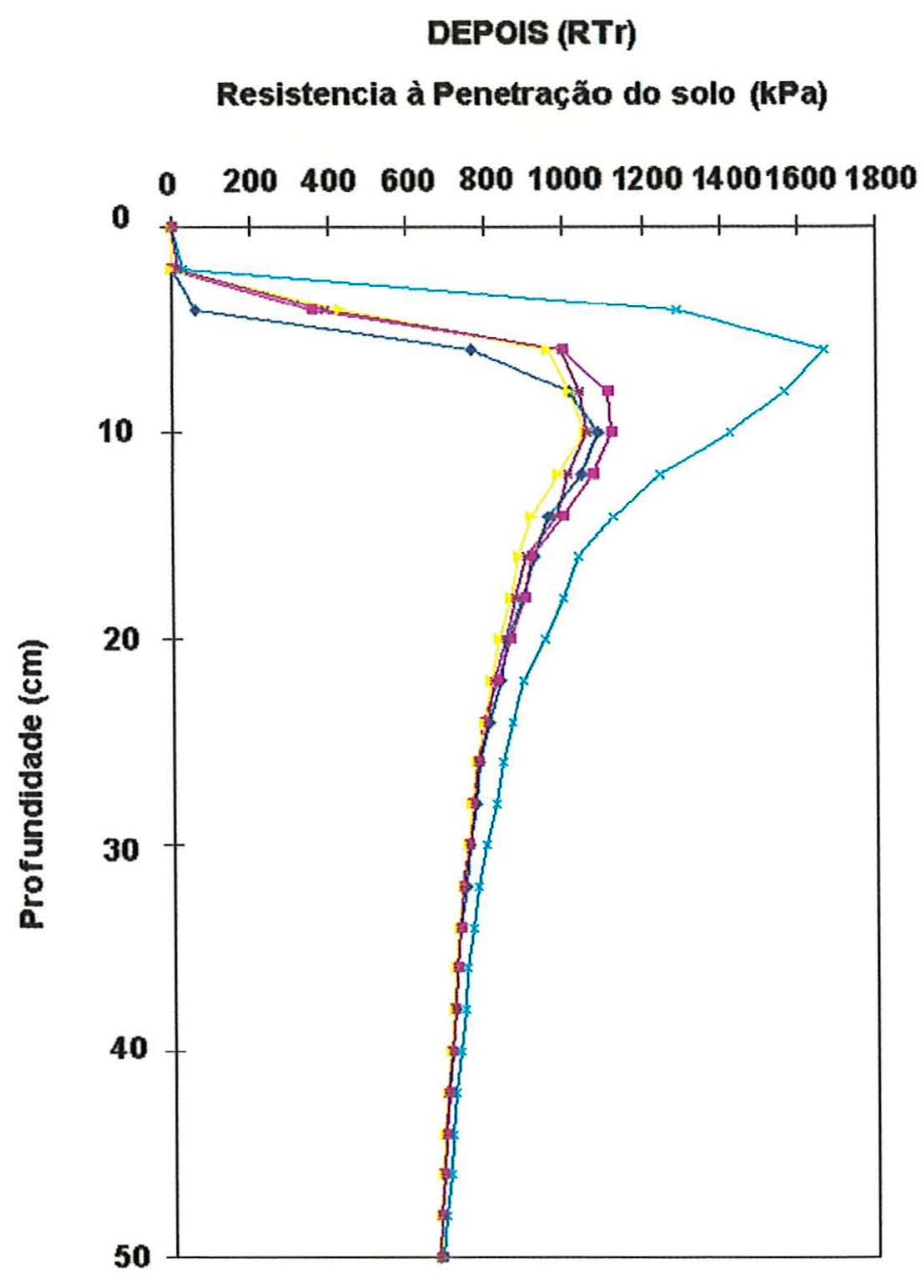

$\rightarrow$ Amostra $8-$ Amostra $9 \rightarrow$ Amostra $10 \rightarrow-$ Amostra $11 \rightarrow$ Amostra 12

Figura 18 - Resistência à penetração do solo $(\mathrm{kPa})$ para o tratamento $\mathrm{RTr}$, depois da colheita

Embora devendo-se levar em conta a diferença do teor de água do solo, a Figura 19 apresenta os valores referentes a amostra 11 para a situação antes e depois da colheita, onde o valor máximo na profundidade de $6 \mathrm{~cm}$ obtido depois da passagem dos veículos supera em aproximadamente 55\% o valor máximo obtido antes da passagem dos equipamentos. O teor de água 
médio correspondente é de $26,22 \%$ e $28,08 \%$ para a situação antes e depois da colheita respectivamente

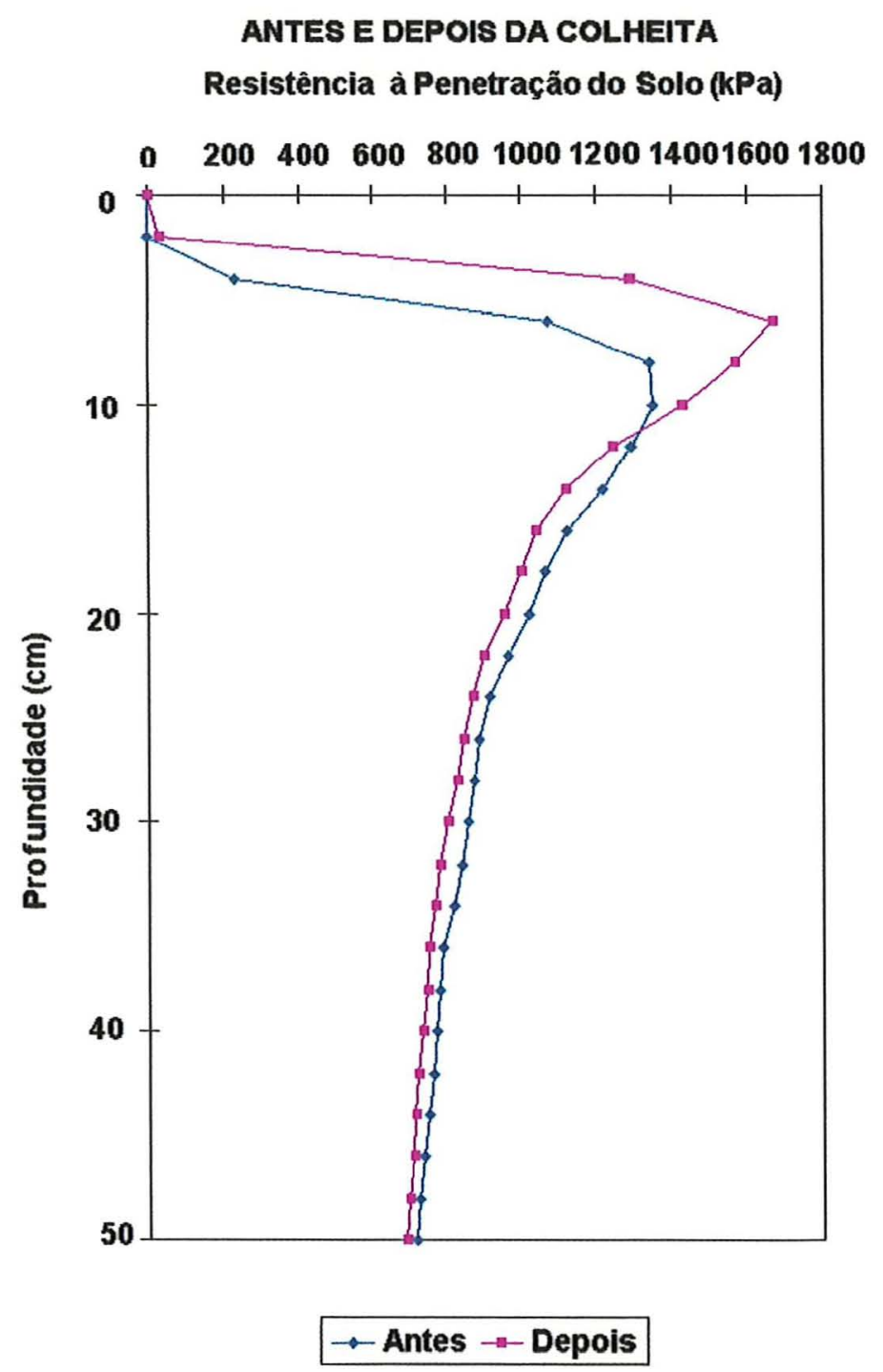

Figura 19 - Resistência à penetração do solo $(\mathrm{kPa})$ para a amostra 11 , antes e depois da colheita. 


\subsubsection{Linha}

Para as linhas de plantas, a tendência é a mesma da apresentada para a situação antes da colheita. Os valores da resistência a penetração são maiores próximos a superfícies, aumentando com a profundidade, Figura 20. As amostras 1, 7 e 13 referem-se à linha e as amostras 3 e 10 ao maior e menor valores respectivamente obtidos nas entrelinhas.

DEPOIS (LINHAS DE PLANTAS, AMOSTRAS 3 e 10)

Resistência à Penetração do Solo $(\mathrm{kPa})$

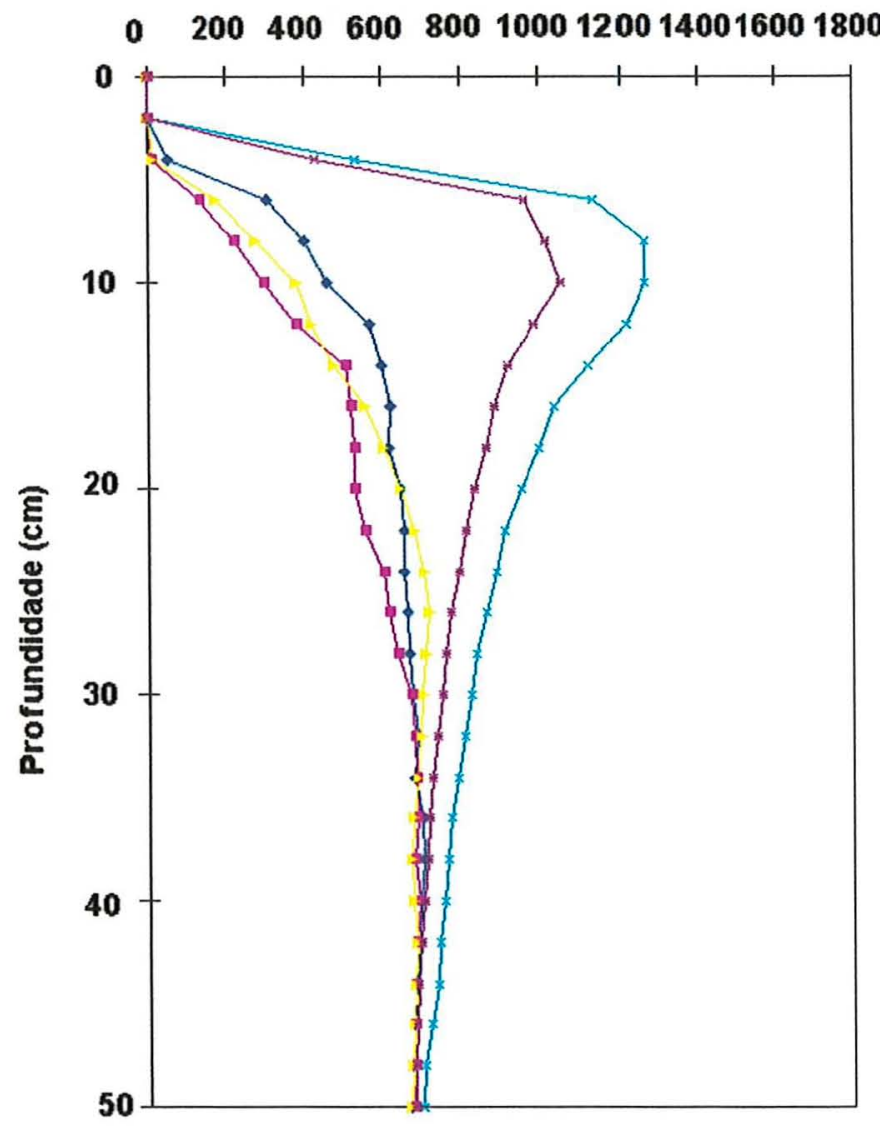

$\rightarrow$ Amostra $1-$-Amostra $7-$ Amostra13 $*$ Amostra $3 \rightarrow$ Amostra 10

Figura 20 - Resistência do solo a penetração $(\mathrm{kPa})$ das linhas de plantas, comparandas com os valores das amostras 3 e 10, obtidas nas entrelinhas (depois da colheita). 


\subsubsection{Densidade}

Quando analisados os resultados médios referentes a $\mathrm{RMa}$ constata-se que são estatisticamente iguais aos valores da $\mathrm{RTr}$ para todas as profundidades avaliadas, conforme Tabela 16 e Figura 21. O coeficiente de variação das amostras são inferiores aos obtidos para a resistência à penetração do solo principalmente para a profundidade de 5 a $10 \mathrm{~cm}$. Os resultados para a $\mathrm{RTr}$ antes da colheita, tiveram um acréscimo de 4,7 a 7,9\% em relação aos resultados médios obtidos depois da colheita.

Tabela 16 - Resultados médios de densidade do solo $\left(\mathrm{g} / \mathrm{cm}^{3}\right)$ para as amostras nas diferentes profundidades $(\mathrm{cm})$ analisadas, depois da colheita para os tratamentos da RMa e RTr.

\begin{tabular}{cccc}
\hline \multicolumn{4}{c}{ Densidade do solo $\left(\mathrm{g} / \mathrm{cm}^{3}\right)$} \\
\hline Tratamentos & Prof. 5-10 $(\mathrm{cm})$ & Prof. 15-20 $(\mathrm{cm})$ & Prof. 25- 30(cm) \\
\hline Rma & $1.35 \mathrm{a}$ & $1.37 \mathrm{a}$ & $1.39 \mathrm{a}$ \\
$\mathrm{RTr}$ & $1.33 \mathrm{a}$ & $1.36 \mathrm{a}$ & $1.38 \mathrm{a}$ \\
\hline C.V. (\%) & 6.81 & 7.86 & 8.17 \\
\hline
\end{tabular}

Médias seguidas da mesma letra não diferem significativamente entre si.

Analisando os resultados da densidade depois da colheita, pode-se observar que o maior valor médio na profundidade $25-30 \mathrm{~cm}$ que é de $1,39 \mathrm{~g} / \mathrm{cm}^{3}$ para a RMa está $24 \%$ abaixo da máxima densidade encontrada no teste de Proctor. 
DEPOIS DA COLHEITA

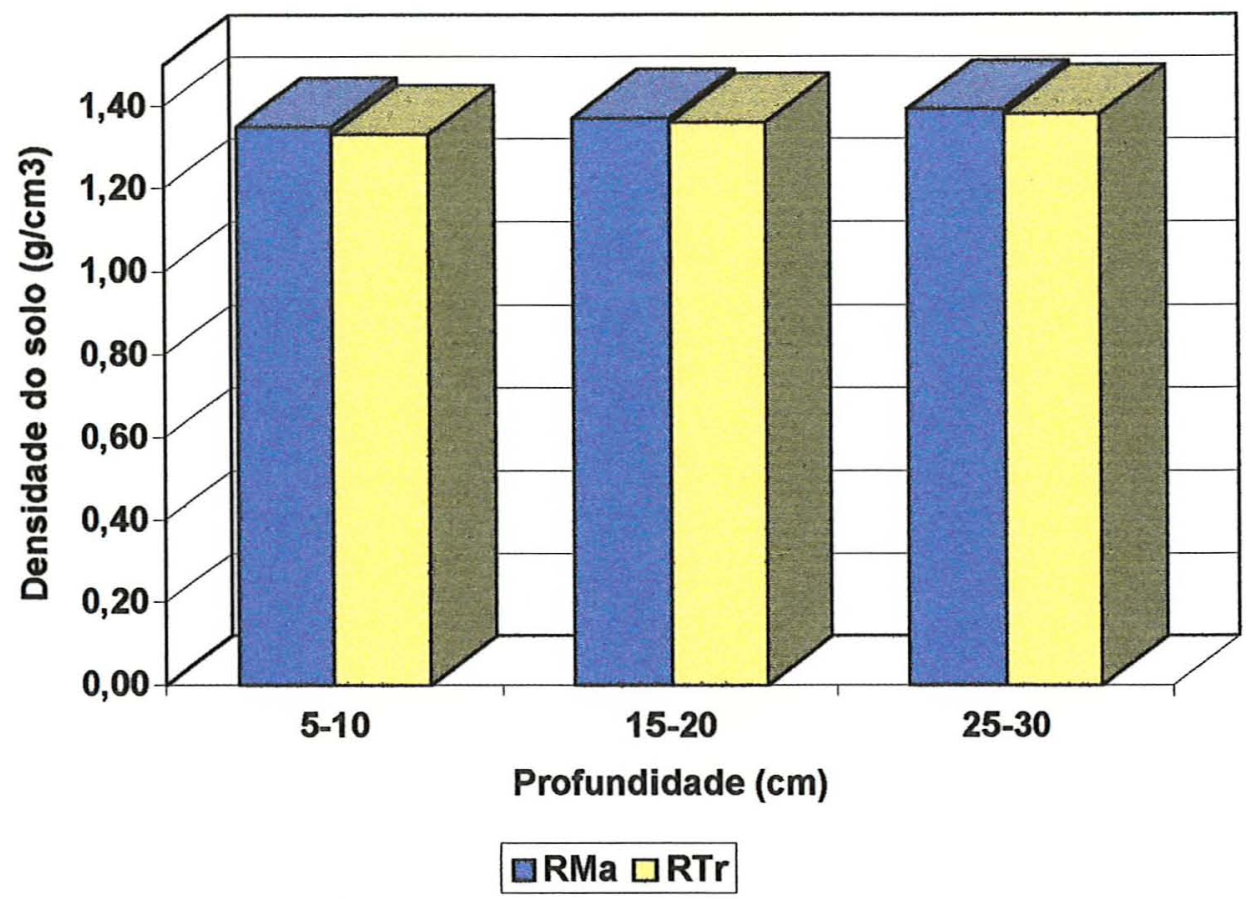

Figura 21 - Densidade do solo $\left(\mathrm{g} / \mathrm{cm}^{3}\right)$ para os tratamentos RMa e RTr, depois da colheita.

$\mathrm{Na}$ entrelinha para a condição da RTr depois da colheita, verificouse que permaneceu a diferença estatística entre os tratamentos, Tabela 17; para a amostra 4 , onde ocorreu o tráfego obteve-se um acréscimo nos valores entre 11 a $15 \%$ superior a amostra 3, Figura 22.

Tabela 17 - Resultados médios da densidade do solo $\left(\mathrm{g} / \mathrm{cm}^{3}\right)$ para as amostras 3 e 4 nas diferentes profundidades $(\mathrm{cm})$ analisadas, depois da colheita para o tratamento da RTr.

$$
\text { Densidade do solo }\left(\mathrm{g} / \mathrm{cm}^{3}\right)
$$

\begin{tabular}{cccc}
\hline Tratamentos & Prof. 5-10 (cm) & Prof. 15-20 (cm) & Prof. 25- 30(cm) \\
\hline Amostra 3 & $1,30 \mathrm{a}$ & $1,31 \mathrm{a}$ & $1,34 \mathrm{a}$ \\
Amostra 4 & $1,39 \mathrm{~b}$ & $1,40 \mathrm{~b}$ & $1,41 \mathrm{~b}$ \\
\hline C.V. (\%) & 5,20 & 6,03 & 5,82
\end{tabular}

Médias seguidas da mesma letra não diferem significativamente entre si pelo teste de Tukey ao nivel de $5 \%$ de probabilidade. 
DEPOIS DA COLHEITA

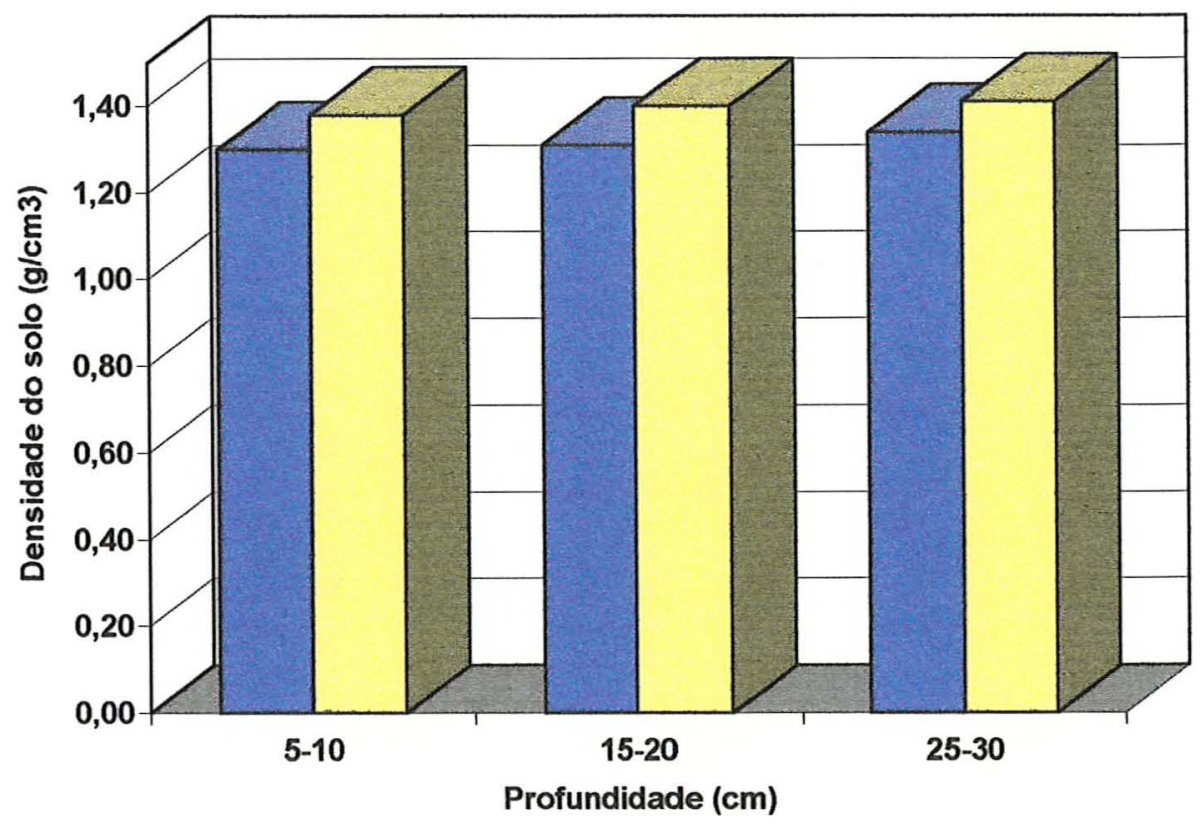

Damostra 3 口amostra 4

Figura 22 - Densidade do solo $\left(\mathrm{g} / \mathrm{cm}^{3}\right)$ para as amostras 3 e 4 , depois da colheita.

Comparando-se os dados referentes a amostra 4, amostra onde ocorreu a passagem dos rodados, verificou-se que a situação depois da colheita apresenta valores superiores em até $15 \%$ quando comparado com os valores antes da colheita. Estes resultados para as diferentes profundidades podem ser visualizadas na Tabela 18 e Figura 23.

Tabela 18 - Resultados médios de densidade do solo $\left(\mathrm{g} / \mathrm{cm}^{3}\right)$ nas diferentes profundidades $(\mathrm{cm})$ analisadas, para a amostra 4 antes e depois da colheita.

\begin{tabular}{cccc}
\hline \multicolumn{4}{c}{ Densidade do solo $\left(\mathrm{g} / \mathrm{cm}^{3}\right)$} \\
\hline Tratamentos & Prof. 5-10 $(\mathrm{cm})$ & Prof. 15-20 $(\mathrm{cm})$ & Prof. 25- 30(cm) \\
\hline Antes & $1,23 \mathrm{a}$ & $1,22 \mathrm{a}$ & $1,25 \mathrm{a}$ \\
Depois & $1,39 \mathrm{~b}$ & $1,40 \mathrm{~b}$ & $1,41 \mathrm{~b}$ \\
\hline C.V. (\%) & 5,28 & 5,99 & 6,16 \\
\hline
\end{tabular}

Médias seguidas da mesma letra não diferem significativamente entre si pelo teste de Tukey ao nível de $5 \%$ de probabilidade. 
AMOSTRA 4

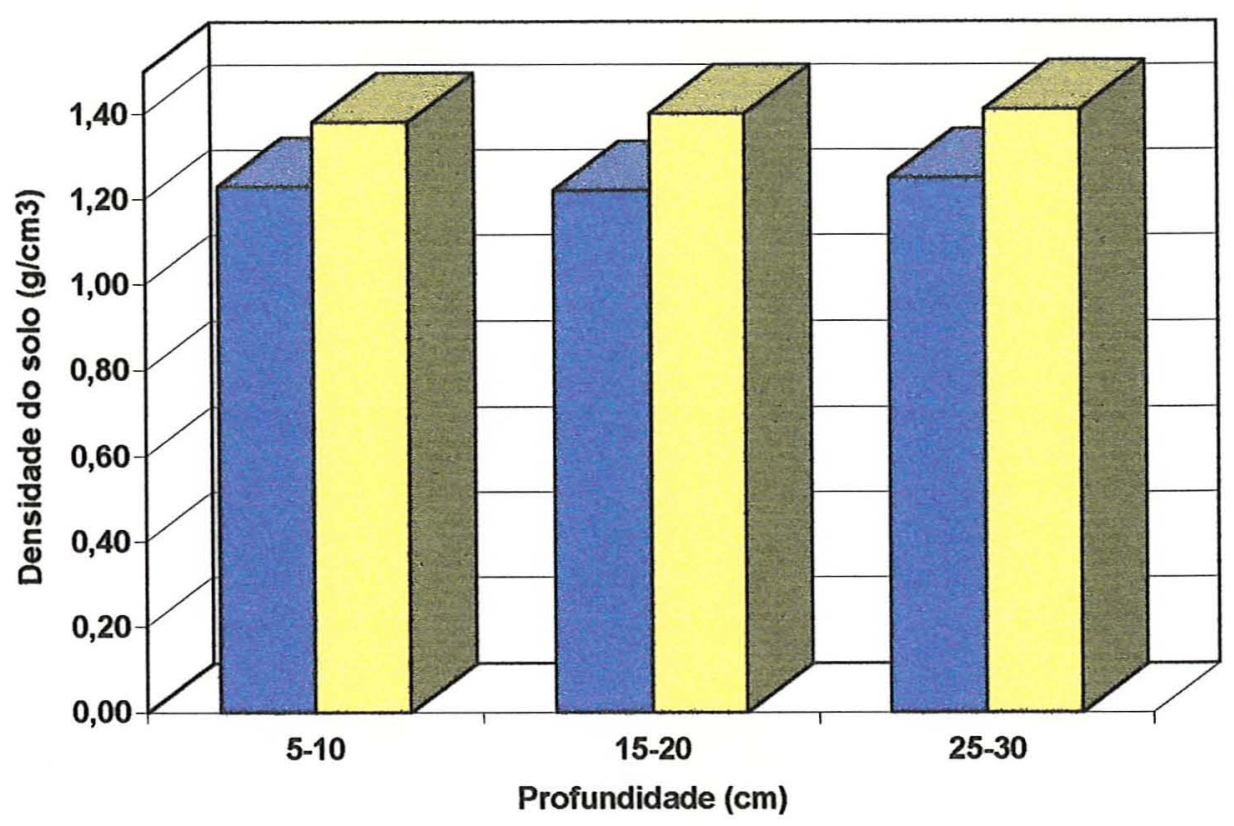

口Antes 口Depois

Figura 23 - Densidade do solo $\left(\mathrm{g} / \mathrm{cm}^{3}\right)$ para a amostra 4 antes e depois da colheita.

\subsection{Considerações Gerais}

Os resultados referentes à resistência à penetração do solo, mostram que para as linhas de plantas existem uma tendência definida que reflete os efeitos do preparo do solo realizado para a implantação da cultura. Os valores obtidos mais próximos à superfície são menores do que os mais profundos e este fato ocorreu após um período de nove anos, período este correspondente entre o plantio das mudas e a realização das amostras.

Para as entrelinhas mantêm-se a tendência normal para os valores da resistência à penetração do solo, com as camadas mais proximas da superfície apresentando os maiores valores. Os efeitos do tráfego na época de colheita podem ser considerados como localizados o que para o caso deste 
trabalho foi obtido em uma das amostras. Quanto aos valores menores da resistência à penetração do solo obtidos na situação depois da colheita podem ser atribuídos ao teor de água.

Os resultados referentes à densidade do solo indicam um aumento dos valores no tratamento Rtr, depois da passagem dos veículos, mantendo-se a tendência dos maiores valores serem obtidos onde ocorre o tráfego. Um ponto importante é que, embora a densidade do solo exija um tempo maior para ser efetuada, em relação à resistência à penetração do solo, a uniformidade dos dados é melhor quando se compara os resultados do CV (\%). A densidade das amostras não foi influenciada pelo teor de água no solo.

A desuniformidade nas características dimensionais das plantas pode estar refletindo as diferenças referentes ao material genético, à fertilidade do solo, deposição de material orgânico, padrões das operações ou mesmo efeitos do tráfego ao longo do ciclo da cultura. Com os dados coletados e as análises efetuadas não foi observada uma tendência de concentração de indices de compactação antes da retirada da madeira, não sendo possível realizar observações quanto a influência da compactação no desenvolvimento da floresta.

Quanto ao tráfego de veículos, o que se observa é que os equipamentos que possuem esteiras ou rodados desenvolvidos para o trabalho em áreas agrícolas e florestais, aplicam pressões bem inferiores àqueles de uso em estradas como é o caso dos caminhões. Para o caso específico de carreta utilizada neste trabalho, o equipamento é inadequado quando o objetivo básico é evitar altas cargas sobre o solo. É aconselhável a substituição dos rodados por outros com uma área de contato maior e, portanto, uma melhor distribuição de carga. 


\section{CONCLUSÕES}

Para as condições sob as quais se desenvolveu o experimento, considerando-se os diversos fatores influentes como decorrência de um trabalho em regime de campo, os resultados permitem as seguintes conclusões:

- Embora não existam diferenças significativas entre as linhas de árvores com relação às dimensões, observou-se uma desuniformidade nas medições de altura e DAP.

- O tráfego de máquinas na época da colheita influencia nos valores de compactação em áreas localizadas.

- Existem diferenças básicas na compactação entre as linhas e entrelinhas devido ao efeito do preparo do solo adotado na implantação da cultura, mesmo após 9 anos.

- Foram obtidos valores médios menores de resistência à penetração do solo e densidade para a $\mathrm{RMa}$ em relação a $\mathrm{RTr}$ antes da colheita, resultados que persistiram depois da colheita.

- Para a resistência à penetração do solo as profundidades que apresentaram maiores valores estão na faixa entre 5 a $15 \mathrm{~cm}$. Obteve-se no local onde ocorreu o tráfego dos veículos um acréscimo de aproximadamente 
$55 \%$, na resistência à penetração do solo variando de $1075,2 \mathrm{kPa}$ antes da colheita e 1666,4 kPa depois da colheita.

- Os valores que apresentaram um decréscimo para a resistência a penetração do solo, depois da colheita, podem ser atribuídos ao teor de água que antes da colheita era de $26,22 \%$ e aumentou para $28,08 \%$.

- Para a densidade do solo, a amostra onde ocorreu o tráfego dos veículos apresentou um acréscimo mais elevado na faixa de 15 a $20 \mathrm{~cm}$ de profundidade. Antes da colheita o resultado foi de $1,22 \mathrm{~g} / \mathrm{cm}^{3}$ e depois 1,40 $\mathrm{g} / \mathrm{cm}^{3}$, verificando-se um aumento de aproximadamente $15 \%$. 
ANEXOS 
Anexo A - Análise granulométrica do solo

\begin{tabular}{cccc}
\hline Amostras & Argila (\%) & Silte (\%) & Areia (\%) \\
\hline $0-10$ & 19,30 & 23,65 & 57,05 \\
$10-20$ & 32,98 & 19,36 & 47,66 \\
$20-30$ & 33,08 & 15,97 & 50,95 \\
$30-40$ & 32,97 & 16,70 & 50,30 \\
$40-50$ & 37,21 & 15,07 & 47,72 \\
\hline
\end{tabular}

Anexo B - Análise química do solo

\begin{tabular}{ccccccccccc}
\hline Amostra & $\begin{array}{c}\mathrm{PH} \\
\mathrm{CaCl} 2\end{array}$ & $\begin{array}{c}\mathrm{M} . \mathrm{O} . \\
\%\end{array}$ & $\begin{array}{c}\mathrm{P} \\
\mathrm{ug} / \mathrm{cm}^{3}\end{array}$ & $\mathrm{~K}$ & $\mathrm{Ca}$ & $\begin{array}{c}\mathrm{Mg} \\
\mathrm{meq}\end{array}$ & $\begin{array}{c}\mathrm{H}+\mathrm{Al} \\
100\end{array}$ & $\begin{array}{c}\mathrm{SB} \\
\mathrm{cm}^{3}\end{array}$ & $\begin{array}{c}\mathrm{T} \\
\%\end{array}$ \\
\hline $0-10$ & 4,0 & 3,4 & 6 & 0,08 & 0,7 & 0,4 & 12,1 & 1,2 & 13,3 & 9 \\
$10-20$ & 3,9 & 2,9 & 3 & 0,04 & 0,4 & 0,2 & 10,9 & 0,6 & 11,5 & 5 \\
$20-30$ & 3,9 & 2,3 & 2 & 0,04 & 0,3 & 0,1 & 9,8 & 0,4 & 10,2 & 4 \\
\hline
\end{tabular}

Anexo C - Precipitação média pluviométrica de Janeiro à Dezembro nos anos de 1987 à 1996.

\begin{tabular}{cccccccccccccc}
\hline \multicolumn{10}{c}{ Mês } \\
\hline Ano & Jan & Fev & Mar & Abr & Mai & Jun & Jul & Ago & Set & Out & Nov & Dez & Média \\
\hline 1987 & 377 & 276 & 57 & 52 & 125 & 180 & 9 & 32 & 38 & 114 & 80 & 120 & 1460 \\
1988 & 137 & 193 & 178 & 108 & 241 & 58 & 11 & 0 & 68 & 213 & 131 & 166 & 1504 \\
1989 & 300 & 222 & 113 & 82 & 41 & 38 & 236 & 57 & 113 & 106 & 192 & 113 & 1613 \\
1990 & 375 & 164 & 142 & 30 & 54 & 47 & 155 & 46 & 73 & 58 & 55 & 134 & 1333 \\
1991 & 168 & 342 & 271 & 85 & 41 & 110 & 15 & 33 & 111 & 167 & 39 & 170 & 1552 \\
1992 & 55 & 167 & 340 & 54 & 71 & 13 & 56 & 37 & 149 & 144 & 119 & 87 & 1292 \\
1993 & 275 & 249 & 130 & 38 & 62 & 76 & 44 & 38 & 258 & 121 & 87 & 69 & 1447 \\
1994 & 206 & 216 & 48 & 69 & 37 & 42 & 40 & 0 & 4 & 135 & 78 & 220 & 1095 \\
1995 & 290 & 266 & 161 & 53 & 63 & 67 & 54 & 27 & 111 & 181 & 42 & 126 & 1441 \\
1996 & 94 & 293 & 186 & 53 & 22 & 66 & 27 & 37 & 145 & 146 & 95 & 277 & 1441 \\
\hline
\end{tabular}


Anexo D - Análise da variância para o teor de água (\%) antes e depois da colheita na profundidade de $10 \mathrm{~cm}$

Teor de água no solo (\%) - Prof. $10 \mathrm{~cm}$

\begin{tabular}{cccccccc}
\hline & \multicolumn{3}{c}{ Antes da colheita } & \multicolumn{3}{c}{ Depois da colheita } \\
\hline C.V. & G. L. & S.Q. & Q.M. & F & S.Q. & Q.M. & F \\
\hline Bloco & 2 & 235,1908 & 117,5954 & & 324,8952 & 162,4476 & \\
Trat. & 1 & 48,6413 & 48,6413 & $9,41^{* *}$ & 21,0840 & 21,0840 & $1,38^{*}$ \\
Resíduo & 116 & 599,9338 & 5,1718 & & 177,8317 & 15,3303 & \\
\hline Total & 118 & 883,7660 & & & 2124.2970 & & \\
\hline ** significativo ao nível de 5\% de probabilidade & \\
* não significativo &
\end{tabular}

Anexo E - Análise da variância para o teor de água (\%) antes e depois da colheita na profundidade de $20 \mathrm{~cm}$

Teor de água no solo (\%) - Prof. $20 \mathrm{~cm}$

\begin{tabular}{cccccccc}
\hline & \multicolumn{3}{c}{ Antes da colheita } & \multicolumn{3}{c}{ Depois da colheita } \\
\hline C.V. & G. L. & S.Q. & Q.M. & F & S.Q. & Q.M. & F \\
\hline Bloco & 2 & 145.3082 & 72.6541 & & 115.9152 & 57.9576 & \\
Trat. & 1 & 53.0138 & 53.0138 & $9.56^{* *}$ & 88.1510 & 88.1510 & $10.27^{* *}$ \\
Residuo & 116 & 643.0085 & 5.5431 & & 995.2664 & 8.5798 & \\
\hline Total & 118 & 841.3305 & & & 1199.3326 & & \\
\hline ** significativo ao nivel de 5\% de probabilidade \\
* não significativo
\end{tabular}

Anexo $\mathrm{F}$ - Análise da variância para o teor de água (\%) antes e depois da colheita na profundidade de $30 \mathrm{~cm}$

Teor de água no solo (\%)- Prof. $30 \mathrm{~cm}$

\begin{tabular}{cccccccc}
\hline & \multicolumn{3}{c}{ Antes da colheita } & \multicolumn{3}{c}{ Depois da colheita } \\
\hline C.V. & G. L. & S.Q. & Q.M. & F & S.Q. & Q.M. & F \\
\hline Bloco & 2 & 34.0640 & 17.0320 & & 34.0125 & 17.0062 & \\
Trat. & 1 & 11.1874 & 11.1874 & $6.32^{\text {** }}$ & 20.3363 & 20.3363 & $2.17^{*}$ \\
Resíduo & 116 & 205.3101 & 1.7699 & & 1089.0956 & 9.3887 & \\
\hline Total & 118 & 250.5615 & & & 1143.4445 & & \\
** significativo ao nivel de 5\% de probabilidade \\
* não significativo
\end{tabular}


Anexo G - Análise da variância para o teor de água (\%) antes e depois da colheita na profundidade de $40 \mathrm{~cm}$.

Teor de água no solo (\%)- Prof. $40 \mathrm{~cm}$

\begin{tabular}{cccccccc}
\hline & \multicolumn{4}{c}{ Antes da colheita } & \multicolumn{3}{c}{ Depois da colheita } \\
\hline C.V. & G. L. & S.Q. & Q.M. & F & S.Q. & Q.M. & F \\
\hline Bloco & 2 & 24.7153 & 12.35766 & & 68.3793 & 34.1896 & \\
Trat. & 1 & 35.1866 & 35.18667 & $17.28^{* *}$ & 19.5052 & 19.5052 & $7.21^{\text {** }}$ \\
Resíduo & 116 & 236.1969 & 2.0361 & & 313.7644 & 2.7048 & \\
\hline Total & 118 & 296.0989 & & 401.6490 & & \\
\hline ** significativo ao nível de 5\% de probabilidade & & & \\
* não significativo & & & & &
\end{tabular}

Anexo $\mathrm{H}$ - Análise da variância para o teor de água (\%) antes da colheita na profundidade de $50 \mathrm{~cm}$

Teor de água no solo (\%)- Prof. $50 \mathrm{~cm}$

\begin{tabular}{cccccccc}
\hline & \multicolumn{4}{c}{ Antes da colheita } & \multicolumn{3}{c}{ Depois da colheita } \\
\hline C.V. & G. L. & S.Q. & Q.M. & F & S.Q. & Q.M. & F \\
\hline Bloco & 2 & 43.9011 & 21.9505 & & 37.1336 & 18.5668 & \\
Trat. & 1 & 36.8188 & 36.8188 & $6.06^{\star *}$ & 3.2078 & 3.2078 & $1.05^{*}$ \\
Residuo & 116 & 704.4639 & 704.4639 & & 354.7469 & 3.0581 & \\
\hline Total & 118 & 785.1839 & & & 395.0884 & & \\
\hline
\end{tabular}

** significativo ao nível de $5 \%$ de probabilidade

* não significativo

Anexo I - Análise da variância para a resistência do solo à penetração $(\mathrm{kPa})$ antes e depois o tráfego na profundidade de $10 \mathrm{~cm}$

Resistência do Solo à Penetração (kPa) - Prof. $10 \mathrm{~cm}$

\begin{tabular}{cccccccc}
\hline & \multicolumn{4}{c}{ Antes da colheita } & \multicolumn{3}{c}{ Depois da colheita } \\
\hline C.V. & G. L. & S.Q. & Q.M. & F & S.Q. & Q.M. & F \\
\hline Bloco & 2 & 200217.1 & 100108.6 & 5343841.4 & 2671920.7 & \\
Trat. & 1 & 7209889.7 & 7209889.7 & $33.93^{*}$ & 209626.3 & 209626.3 & $1.78^{* *}$ \\
Resíduo & 746 & 158525780.8 & 212501.04 & 87718373.5 & 117585.0 & \\
\hline Total & 749 & 165935887.6 & \multicolumn{5}{c}{1,0157} \\
\hline
\end{tabular}

** significativo ao nivel de $5 \%$ de probabilidade

* não significativo 
Anexo J - Análise da variância para a resistência do solo à penetração $(\mathrm{kPa})$ antes e depois o tráfego na profundidade de $20 \mathrm{~cm}$

Resistência do Solo à Penetração (kPa) - Prof. $20 \mathrm{~cm}$

\begin{tabular}{cccccccc}
\hline & \multicolumn{3}{c}{ Antes da colheita } & \multicolumn{3}{c}{ Depois da colheita } \\
\hline C.V. & G. L. & S.Q. & Q.M. & F & S.Q. & Q.M. & F \\
\hline Bloco & 2 & 104402.8 & 52201.4 & & 1220540.0 & 610270.0 & \\
Trat. & 1 & 2053196.7 & 2053196.7 & $56.87^{* *}$ & 468272.9 & 468272.9 & $34.47^{* *}$ \\
Resíduo & 746 & 26932143.7 & 36102.1 & & 10135720.7 & 13586.8 & \\
\hline Total & 749 & 1655935887.6 & & & 11824533.6 & \\
\hline ** significativo ao nível de 5\% de probabilidade & & & \\
* não significativo
\end{tabular}

Anexo $\mathrm{K}$ - Análise da variância para a resistência do solo à penetração $(\mathrm{KPa})$ antes e depois o tráfego na profundidade de $30 \mathrm{~cm}$

Resistência do Solo à Penetração (kPa) - Prof. $30 \mathrm{~cm}$

\begin{tabular}{cccccccc}
\hline & \multicolumn{3}{c}{ Antes da colheita } & \multicolumn{3}{c}{ Depois da colheita } \\
\hline C.V. & G. L. & S.Q. & Q.M. & F & S.Q. & Q.M. & F \\
\hline Bloco & 2 & 106743.1 & 53371.5 & & 306571.0 & 153285.5 & \\
Trat. & 1 & 873547.8 & 873547.8 & $71.81^{* *}$ & 290189.2 & 290189.2 & $62.05^{\star *}$ \\
Residuo & 746 & 9074473.1 & 12164.2 & & 3488764.5 & 4676.6 & \\
\hline Total & 749 & 10054763.1 & & & 4085524.7 & & \\
\hline ** significativo ao nivel de 5\% de probabilidade & & &
\end{tabular}

Anexo $\mathrm{L}$ - Análise da variância para a resistência do solo à penetração $(\mathrm{kPa})$ antes e depois o tráfego na profundidade de $40 \mathrm{~cm}$

Resistência do Solo à Penetração $(\mathrm{kPa})$ - Prof. $40 \mathrm{~cm}$

\begin{tabular}{cccccccc}
\hline & \multicolumn{3}{c}{ Antes da colheita } & \multicolumn{3}{c}{ Depois da colheita } \\
\hline C.V. & G. L. & S.Q. & Q.M. & F & S.Q. & Q.M. & F \\
\hline Bloco & 2 & 87960.8 & 43980.4 & & 124945.8 & 62472.8 & \\
Trat. & 1 & 441815.9 & 441815.9 & $73.04^{\star *}$ & 121647.3 & 121647.3 & $55.91^{\star *}$ \\
Resíduo & 746 & 4512262.6 & 6048.6 & & 1623060.3 & 2175.7 & \\
\hline Total & 749 & 5042039.5 & & & 1869653.4 & & \\
\hline
\end{tabular}

** significativo ao nível de $5 \%$ de probabilidade

* não significativo 
Anexo $\mathrm{M}$ - Análise da variância para a resistência do solo à penetração $(\mathrm{kPa})$ antes e depois do tráfego na profundidade de $50 \mathrm{~cm}$

Resistência do Solo à Penetração (kPa) - Prof. $50 \mathrm{~cm}$

\begin{tabular}{cccccccc}
\hline & \multicolumn{4}{c}{ Antes da colheita } & & \multicolumn{3}{c}{ Depois da colheita } \\
\hline C.V. & G. L. & S.Q. & Q.M. & F & S.Q. & Q.M. & F \\
\hline Bloco & 2 & 90517.7 & 45258.9 & & 18448.2 & 9224.1 & \\
Trat. & 1 & 88895.9 & 88895.9 & $23.97^{* *}$ & 22234.1 & 22234.1 & $25.66^{* *}$ \\
Resíduo & 746 & 2766629.6 & 3708.6 & & 646285.5 & 866.3 & \\
\hline Total & 749 & 2946043.3 & & 686967.7 & & \\
** & & & & &
\end{tabular}

Anexo $\mathrm{N}$ - Análise da variância para a resistência do solo à penetração (kPa) para as amostras $2,3,4,5$ e 6, antes e depois da colheita para $\mathrm{RMa}$, na profundidade de $10 \mathrm{~cm}$.

Resistência do Solo à Penetração (kPa) - Prof. $10 \mathrm{~cm}$

\begin{tabular}{cccccccc}
\hline & \multicolumn{4}{c}{ Antes da colheita } & \multicolumn{3}{c}{ Depois da colheita } \\
\hline C.V. & G. L. & S.Q. & Q.M. & F & S.Q. & Q.M. & F \\
\hline Bloco & 2 & 7562693.7 & 3781346.8 & & 7864307.1 & 3932153.5 & \\
Trat. & 4 & 2407273.7 & 2407273.7 & $3.91^{\star *}$ & 1777203.5 & 1777203.5 & $3.28^{* *}$ \\
Residuo & 368 & 56628667.9 & 153882.2 & & 49777244.1 & 135264.2 & \\
\hline Total & 374 & 66598635.2 & & 59418754.8 & \\
** & significativo ao nível de 5\% de probabilidade \\
* não significativo
\end{tabular}

Anexo $\mathrm{O}$ - Análise da variância para a resistência do solo à penetração $(\mathrm{kPa})$ para as amostras 2, 3, 4, 5 e 6, antes e depois da colheita para RMa, na profundidade de $20 \mathrm{~cm}$.

Resistência do Solo à Penetração (kPa) - Prof. $20 \mathrm{~cm}$

\begin{tabular}{cccccccc}
\hline & \multicolumn{4}{c}{ Antes da colheita } & \multicolumn{3}{c}{ Depois da colheita } \\
\hline C.V. & G. L. & S.Q. & Q.M. & F & S.Q. & Q.M. & F \\
\hline Bloco & 2 & 585444.9 & 292722.4 & & 1657745.9 & 828872.9 & \\
Trat. & 4 & 43778.3 & 43778.3 & $0.71^{*}$ & 239583.6 & 239583.6 & $3.90^{* *}$ \\
Resíduo & 368 & 5674777.9 & 15420.5 & & 5653463.8 & 15362.6 & \\
\hline Total & 374 & 6304001.1 & & 7550793.4 & & \\
\hline ** & & & & & \\
significativo ao nível de 5\% de probabilidade \\
não significativo
\end{tabular}


Anexo $P$ - Análise da variância para a resistência do solo à penetração (kPa) para as amostras 2, 3, 4, 5 e 6, antes e depois da colheita para RMa, na profundidade de $30 \mathrm{~cm}$.

Resistência do Solo à Penetração (kPa) - Prof. $30 \mathrm{~cm}$

\begin{tabular}{cccccccc}
\hline \multicolumn{4}{c}{} & \multicolumn{2}{c}{ Antes da colheita } & \multicolumn{3}{c}{ Depois da colheita } \\
\hline C.V. & G. L. & S.Q. & Q.M. & F & S.Q. & Q.M. & F \\
\hline Bloco & 2 & 483609.4 & 241804.7 & & 566340.9 & 283170.4 & \\
Trat. & 4 & 55809.8 & 55809.8 & $1.97^{*}$ & 134671.5 & 134671.5 & $5.44^{\star \star}$ \\
Resíduo & 368 & 2601582.9 & 7069.5 & & 2276718.4 & 6186.7 & \\
\hline Total & 374 & 3141002.2 & & & 2977730.9 & &
\end{tabular}

** significativo ao nivel de $5 \%$ de probabilidade

* não significativo

Anexo $Q$ - Análise da variância para a resistência do solo à penetração $(\mathrm{kPa})$ para as amostras 2, 3, 4, 5 e 6, antes e depois da colheita para $\mathrm{RMa}$, na profundidade de $40 \mathrm{~cm}$.

Resistência do Solo à Penetração (kPa) - Prof. $40 \mathrm{~cm}$

\begin{tabular}{cccccccc}
\hline & \multicolumn{4}{c}{ Antes da colheita } & \multicolumn{3}{c}{ Depois da colheita } \\
\hline C.V. & G. L. & S.Q. & Q.M. & F & S.Q. & Q.M. & F \\
\hline Bloco & 2 & 267604.4 & 133802.2 & & 237115.6 & 118557.8 & \\
Trat. & 4 & 15410.5 & 15410.5 & $0.96^{*}$ & 70639.1 & 17659.7 & $5.82^{* *}$ \\
Residuo & 368 & 1480706.6 & 4023.6 & & 1116350.6 & 3033.5 & \\
\hline Total & 374 & 1763721.5 & & & 1424105.4 & &
\end{tabular}

** significativo ao nivel de $5 \%$ de probabilidade

* não significativo

Anexo $\mathrm{R}$ - Análise da variância para a resistência do solo à penetração (kPa) para as amostras $2,3,4,5$ e 6 , antes e depois da colheita para $\mathrm{RMa}$, na profundidade de $50 \mathrm{~cm}$.

Resistência do Solo à Penetração (kPa) - Prof. $50 \mathrm{~cm}$ Antes da colheita Depois da colheita

\begin{tabular}{cccccccc}
\hline C.V. & G. L. & S.Q. & Q.M. & F & S.Q. & Q.M. & F \\
\hline Bloco & 2 & 162911.2 & 81455.6 & & 45369.8 & 22684.9 & \\
Trat. & 4 & 25438.2 & 25438.2 & $1.74^{*}$ & 24394.3 & 24394.3 & $4.51^{* *}$ \\
Residuo & 368 & 1347484.4 & 3661.6 & & 498023.3 & 1353.3 & \\
\hline Total & 374 & 1535833.9 & & & 567787.5 & & \\
\hline
\end{tabular}

** significativo ao nivel de $5 \%$ de probabilidade

* não significativo 
Anexo $\mathrm{S}$ - Análise da variância para a resistência do solo à penetração $(\mathrm{kPa})$ para as amostras 8, 9, 10, 11 e 12, antes e depois da colheita para RTr, na profundidade de $10 \mathrm{~cm}$.

Resistência do Solo à Penetração $(\mathrm{kPa})$ - Prof. $10 \mathrm{~cm}$

\begin{tabular}{cccccccc}
\hline & \multicolumn{4}{c}{ Antes da colheita } & \multicolumn{3}{c}{ Depois da colheita } \\
\hline C.V. & G. L. & S.Q. & Q.M. & F & S.Q. & Q.M. & F \\
\hline Bloco & 2 & 4735026.3 & 2367513.1 & & 250584.2 & 125292.1 & \\
Trat. & 4 & 21683846.2 & 21683846.2 & $30.36^{\star \star}$ & 7252173.7 & 7252173.7 & $25.45^{* *}$ \\
Resíduo & 368 & 65708490.0 & 178555.68 & & 26213797.8 & 71233.1 & \\
\hline Total & 374 & 92127362.6 & & 43716555.8 & & \\
\hline
\end{tabular}

** significativo ao nivel de $5 \%$ de probabilidade

* não significativo

Anexo $\mathrm{T}$ - Análise da variância para a resistência do solo à penetração $(\mathrm{kPa})$ para as amostras 8, 9, 10, 11 e 12, antes e depois da colheita para RTr, na profundidade de $20 \mathrm{~cm}$.

Resistência do Solo à Penetração (kPa) - Prof. $20 \mathrm{~cm}$

\begin{tabular}{cccccccc}
\hline & \multicolumn{4}{c}{ Antes da colheita } & \multicolumn{3}{c}{ Depois da colheita } \\
\hline C.V. & G. L. & S.Q. & Q.M. & F & S.Q. & Q.M. & F \\
\hline Bloco & 2 & 1094496.7 & 547248.3 & & 75750.5 & 37875.2 & \\
Trat. & 4 & 4388204.1 & 4388204.1 & $26.47^{* *}$ & 685599.3 & 685599.3 & $20.62^{* *}$ \\
Resíduo & 368 & 15249844.5 & 41439.8 & & 3058907.9 & 8312.2 & \\
\hline Total & 374 & 20732545.4 & & & 3820257.7 & & \\
\hline ** significativo ao nivel de 5\% de probabilidade \\
*ão significativo
\end{tabular}

Anexo $\mathrm{U}$ - Análise da variância para a resistência do solo à penetração $(\mathrm{kPa})$ para as amostras $8,9,10,11$ e 12 , antes e depois da colheita para $\mathrm{RTr}$, na profundidade de $30 \mathrm{~cm}$.

Resistência do Solo à Penetração (kPa) - Prof. $30 \mathrm{~cm}$

\begin{tabular}{cccccccc}
\hline \multicolumn{9}{c}{ Antes da colheita } & \multicolumn{3}{c}{ Depois da colheita } \\
\hline C.V. & G. L. & S.Q. & Q.M. & F & S.Q. & Q.M. & F \\
\hline Bloco & 2 & 445229.9 & 222614.9 & & 16531.8 & 8265.9 & \\
Trat. & 4 & 891462.3 & 891462.3 & $17.44^{* *}$ & 129158.5 & 32289.6 & $17.6^{* *}$ \\
Resíduo & 368 & 4703521.7 & 12781.3 & & 674999.6 & 1834.2 & \\
\hline Total & 374 & 60402213.9 & & 820689.9 & & \\
\hline ** significativo ao nível de 5\% de probabilidade \\
não significativo
\end{tabular}


Anexo V - Análise da variância para a resistência do solo à penetração (kPa) para as amostras $8,9,10,11$ e 12, antes e depois da colheita para RTr, na profundidade de $40 \mathrm{~cm}$.

Resistência do Solo à Penetração (kPa) - Prof. $40 \mathrm{~cm}$

\begin{tabular}{cccccccc}
\hline & \multicolumn{4}{c}{ Antes da colheita } & \multicolumn{3}{c}{ Depois da colheita } \\
\hline C.V. & G. L. & S.Q. & Q.M. & F & S.Q. & Q.M. & F \\
\hline Bloco & 2 & 218030.4 & 109015.2 & & 953.5 & 476.7 & \\
Trat. & 4 & 240112.2 & 240112.2 & $9.29^{* *}$ & 33121.9 & 33121.9 & $10.50^{* *}$ \\
Resíduo & 368 & 2378359.3 & 6462.9 & & 290296.5 & 788.8 & \\
\hline Total & 374 & 2836501.8 & & 324372.0 & & \\
\hline ** significativo ao nível de 5\% de probabilidade \\
não significativo
\end{tabular}

Anexo W - Análise da variância para a resistência do solo à penetração (kPa) para as amostras $8,9,10,11$ e 12, antes e depois da colheita para RTr, na profundidade de $50 \mathrm{~cm}$.

Resistência do Solo à Penetração (kPa) - Prof. $50 \mathrm{~cm}$

\begin{tabular}{cccccccc}
\hline & \multicolumn{4}{c}{ Antes da colheita } & \multicolumn{3}{c}{ Depois da colheita } \\
\hline C.V. & G. L. & S.Q. & Q.M. & F & S.Q. & Q.M. & F \\
\hline Bloco & 2 & 90357.1 & 45178.5 & & 2719.2 & 1959.6 \\
Trat. & 4 & 51403.4 & 51403.4 & $4.01^{* *}$ & 4092.4 & 4092.4 & $4.17^{* *}$ \\
Residuo & 368 & 1179552.8 & 3205.3 & & 90180.4 & 245.0 & \\
\hline Total & 374 & 1321313.3 & & 96992.1 & & \\
\hline
\end{tabular}

** significativo ao nível de $5 \%$ de probabilidade

* não significativo

Anexo $Y$ - Análise da variância para a densidade $\left(\mathrm{g} / \mathrm{cm}^{3}\right)$ antes e depois da colheita na profundidade de $5-10 \mathrm{~cm}$

Densidade $\left(\mathrm{g} / \mathrm{cm}^{3}\right)$ - Prof. 5-10cm

\begin{tabular}{cccccccc}
\hline & \multicolumn{4}{c}{ Antes da colheita } & \multicolumn{3}{c}{ Depois da colheita } \\
\hline C.V. & G. L. & S.Q. & Q.M. & F & S.Q. & Q.M. & F \\
\hline Bloco & 2 & 0.0059 & 0.0029 & & 0,0699 & 0.0349 & \\
Trat. & 1 & 0.1333 & 0.1333 & $16.42^{* *}$ & 0,0085 & 0.0085 & $1.05^{*}$ \\
Residuo & 116 & 0.9419 & 0.0081 & & 0.9372 & 0.0080 & \\
\hline Total & 119 & 1.0812 & & & 1,0157 & \\
\hline
\end{tabular}

** significativo ao nível de $5 \%$ de probabilidade

* não significativo 
Anexo $\mathrm{Z}$ - Análise da variância para a densidade $\left(\mathrm{g} / \mathrm{cm}^{3}\right)$ antes e depois da colheita na profundidade de $15-20 \mathrm{~cm}$.

Densidade $\left(\mathrm{g} / \mathrm{cm}^{3}\right)$ - Prof. $15-20 \mathrm{~cm}$

\begin{tabular}{cccccccc}
\hline & \multicolumn{4}{c}{ Antes da colheita } & \multicolumn{3}{c}{ Depois da colheita } \\
\hline C.V. & G. L. & S.Q. & Q.M. & F & S.Q. & Q.M. & F \\
\hline Bloco & 2 & 0.1435 & 0.0717 & & 0.0742 & 0.0371 & \\
Trat. & 1 & 0.2960 & 0.2960 & $17.92^{* *}$ & 0.0060 & 0.0060 & $0.59^{*}$ \\
Residuo & 116 & 1.9159 & 0.0165 & & 1.1842 & 0.0102 & \\
\hline Total & 119 & 2.3555 & \multicolumn{6}{c}{1.2644} \\
\hline
\end{tabular}

** significativo ao nível de $5 \%$ de probabilidade

* não significativo

Anexo AA - Análise da variância para a densidade $\left(\mathrm{g} / \mathrm{cm}^{3}\right)$ antes e depois da colheita na profundidade de $25-30 \mathrm{~cm}$.

Densidade $\left(\mathrm{g} / \mathrm{cm}^{3}\right)$ - Prof. $25-30 \mathrm{~cm}$

\begin{tabular}{cccccccc}
\hline & \multicolumn{4}{c}{ Antes da colheita } & \multicolumn{3}{c}{ Depois da colheita } \\
\hline C.V. & G. L. & S.Q. & Q.M. & F & S.Q. & Q.M. & F \\
\hline Bloco & 2 & 0.1221 & 0.0610 & & 0.0629 & 0.0314 & \\
Trat. & 1 & 0.2679 & 0.2679 & $13.72^{* *}$ & 0.0061 & 0.0061 & $0.65^{*}$ \\
Resíduo & 116 & 2.2651 & 0.0195 & & 1.0972 & 0.0094 & \\
\hline Total & 119 & 2.6552 & & & 1.1663 & & \\
\hline
\end{tabular}

** significativo ao nível de $5 \%$ de probabilidade

* não significativo

Anexo $A B$ - Análise da variância da densidade $(\mathrm{g} / \mathrm{cm} 3)$ para as amostras 3 e 4, nas profundidades de 5-10 $(\mathrm{cm})$, depois da colheita para $R T r$

Densidade $\left(\mathrm{g} / \mathrm{cm}^{3}\right)$ - Prof. $5-10 \mathrm{~cm}$

\begin{tabular}{ccccc}
\hline C.V. & G. L. & S.Q. & Q.M. & F \\
Bloco & 2 & 0.0298 & 0.0149 & \\
Trat. & 1 & 0.1092 & 0.1092 & $22.31^{* *}$ \\
Resíduo & 56 & 0.2741 & 0.0048 & \\
\hline Total & 59 & 0.4133 & & \\
\hline
\end{tabular}

** significativo ao nivel de $5 \%$ de probabilidade

* não significativo 
Anexo AC - Análise da variância da densidade $(\mathrm{g} / \mathrm{cm} 3)$ para as amostras 3 e 4 , nas profundidades de $15-20(\mathrm{~cm})$, depois da colheita para $\mathrm{RTr}$

\section{Densidade $\left(\mathrm{g} / \mathrm{cm}^{3}\right)$ - Prof. $5-10 \mathrm{~cm}$}

\begin{tabular}{ccccc}
\hline C.V. & G. L. & S.Q. & Q.M. & F \\
Bloco & 2 & 0.0443 & 0.0221 & \\
Trat. & 1 & 0.1050 & 0.1050 & $15.62^{\text {** }}$ \\
Residuo & 56 & 0.3764 & 0.0067 & \\
\hline Total & 59 & 0.5258 & & \\
\hline
\end{tabular}

** significativo ao nível de $5 \%$ de probabilidade

* não significativo

Anexo AD - Análise da variância da densidade $(\mathrm{g} / \mathrm{cm} 3)$ para as amostras 3 e 4, nas profundidades de $15-20(\mathrm{~cm})$, depois da colheita para RTr

\section{Densidade $\left(\mathrm{g} / \mathrm{cm}^{3}\right)$ - Prof. $15-20 \mathrm{~cm}$}

\begin{tabular}{ccccc}
\hline C.V. & G. L. & S.Q. & Q.M. & F \\
Bloco & 2 & 0.0872 & 0.0436 & \\
Trat. & 1 & 0.0770 & 0.0770 & $11,96^{* *}$ \\
Resíduo & 56 & 0.3606 & 0.0064 & \\
\hline Total & 59 & 0.5249 & & \\
\hline
\end{tabular}

** significativo ao nivel de $5 \%$ de probabilidade

* não significativo

Anexo AF - Análise da variância da densidade $(\mathrm{g} / \mathrm{cm} 3)$ para a amostra 4 na $R T r$, nas profundidades de $5-10(\mathrm{~cm})$,

Densidade $\left(\mathrm{g} / \mathrm{cm}^{3}\right)$ - Prof. $5-10 \mathrm{~cm}$

\begin{tabular}{ccccc}
\hline C.V. & G. L. & S.Q. & Q.M. & F \\
Bloco & 2 & 0.0014 & 0.0007 & \\
Trat. & 1 & 0.3467 & 0.3467 & $72.09^{\star \star}$ \\
Residuo & 56 & 0.2693 & 0.0048 & \\
\hline Total & 59 & 0.6175 & &
\end{tabular}

** significativo ao nível de $5 \%$ de probabilidade

* não significativo 
Anexo AG - Análise da variância da densidade $(\mathrm{g} / \mathrm{cm} 3)$ para a amostra 4 na $R T r$, nas profundidades de 15-20 (cm).

Densidade $\left(\mathrm{g} / \mathrm{cm}^{3}\right)$ - Prof. $5-10 \mathrm{~cm}$

\begin{tabular}{ccccc}
\hline C.V. & G. L. & S.Q. & Q.M. & F \\
Bloco & 2 & 0.0298 & 0.0149 & \\
Trat. & 1 & 0.4827 & 0.4827 & $78.32^{* *}$ \\
Residuo & 56 & 0.3452 & 0.0061 & \\
\hline Total & 59 & 0.8577 & &
\end{tabular}

** significativo ao nível de $5 \%$ de probabilidade

* não significativo

Anexo $\mathrm{AH}$ - Análise da variância da densidade $(\mathrm{g} / \mathrm{cm} 3)$ para a amostra 4 na $\mathrm{RTr}$, nas profundidades de 15-20 (cm).

Densidade $\left(\mathrm{g} / \mathrm{cm}^{3}\right)$ - Prof. $15-20 \mathrm{~cm}$

\begin{tabular}{ccccc}
\hline C.V. & G. L. & S.Q. & Q.M. & F \\
Bloco & 2 & 0.0406 & 0.0203 & \\
Trat. & 1 & 0.3917 & 0.3917 & $58.02^{* *}$ \\
Resíduo & 56 & 0.3780 & 0.0067 & \\
\hline Total & 59 & 0.8104 & & \\
** significativo ao nível de 5\% de probabilidade &
\end{tabular}

Anexo Al - Análise da variância da cobertura vegetal para os tratamentos das $\mathrm{RMa}$ e $R T r$

Cobertura Vegetal (kg/m2)

\begin{tabular}{cccccccc}
\hline \multicolumn{1}{c}{ Folha } & \multicolumn{3}{c}{ Galho } \\
\hline C.V. & G. L. & S.Q. & Q.M. & F & S.Q. & Q.M. & F \\
\hline Bloco & 2 & 861010.6 & 430505.3 & & 7031370.6 & 3515685.3 & \\
Trat. & 1 & 2284641.3 & 2284641.3 & $8.46^{* *}$ & 13364741.3 & 13364741.3 & $3.26^{*}$ \\
Resíduo & 8 & 2159898.6 & 269987.3 & & 32834090.67 & 41104261.3 & \\
\hline Total & 11 & 5305550.6 & & 53230202.67 & \\
** significativo ao nível de 5\% de probabilidade & & & \\
* não significativo & & & & &
\end{tabular}


Anexo AJ - Análise da variância da cobertura vegetal para os tratamentos das RMa e RTr

Cobertura Vegetal (kg/m2)

\begin{tabular}{cccccccc}
\hline & \multicolumn{3}{c}{ Casca } & \multicolumn{3}{c}{ Resto } \\
\hline C.V. & G. L. & S.Q. & Q.M. & F & S.Q. & Q.M. & F \\
\hline Bloco & 2 & 95877600.0 & 47938800.0 & 70912002.6 & 35456001.3 & \\
Trat. & 1 & 35528325.3 & 35528325.3 & $0.94^{*}$ & 8854572.0 & 8854572.0 & $0.40^{*}$ \\
Residuo & 8 & 300940250.7 & 37617531.3 & 176589504.0 & 22073688.0 & \\
\hline Total & 11 & 432346176.0 & & & 256356078.6 & & \\
\hline
\end{tabular}

** significativo ao nível de $5 \%$ de probabilidade

* não significativo 


\section{REFERÊNCIAS BIBLIOGRÁFICAS}

American Society of Agricultural Engineers. Agricultural Engineers Yearbook. St Joseph. 1983. p.719. Agricultural machinery management. (ASAE, S313.2)

AYERS, P.D.; PERUMPRAL, J.V. Moisture and density effect on cone index. American Society of Agricultural Engineers, v.25, n.5, p.1169-1172, sept./oct. 1982.

BAVER, L.D.; GARDNER, W.H.; GARDNER, W.R. Soil Phtsics. 14. ed. New York: John Wiley, 1972. 498p.

BELTRAME, L.F.S.; TAYLOR, J.C. Causas e efeitos da compactação do solo. Lavoura Arrozeira, v.33, n.318, p.59-62, jan./fev. 1980.

BELTRAME, L.F.S.; GOLDIM, L.A.P.; TAYLOR, J.C. Estrutura e compactação na permeabilidade de solos do Rio Garnde do Sul. Revista Brasileira de Ciência do Solo, v. 5,n.3, p.145-149, set./dez.1981.

BORGES, E.N.; NOVAIS, R.F. de; BARROS, N.F. de; et al. Respostas de mudas de eucalipto a camadas compactadas de solo. Revista Árvore, v.10, n.2, p.181-195, 1986.

BORGES, E.N.; NOVAIS, R.F. de; BARROS, N.F. de; et al. Respostas de variedades de soja à compactação de camadas de solo. Revista Ceres, v.35, n.202, p.553-568, 1988.

BORGES E.N.; F.L. NETO; CORRÊA, G.F. Alterações físicas introduzidas pela compactação em material de Latossolo Vermelho-escuro textura-média. In: 
CONGRESSO LATINO AMERICANO DE CIENNCIA DO SOLO. Campinas. 1996. Anais. Águas de Lindóia: 1996 . p.5.

CAMARGO, O.A. de. Compactação do solo e desenvolvimento das plantas: efeito da compactação em caracteristícas do solo. Campinas: Fundação Cargill, 1983. 44p.

CAMPBELL, R.G.; WILLIS, J.R.; MAY, J.T. Soil disturbance by logging with rubber-tired skidders. Journal of Soil and Water Conservation, v.28, n.5, p.218-220, Sept./Oct. 1973.

CHANCELLOR, W.J. Compaction of soil by agricultural equipment. Califórnia: University of California, Division of Agricultural Sciences, 1977. $53 p$.

COHRON, G.T. Compaction of agricultural soil: forces causing soil compaction. St. Joseph: American Society of Agricultural Engineers. 1971. 471p.

COLETI, J.T; DEMETÉ, J.L.I. Compactaçāo artificial em solos. Alcool e Açúcar, v.2, n.6, p.34-38, set./out., 1983.

CORSINI, P.C. Problemas causados pela compactação dos solos. STAB. Açúcar, Alcool e Sub-produto, v.11, n.5, p.11-13, maio/jun. 1993.

DALLMEYER, A.U. Avaliação energética e desempenho operacional de equipamentos de preparo do solo. Botucatu, 1994. 130p. Tese (Doutorado) - Universidade Estadual Júlio de Mesquita Filho. Faculdade de Ciências Agronômicas

DANIEL, L.A.; LUCARELLI, J.R.de F.; CARVALHO, J.F.de Efeito do método de preparo do solo na formação e localização de camadas compactadas. In: CONGRESSO BRASILEIRO DE ENGENHARIA AGRÍCOLA, 26, Campinas 1995. Anais. Viçosa: SBEA, 1995, 13p.

DANIEL, L.A.; RAUNOUD, C.L.F.; DUTOIT, C.L. Tráfego controlado em parcelas motomecanizadas com os sistemas convensional e plantio direto: avaliação preliminar da resistência do solo à penetração. In: CONGRESSO 
BRASILEIRO DE ENGENHARIA AGRICOLA, 12, Viçosa. 1993. Anais. Ilhéus: SBEA, 1993. p.2091-2101.

DAVIS, G.R.; NEILSEN, W.A.; McDAVITT, J.G. Root distribution of Pinus radiata related to soil characteristcs in five Tasmanian soils. Australian Journal Soil Resesearch, v.21,n.2, p.165-171, 1983.

EMPRESA BRASILEIRA DE PESQUISA AGROPECUÁRIA. Serviço Nacional de Levantamento e Conservação do Solo, Manual de métodos de análise de solo. Rio de Janeiro: 1979. Iv.

FERNANDES, B.; GALLOWAY, H.M. Efeito das rodas do trator em propriedades físicas de dois solos. Revistas Ceres, v.34, n.196, p.562$568,1987$.

FERNANDES, J. A subsolagem no controle da compactação do solo na canasoca (Saccharum Ssp) variedade CB 41-76 e seus efeitos no rendimento agrícola e no sistema radicular. Piracicaba, 1979. 158p. Dissertação (Mestrado) - Escola Superior de Agricultura "Luiz de Queiroz", Universidade de São Paulo.

FERNANDES, J.; RIPOLI, C.T.; MILAN, M. A compactação do solo e a brotação das soqueiras. Alcool e Açúcar, v.3, n.12, p.12-15, set.lout. 1983.

FLOCKER, W.J.; TIMM H.; VOMOCIL, J.A. Effect of soil compaction on tomato and potato yields. Agronomy Journal, v.52, n.1, p.345-349, 1960.

FOIL, R.R.; RALSTON, C.W.; The establishment and growth of loblolly pine seedlings on compacted soils. Soil Science Society of American Proceedings, v.31, n.4, p.565-568, 1967.

GROHMANN, F. Elementos da pedologia: compacidade. São Paulo: Poligono, 1972. 459p.

GROHMANN, F.; QUEIROZ NETO, J.P.de. Efeito da compactação artificial de dois solos limos-argilosos sobre a penetração das raizes de arroz. Bragantina, v.25, n.38, p.421-431, dez. 1966. 
HATCHELL, G.E.; RALSTON, C.W.; FOIL R.R. Soil disturbances in logging. Journal of Forestry, v.68, n.1, p.772-775, Jan. 1970.

HEMSATH, D.L.; MAZURAK, A.P. Seedling growth of sorghum in clay-sand mixtures at various compactions and water contents. Soil Science Society of America Proceedings, v.38,n.3, p.387-390, 1974.

HOWARD, R.; SINGER, M.J.; FRANTZ, G.A. Effects of soil proprieties, water contents, and compactive effort on the compaction of selected California forest and range soils. Soil Science Society of America Journal, v.45, n.2, p.231-236, Mar./Apr. 1981.

JAKOBSEN, B.F.; GREACEN, E.L. Compaction of sandy forest soils by forwarder operations. Soil \& Tillage Research, v.5,n.1, p.55-70, 1985.

JORGE, J.A. Física e manejo do solo tropicais: compactação e subsolagem do solo. Campinas: Instituto Campineiro de Ensino Agrícola, 1986. 328p.

JORGE, J.A.; IGUE,T; ALMEIDA, C.L.F.de. Propriedades hídricas e resistência à penetração de quatro unidades de solo do Estado de São Paulo. Revista de Agricultura, v.63, n.1, p.21-36, jun. 1988.

KEILEN, K. Estudos da alteração do solo pelo transito intensivo. In: SEMINÁRIO DE ATUALIZAÇÃO SOBRE SISTEMAS E EXPLORAÇÃO E TRANSPORTE FLORESTAL, 7. , Curitiba, 1992. Anais. Curitiba: Universidade Federal de Viçosa. Fundação de Pesquisas Florestais do Paraná, 1992. p.217-220.

KHALILIAN, A; HOOD, C.E; PALMER, J.H.; et al. Soil compaction crop response to wheat/soybean interseeding. American Society of Agricultural Engineers, v.34, n.6, p.2299-2303. Nov./Dec. 1991.

KING, A.L. Measuring soil compaction in mechanically thinned pine plantations.

St Joseph: American Society of Agricultural Engineers, 1979. 8 p., (ASAE. Paper, 79 -1600).

KING, T; HAINES, S. Soil compaction absent in plantation thinning. New Orleans: Southern Forest Experiment Station, 1979, 4p. 
KLEIN, V.A. Compactação: o solo quer folga. A Granja, v.46, n.503, p.18-21, maio 1990.

KLEIN, V.A. Densidade do solo em área com plantio direto submetido a diferentes manejos. In: CONGRESSO LATINO AMERICANO DE CIÊNCIA DO SOLO. 13. Águas de Lindóia, 1996. Resumos. Águas de Lindóia: 1996. $4 p$.

KOGER, J.L.; BURT, E.C.; TROUSER JR., A.C. Multiple pass effects os skidder tire on soil compaction. American Society of Agricultural Engineers, p.11-16, 1985.

KREH, R.E.; BURGER, J.A.; TORBERT, J.L. Soil compaction from tracked and rubber-tired tractors and its influence on seedling survival and growth. Southern Silvicultural Research Conference, v.7, n.8, p.327-330, Nov. 1984.

MANTOVANI, E.C. Compactação do solo. Informativo Agropecuário, v.13, n.147, p.52-55, mar. 1987.

MEEK, B.D.; RECHEL E.R.; CARTER, L.M. et al. Bulk density of a sandy loam: traffic, tillage, and irrigation-method effects. Soil Science Society of America Journal, v.56,n.2, p.562 - 565, mar.lapr., 1992.

MIELNICZUK, J.; CARPENEDO, V.; PEDÓ, F. Desenvolvimento de raizes em solos compactados. Lavoura Arrozeira, v.38, n.357, p.42-43, mar.-abr., 1985.

MYHRMAN, D. Factors influencing rut formation from forestry machines. In: INTERNATIONAL CONFERENCE OF THE ISTVS, 10., Kobe, 1990 Kista: The Forest Operations Institute. 1990. p.1-8.

NAMBIAR, E.K.S. Root development and configuration in intensively managed radiata pine plantations. Plant and Soil, v.71,n.1/3, p.37-47, 1983.

NGUNJIRI, G.M.N.; SIEMENS, J.C. Wheel traffic effects on corn growth.

American Society of Agricultural Engineers, v.38, n.3, p.691-699, 1995. 
NÓBREGA, J. C. A.; ANDRADE, A. P. de; SILVA, I. de F. de; et al. Efeito do cultivo contínuo sobre a infiltração de água no solo. In: CONGRESSO LATINO AMERICANO DE CIÉNCIA DO SOLO, 13., Águas de Lindóia, 1996. Resumo. Águas de Lindóia: 1996. 4p.

OHU, J.O.; AYOTAMUNO, M.B.; FOLORUNSO, O.A. Compaction characteristics of prominent agricultural soil in Borno Statr of Nigeria. American Society of Agricultural Engineers, v.30, n.6, p.1575-1577, Nov./Dec. 1987.

REISINGER, T.W.; SIMMONS, G.L.; POPE, P.E. The impact of timber harvesting on soil properties and seedling growth in the south. South. J. Appl. For. v.12, n. 1, p.58-67, 1988.

REISINGER, T.W.; POPE, P.E.; HAMMOND, S.C. Natural recovery of Compacted soils in an upland hardwood forest in indiana. North. J. Appl. For., v.9, n.4, p.138-141, 1992.

SANDS, R.; BOWEN, G.D. Compaction of sandy soils in radiata pine forest II. Effects of compaction on root configuration and growth of Radiata Pine seedling. Australian Forest Research, v.8, n.3/4, p.163-170, 1978.

SANDS, R.; Greacen,E.L.; Gerard, C.J. Compaction of sandy soils in radiata Pine forest. I A penetrometer study. Australian Journal Soil Resesearch, v.17,n.1, p.101-113. 1979.

SCOPEL, I.; ROCHA, H.O. da; MALINOVSKI, J.R.; KOBIYAMA, M. Riscos de compactação do solo na produção florestal. In: SEMINÁRIO DE ATUALIZAÇÃO SOBRE SISTEMAS E EXPLORAÇÃO E TRANSPORTE FLORESTAL, 7. , Curitiba, 1992. Anais. Curitiba: Fundação de Pesquisas Florestais do Paraná, 1992. p.172-193.

SEIXAS, F. Compactação do solo devido à mecanização florestal.

Piracicaba: IPEF, 1988. 10p. (IPEF. Circular Técnica, 163). 
SEIXAS, F. Avaliação de impactos da colheita. In: Programa de reciclagem em métodos quantitativos, 2.,Piracicaba, 1996. Anais. Piracicaba: Escola Superior de Agricultura Luiz de Queiroz'USP, 1996. 21p.

SILVA, J.R. da; FERREIRA, 0.O. Sistemas de preparo do solo para implantação de floresta:Influência na resistência do solo a penetração. In: CONGRESSO BRASILEIRO DE ENGENHARIA AGRICOLA,24, Viçosa, 1995. Anais. Viçosa: SBEA, 1995. 16p.

SOEHNE, W. Fundamentals of pressure distribution and soil compaction under tractors tires. Agricultural Engineering, p.276-281, 290, May, 1958.

TAYLOR, H.M.; RATLIFF, L.F. Root growth pressures of cotton, peans and peanuts. Agronomy Journal. v.61,n.3, p.398-402, May-June, 1969.

VOORHEES, W.B. Soil compaction: our newest natural resource. Crops Soils v.29, n. 6, p.7-10, 1977.

VOORHEES, W.B.; SENST, C.G.; NELSON, W.W. Compaction and soil structure modification by wheel traffic in the northern corn belt. Soil Sciece Society American Journal, v.42,n.2, p.344-349, 1978.

WARKENTIN, B.P. Compaction of agricultural soil: Effects of compaction on content and transmission of water in soils. St. Joseph, Michigan: American Society of Agricultural Engineers, 1971. 471p.

WÄSTERLUND, I. Extent and causes of site damage due to forestry traffic. Scandinavian Journal of Research, v.7, p.135-142, 1992. 